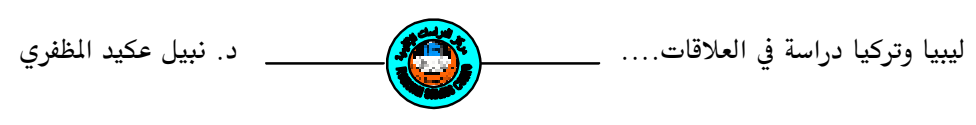

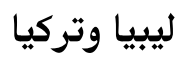

دراسة في العلاقات السياسية والاقتصادية

خلال تسعينيات القرن العشرين

\author{
د. د. نبيل عكيد محمود المظفري \\ مدرس/ جامعة كركوك / كلية التربية / قسم التاريخ
}

مستخلص البحث

تقف هذه الدراسة على العلاقات الليبية التركية خلال عقد التسعينيات من القرن العشـرين، وهي

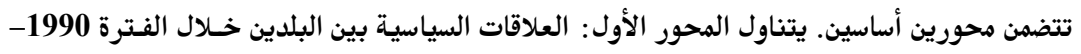

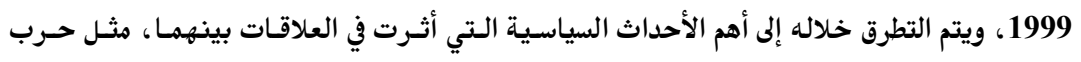

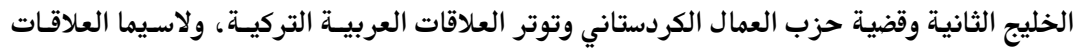

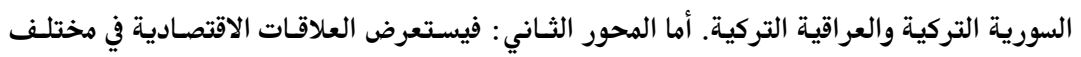

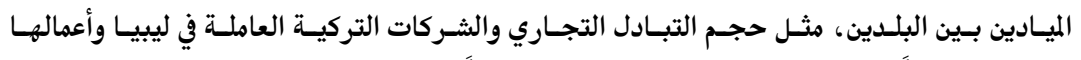

والسياحة، فضلاً عن أهم العوامل والظروف التي تركت أثراً في العلاقات الاقتصادية.

المقدمة

لم تكن العلاقات الليبية التركية تسير بخط بياني مستقيم بعـد سـقوط النظـام الملكي في

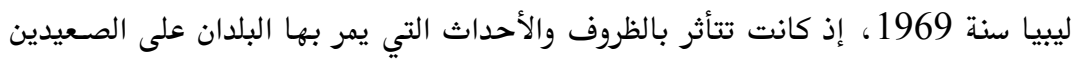

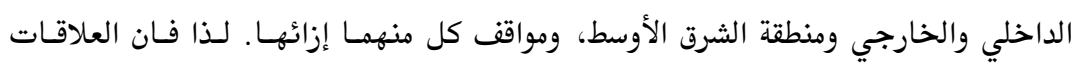

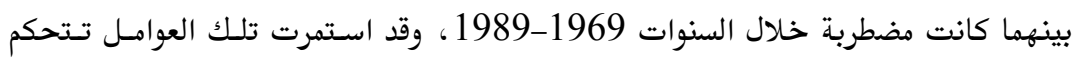

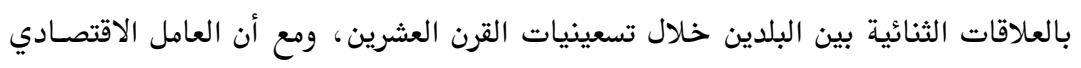

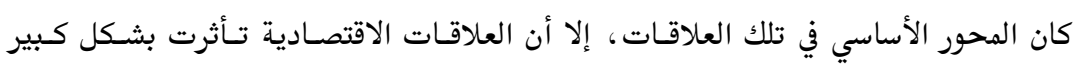

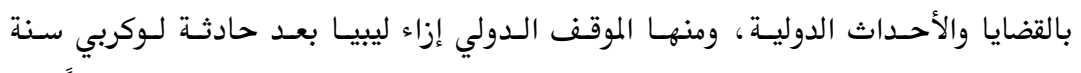

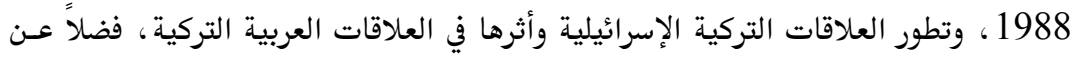




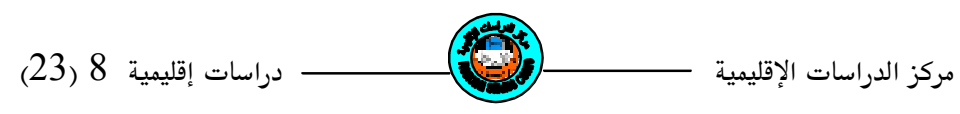

تداعيات القضية الكردية في تركيا التي كـان لهـا انعكـاس واضح في تلك العلاقـات نتيجـــ

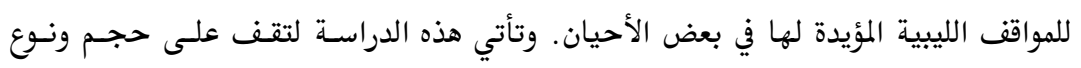

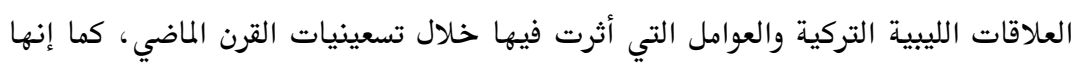

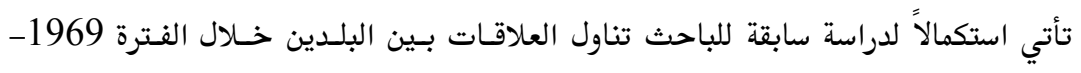

\section{العلاقات السياسية}

بدأت العلاقات الليبية التركية تتدهور بشكل لافت للذظر منذ منتصف الثمانينـات مـن

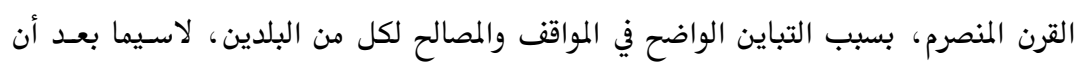

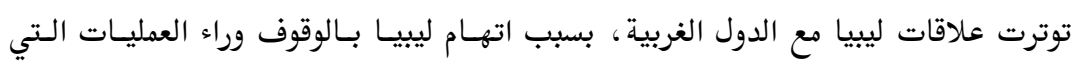

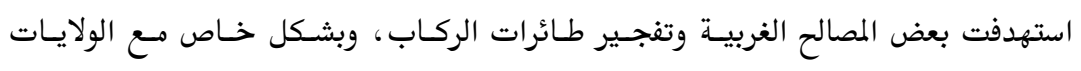

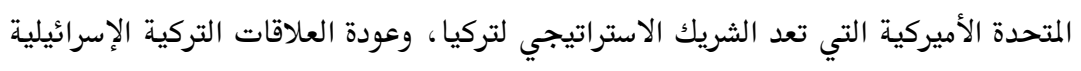

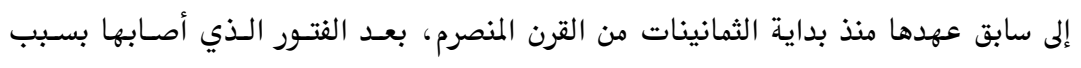

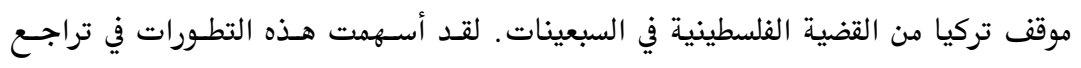

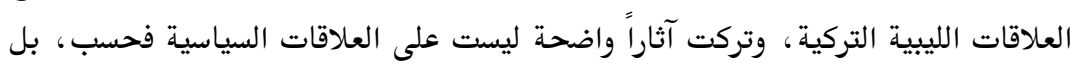

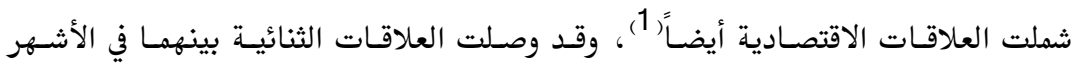

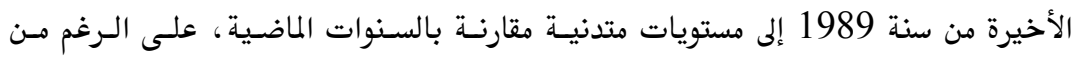

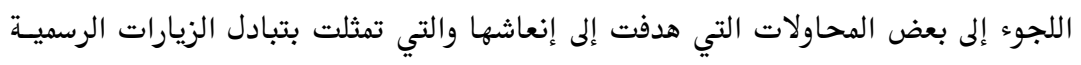

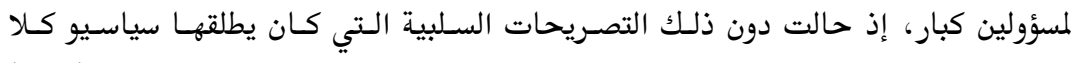

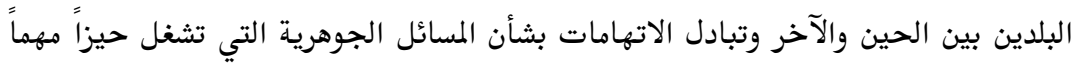

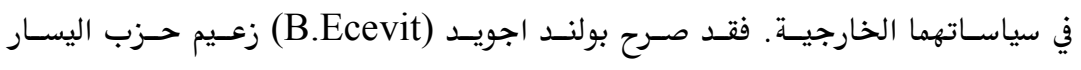

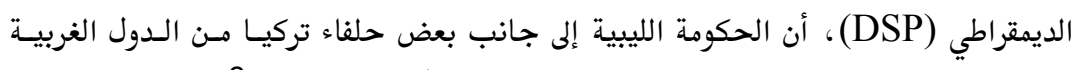

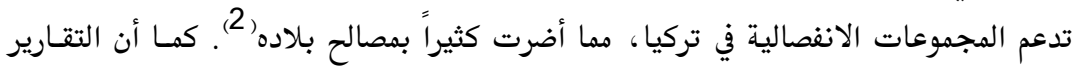

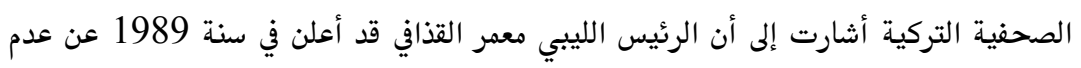

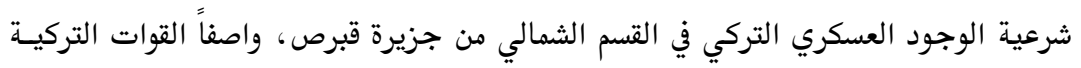


المتمركزة هناك بـ "القوات المحتلة"، مما اغضب الحكومة التركيسة، إلا أن السفارة الليبيـة

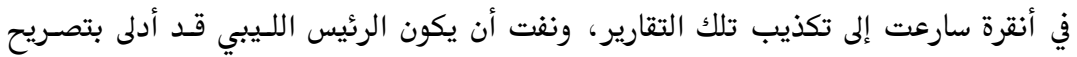
بهذا الشأن (3). وصلت العلاقات الليبية التركية إلى مستوى متدن، وشهدت توتراً لافتاً، بعد الانفجارات

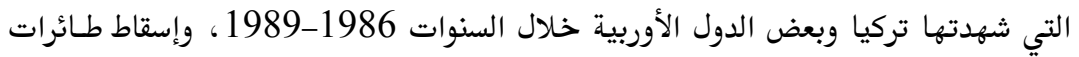
الركاب وتحميل ليبيا مسؤولية تلك الأحداث، فضلاً عن إسقاط الطائرات الأميركية لطائرتين

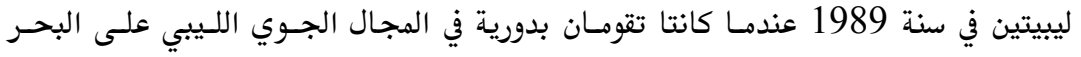

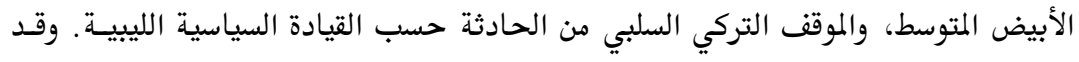

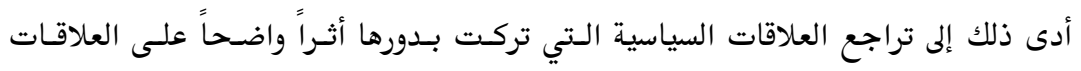
الاقتصادية، إذ أقدمت تركيا على تقليص حجم العمالة التركية في ليبيا، فضلاً عن انخفاض المستوى التجاري بين البلدين (4).

\section{موقع القضايا العربية في العلاقات الليبية التركية}

بدت علامات الـبرود السياسي واضـحة في العلاقـات الليبيـة التركيـة هـع نهايـة سـنة

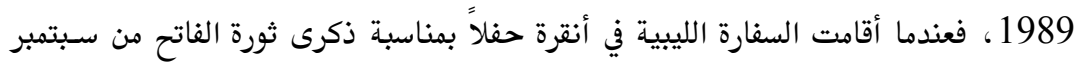

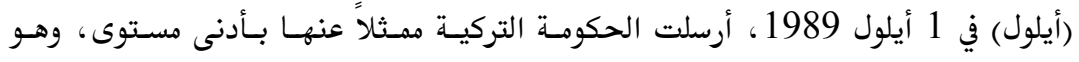
موظف بسيط في وزارة الخارجية، على عكس الاحتفالات السابقة ، التي كان يحضرها كبـار

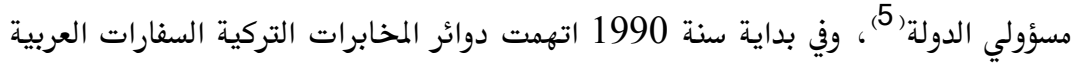

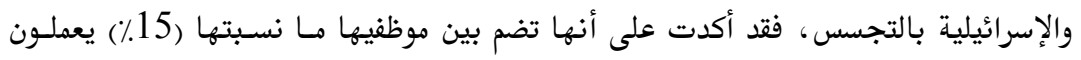

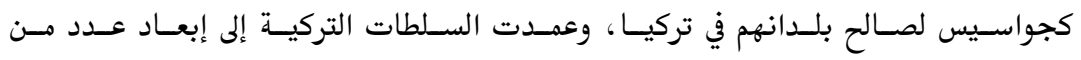

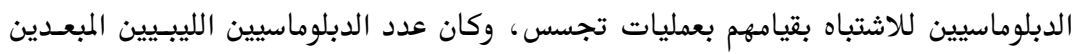

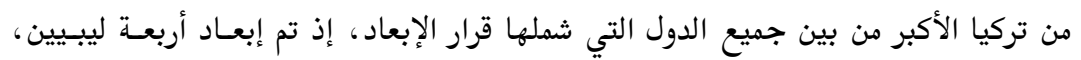

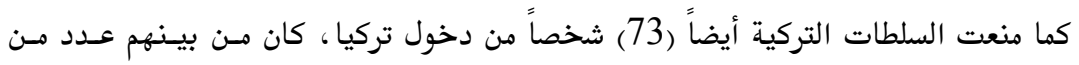




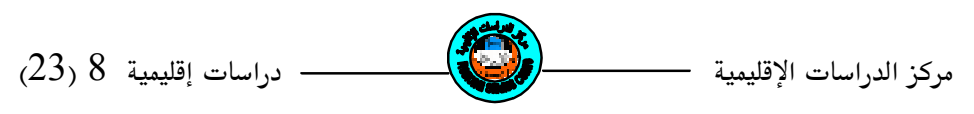

كانت عملية السلام بين "إسرائيل" والفلسطينيين في نهاية سنة 1989 تسير نحو طريق

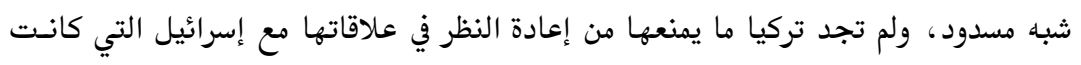

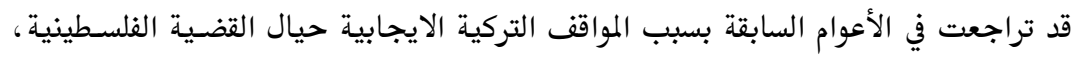

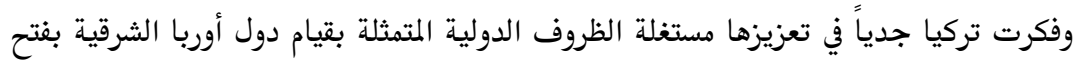

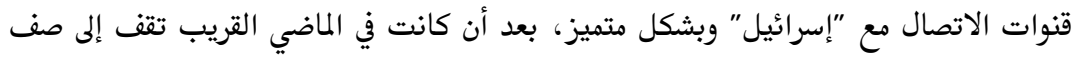

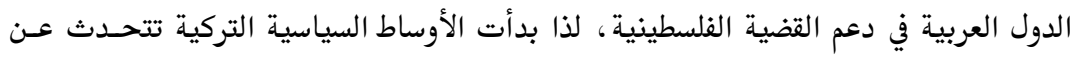

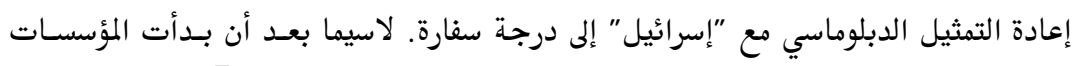

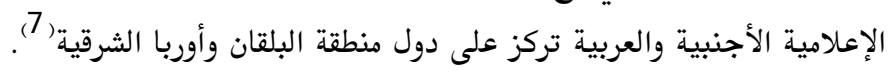

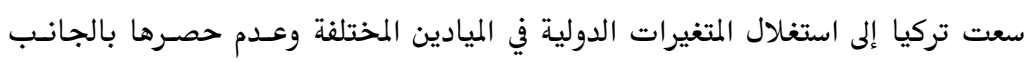

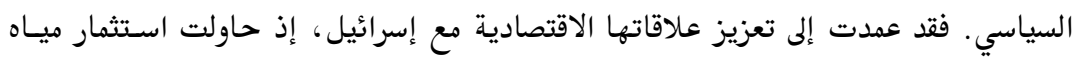

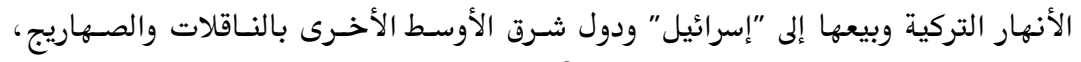

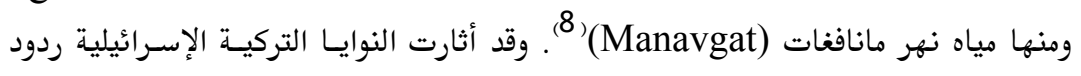
فعل ليبية قوية، فقـد أدلى الـئيس الليبي بتصـريحات ناريسة في شـباط 1990 قـائلاً بـأن

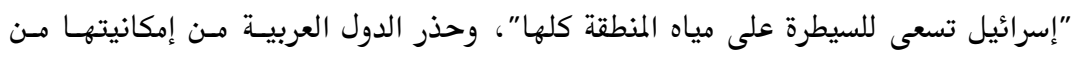

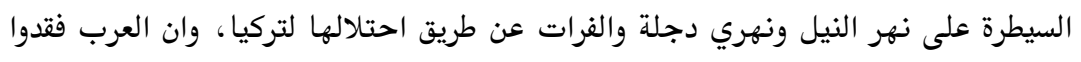

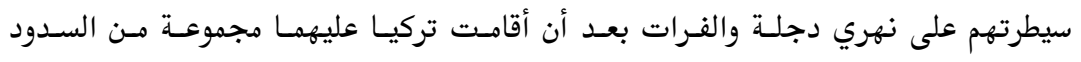

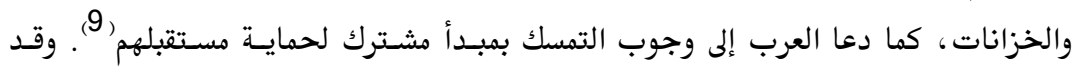

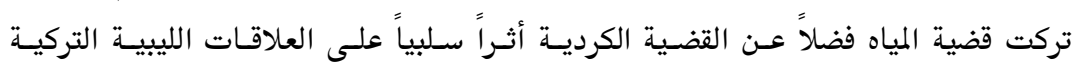
السياسية، وانسحب ذلك على علاقاتهما الاقتصادية( 10 (10).

ومع أن تصريحات الـرئيس الليبي كانست بعيسدة عـن الواقع والإمكانيسات الإسـرائيلية

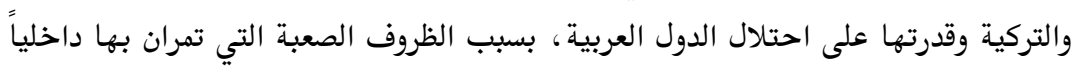

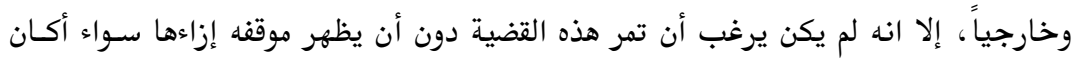

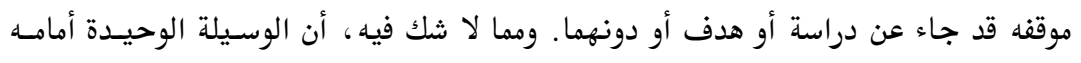

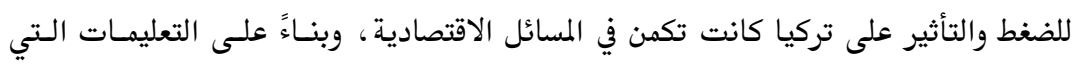

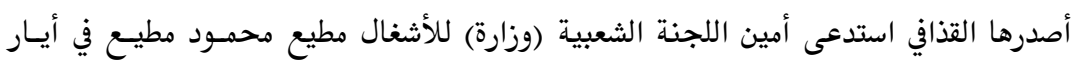


1990 ممثل اتحاد المقاولين الأتراك في ليبيا ايشين جلبي (I.Celebi)، وابلغه قلق بـلاده

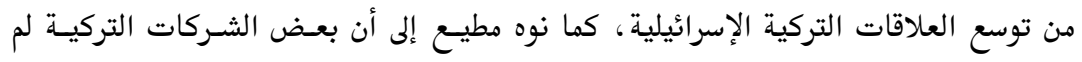

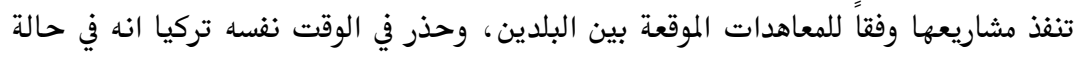

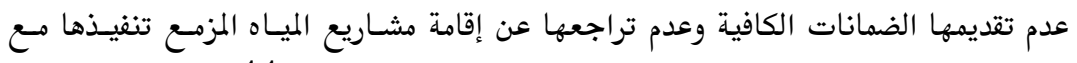
"إسرائيل" "فان ليبيا سوف تنهي أعمال الشركات التركية في ليبيا"(

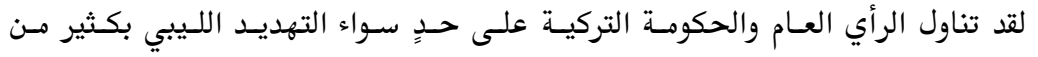

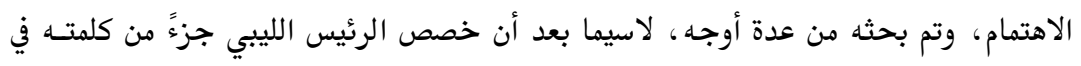

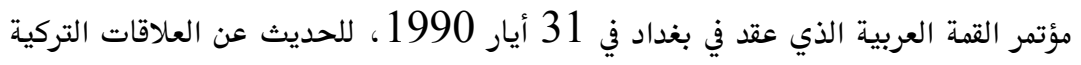

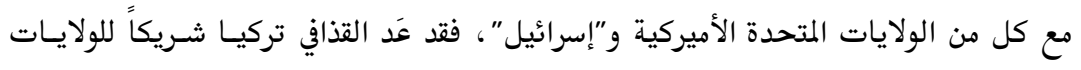

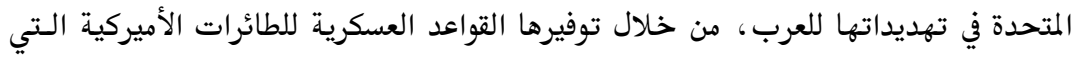

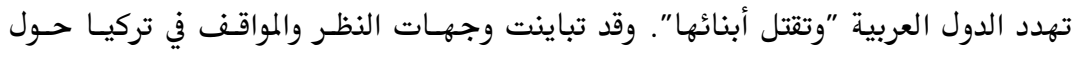

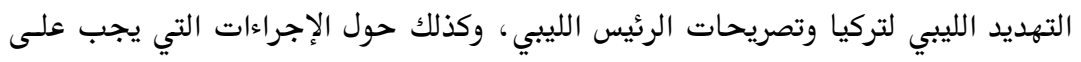

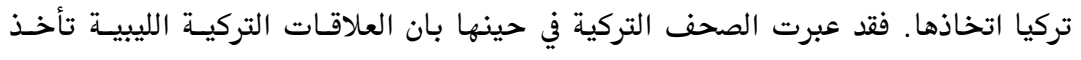

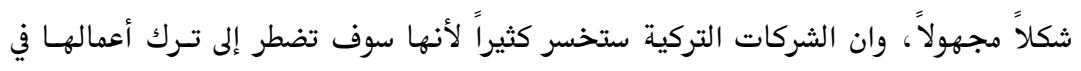

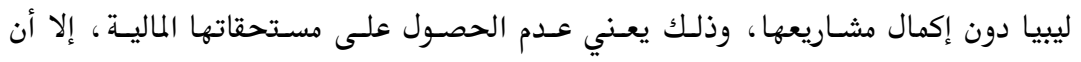

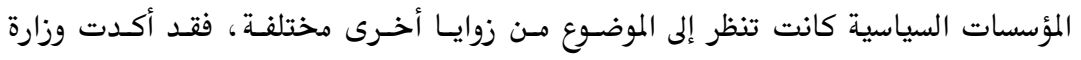

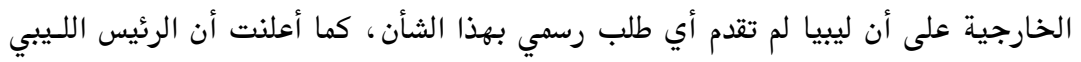

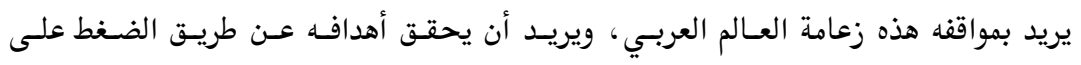

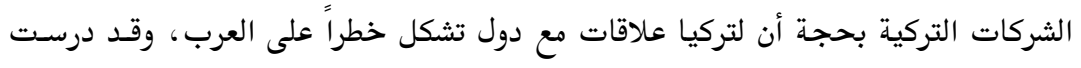

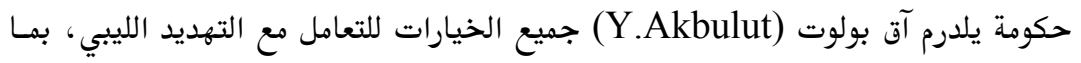

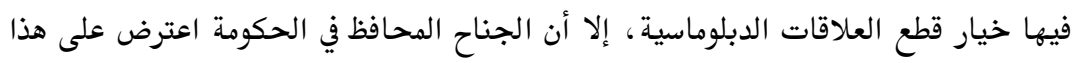

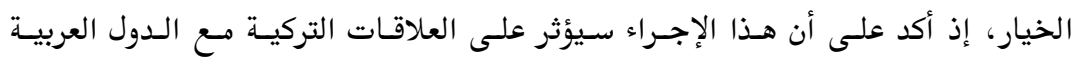

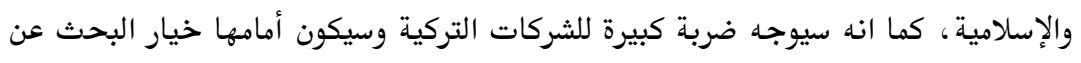

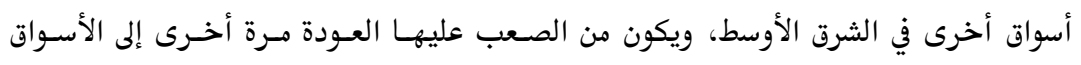

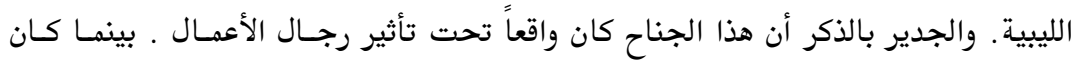




\section{دراسات إقليمية 8 (23)}

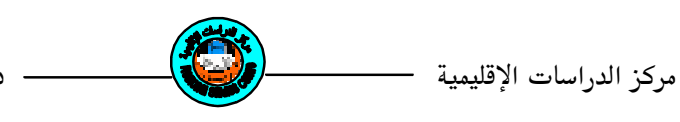

الجناح الليبرالي في الحكومة والعاملين في محيط وزارة الخارجية، يرون وجوب عدم ربط عزة

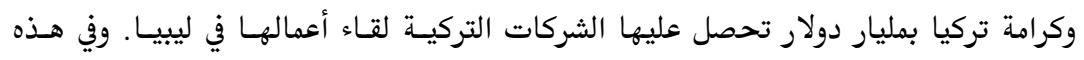

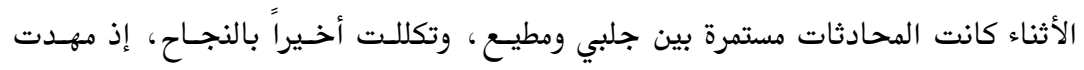

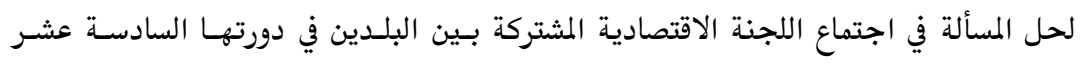

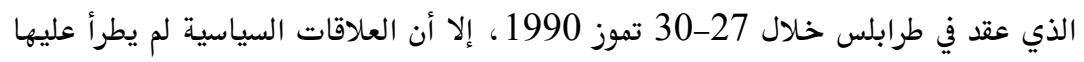
أي تغيير(12).

\section{حرب الخليج الثانية وأثرها في العلاقات الليبية التركية}

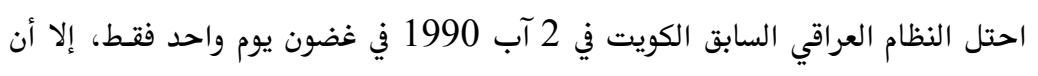

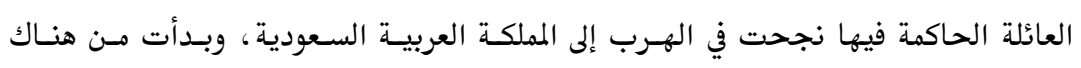

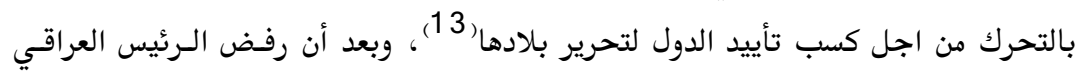

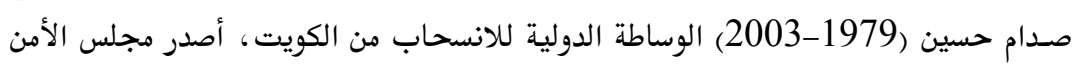

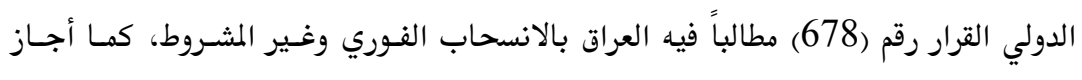

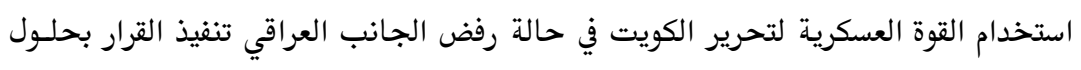

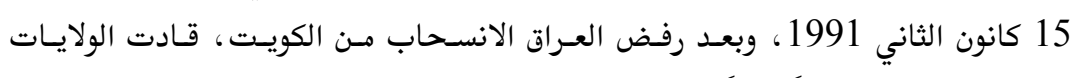

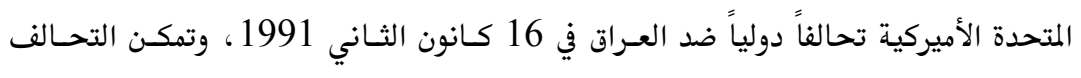

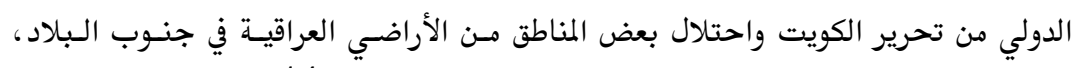

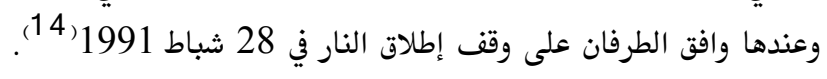

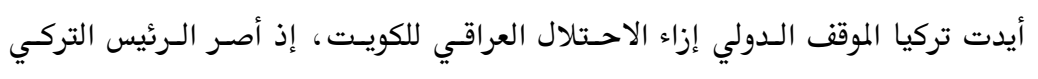

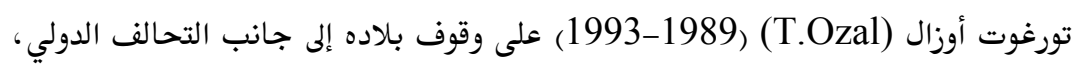

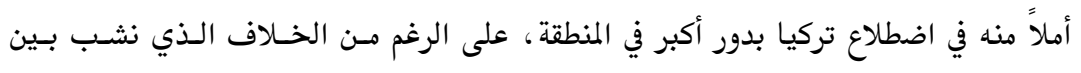

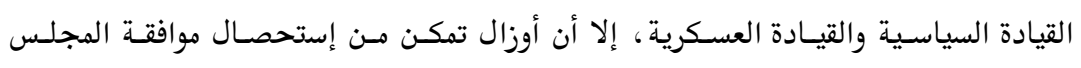

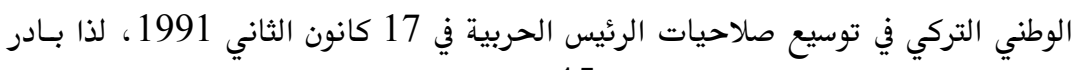

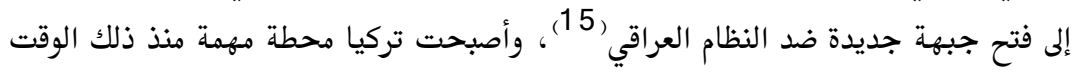




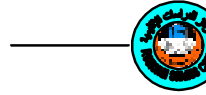

للقوات الغربية، ولاسيما القوات الجويـة الأميركيـة، إذ كانـت أسـراب الطـائرات الغربيـة

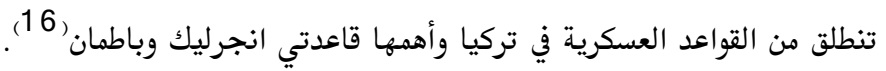

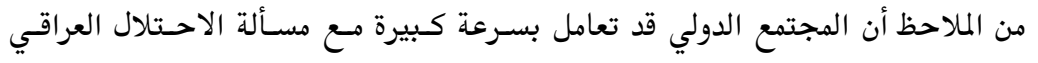

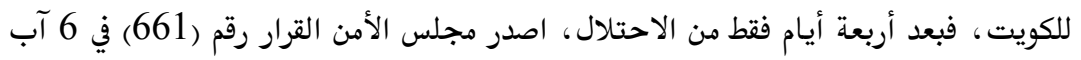

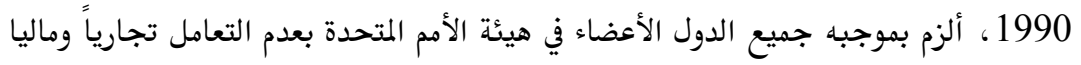

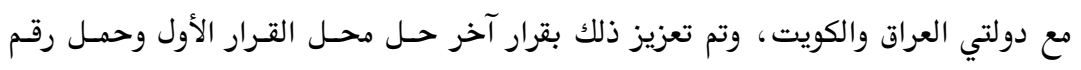

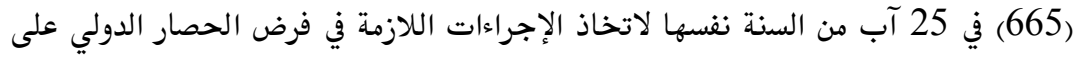

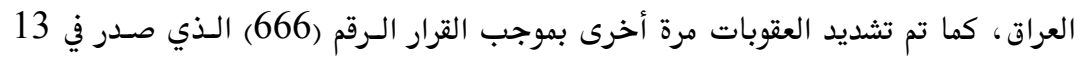
أيلول من السنة نفسها، وتوالت القرارات الأخرى لتأكيد الحظر عليه (17).

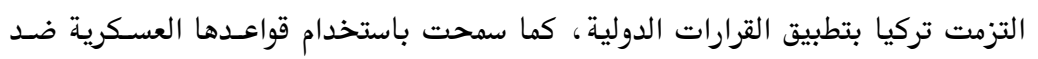

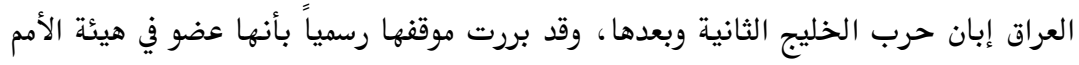

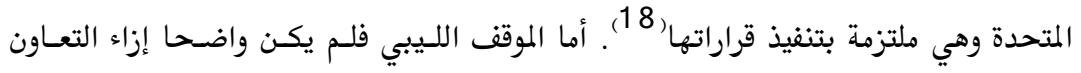

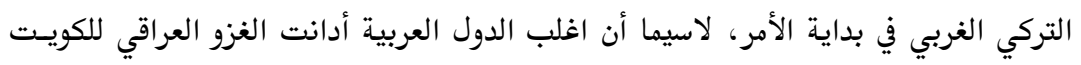

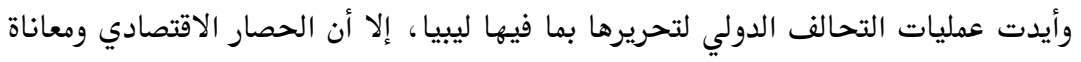

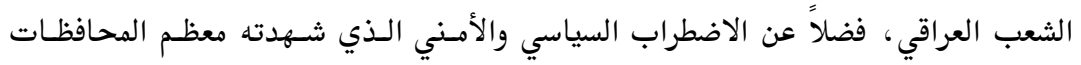

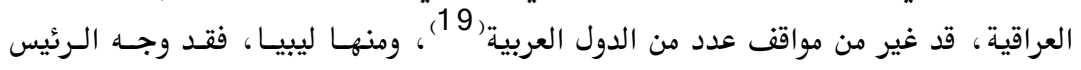

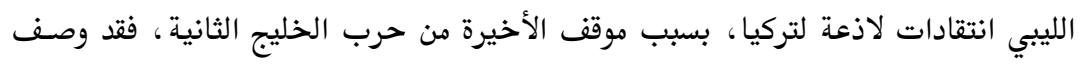

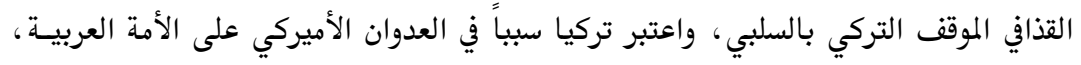

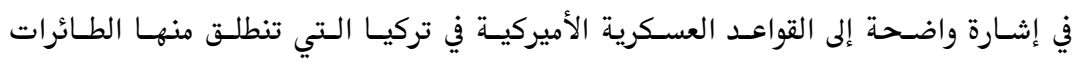

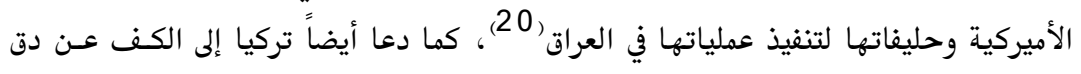

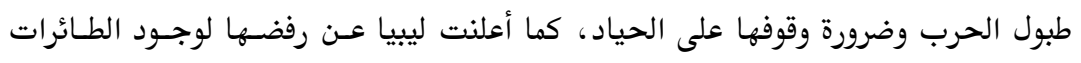

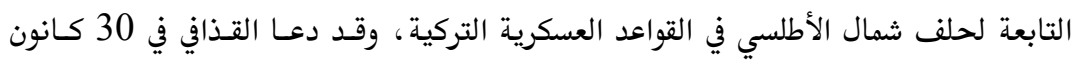

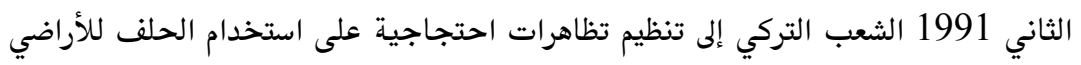

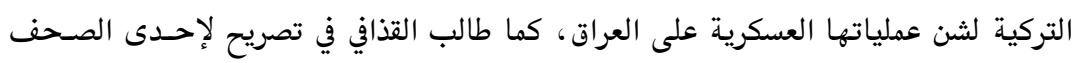

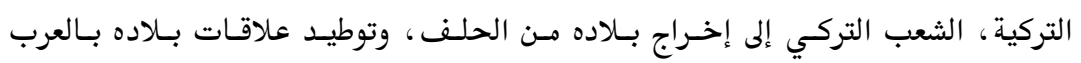




\section{دراسات إقليمية 8 (23)}

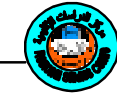

مركز الدراسات الإقليمية

والاتحاد السوفيتي، لان امن تركيا مرتبط بالاتحساد السـوفيتي، وأضـاف إن تركيـا ارتكبـت

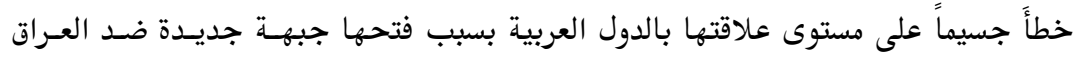

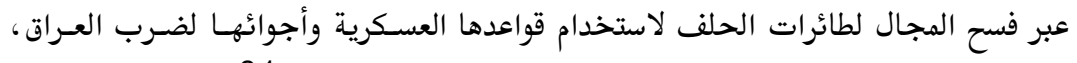

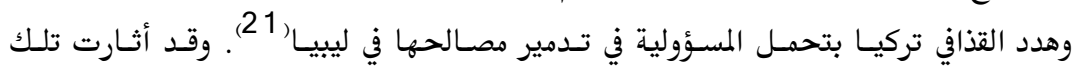

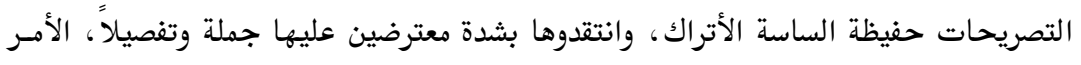

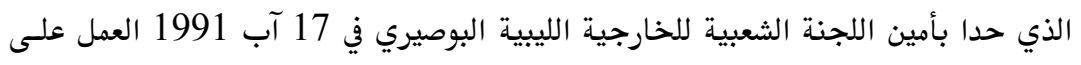

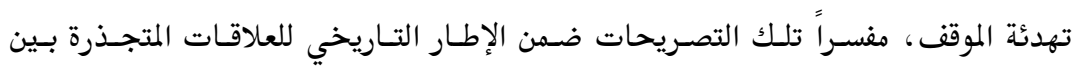

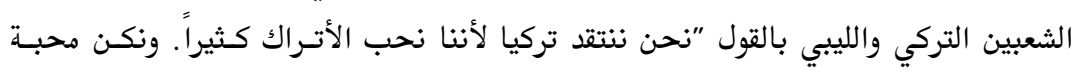

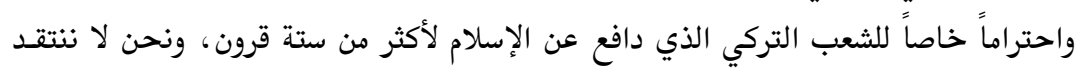

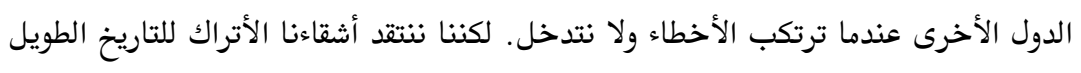

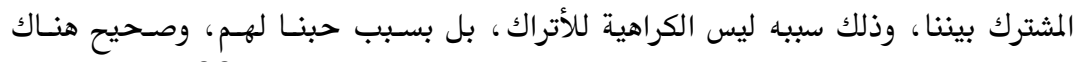

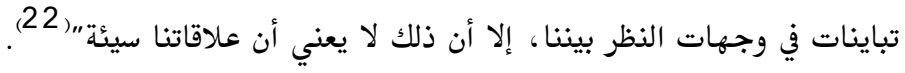

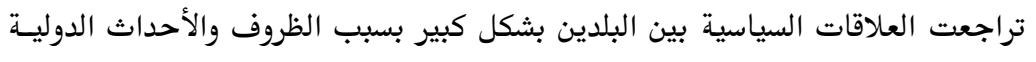

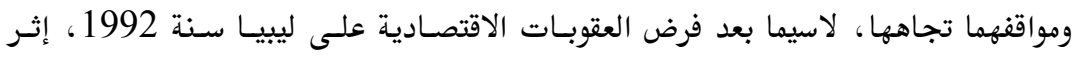

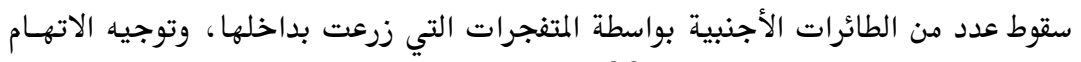
إلى ليبيا بالوقوف وراء تلك العمليات(23).

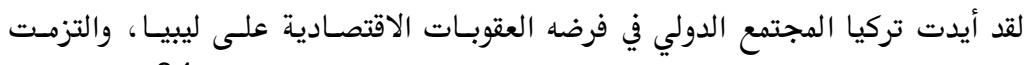

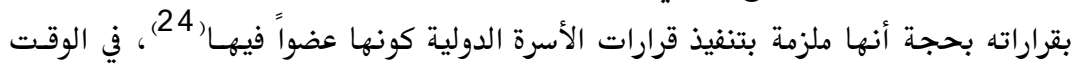

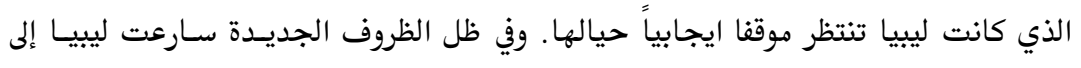

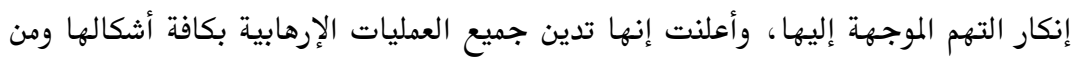

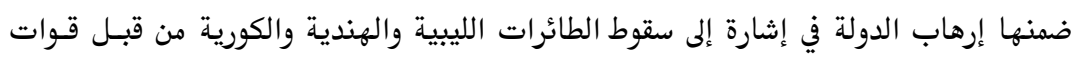

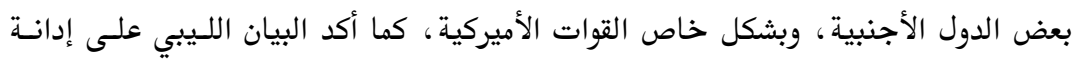

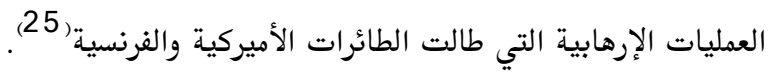

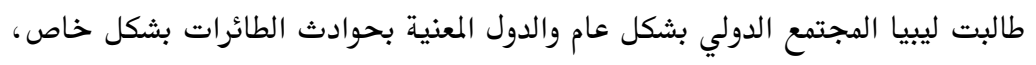

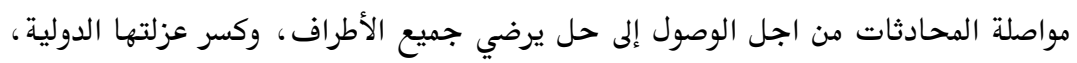


وقد ركزت ليبيا على الجوانب القانونية، والحصول على دعم التكتلات الدولية، مثل جامعة

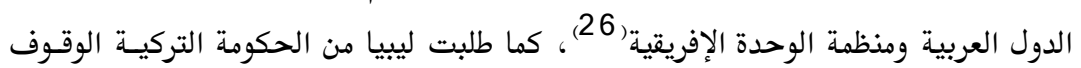

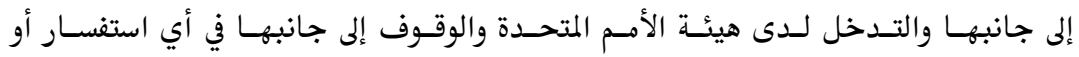

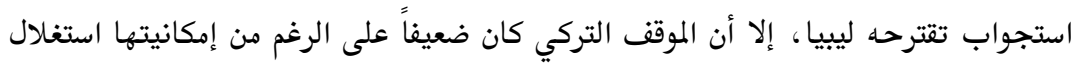

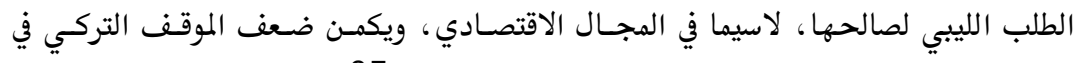

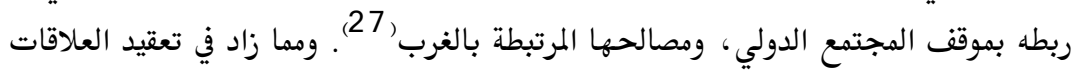

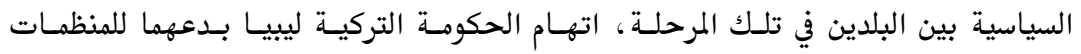
المعارضة للذظام التركي، وقد قدم رئيس الحكومة التركية سليمان ديميريـل (S.Demirel)

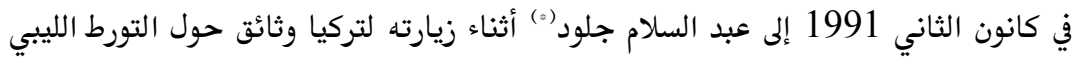

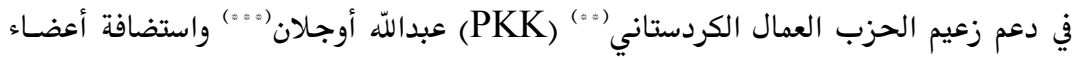

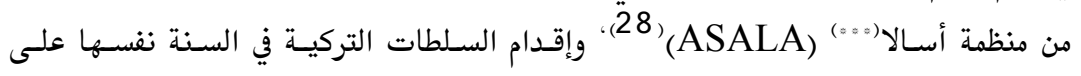

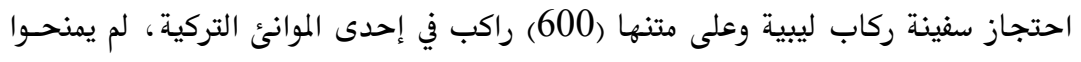

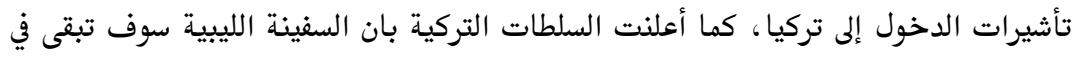

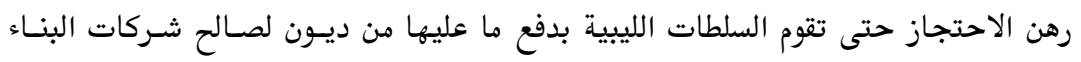

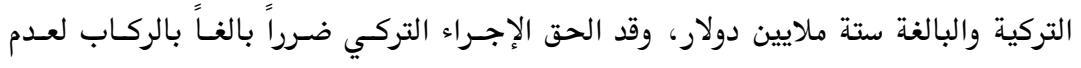

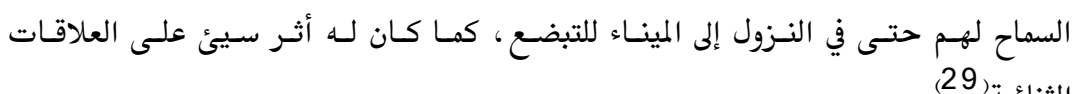
الثنائية)

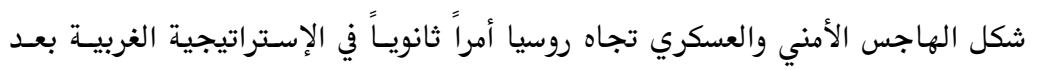

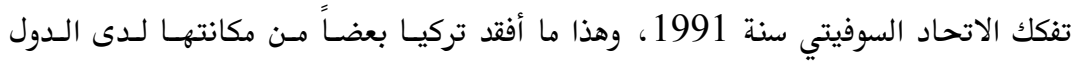
الغربية. ولم ترَ الدول الأوربية ضرورة ملحة في توسيع الجماعة الأوربية ، لاسيما بعد انضمام

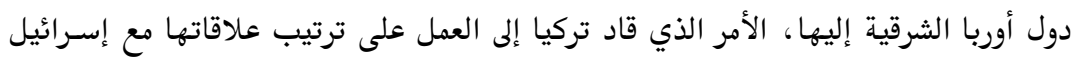

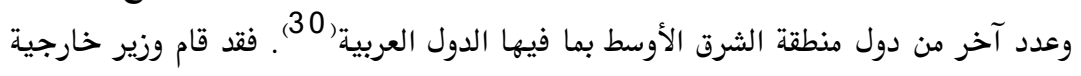

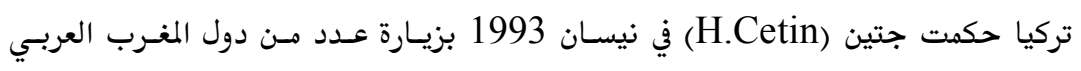

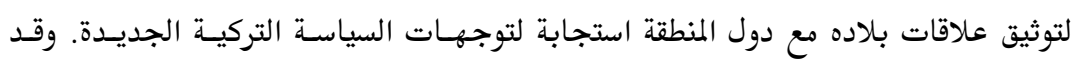


صرح الرئيس الليبي لإحدى محطات التلفزة التركية إزاء المحاولات التركية للعـودة إلى دول

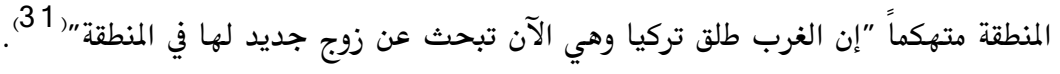

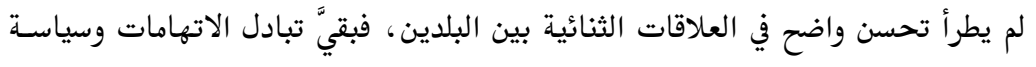

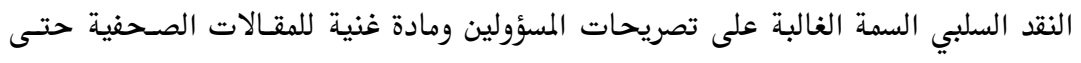

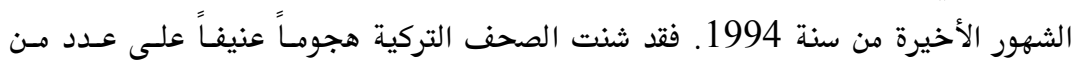
الدول العربية وبشكل خاص ليبيا وسوريا والمملكة العربية السعودية بحجة دعمها للمنظمات

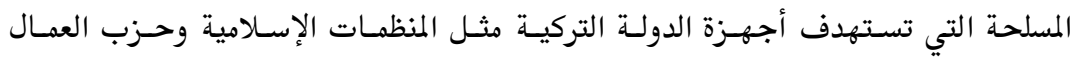
الكردستاني وغيرها، فقد كتبت صحيفة ميلليت (Milliyet) أن اجتماعـات حلف النف النـاتو

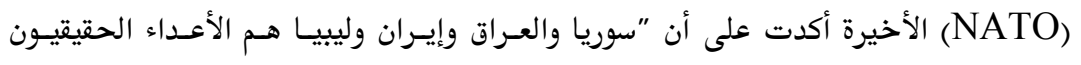

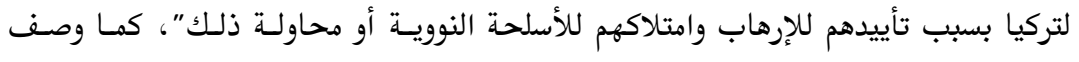

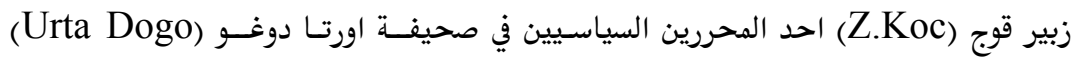

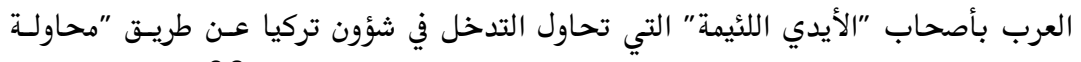

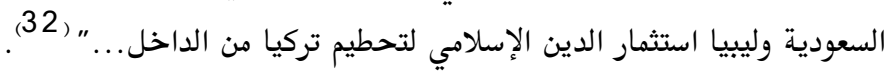

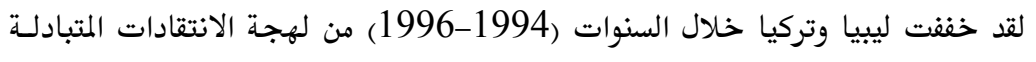

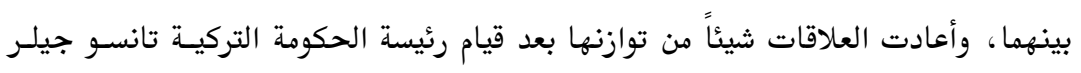

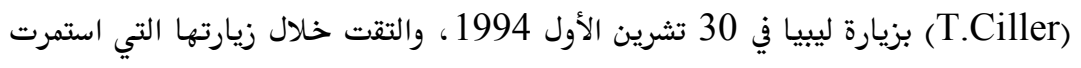

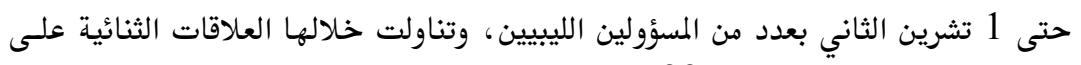
الصعيدين الاقتصادي والسياسي (33).

\section{القضية الكردية وموقعها في العلاقات الليبية التركية}

كان الموقف الليبي أكثر وضوحا من الدول العربية الأخرى تجاه القضية الكرديـة، على ملى

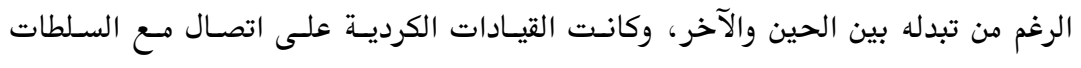

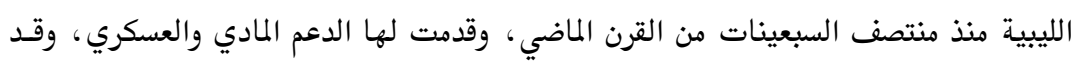

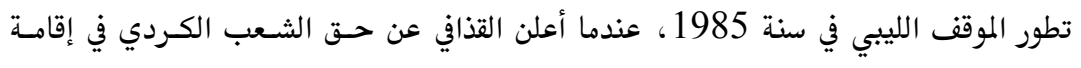

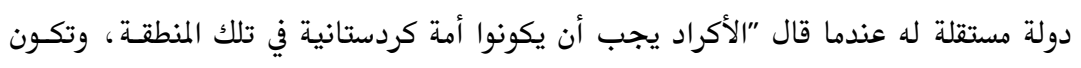


هذه الأمة، شقيقة للأمة العربية، والأمة التركية والأمة الفارسية، وتأخذ مكانهـا على قدم

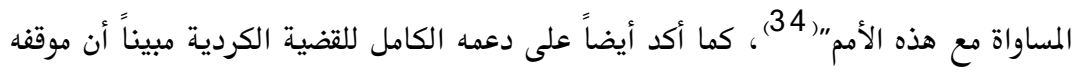

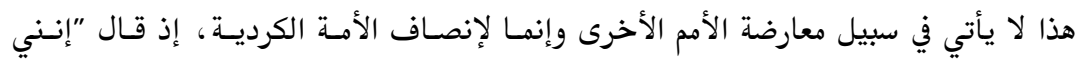

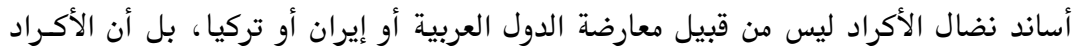

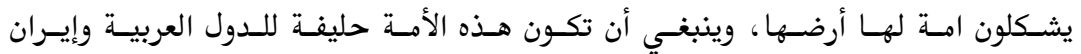
وتركيا"(

لم يقف الدعم الليبي للكرد عند حدود التصريحات، بل تجـاوز ذلك، إذ قـدمت ليبيـا

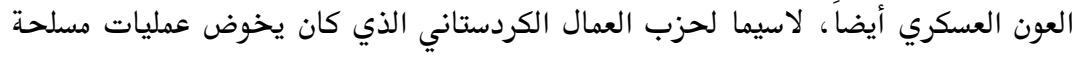

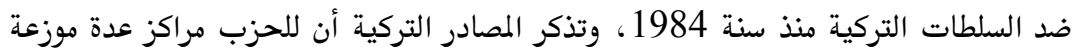

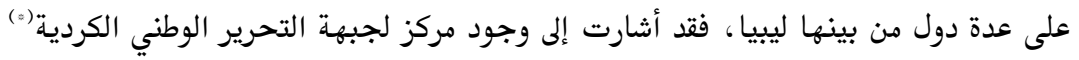
في ليبيا(36)، وكانت تركيا قد وجهت انتقادات شديدة في مطلع سنة 1992 للنظام الليبي ليبي

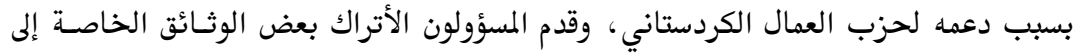

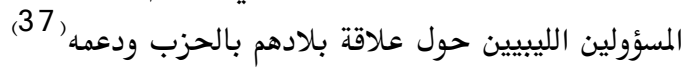

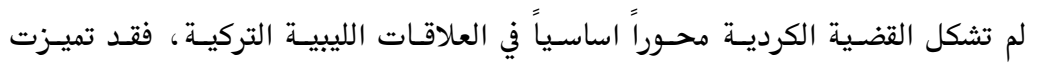

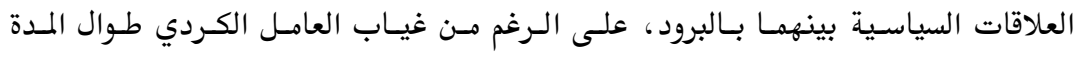

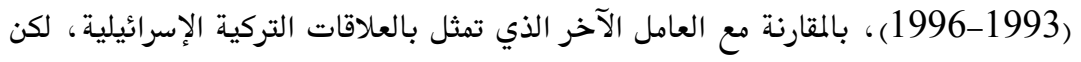

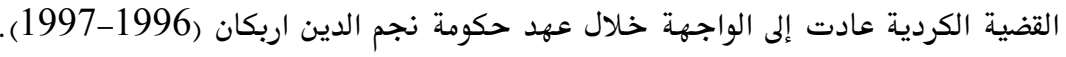

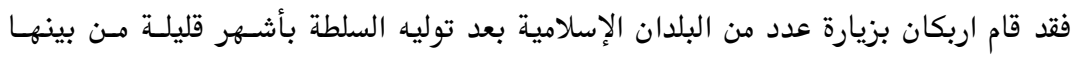

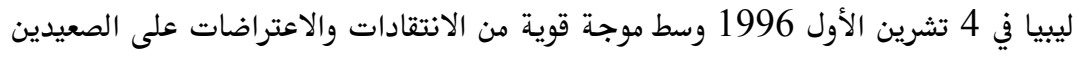

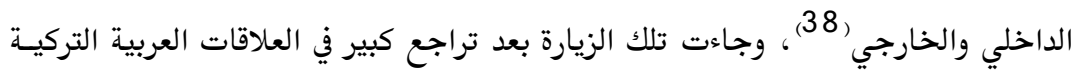
خلال النصف الأول من سـنة 1996، لاسيما بعـد توقيـع الاتفاقيـة العسكرية بـين تركيـا

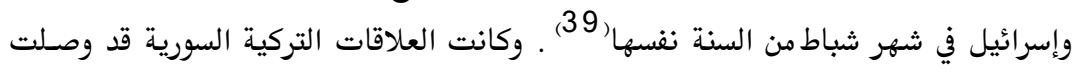

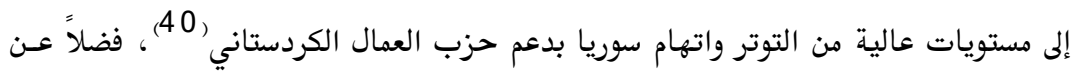

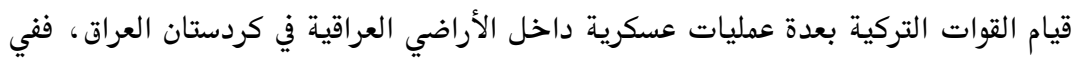
شهر حزيران من سنة 1996، توغلت القوات التركية في الأراضي العراقية مرتين، الأولى في 
الخامس عشر والثانية في السابع والعشرين منه ، واستخدمت خلالهما مختلف أنواع الأسلحة

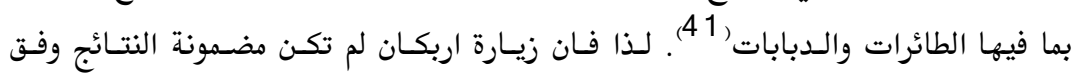

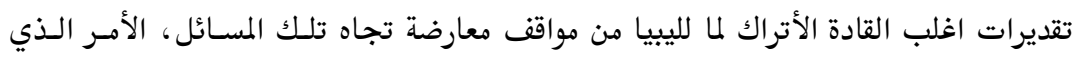
دعا بعضهم للتحفظ على الزيارة واعتراض بعضهم الآخر كما سيتبين لاحقاً.

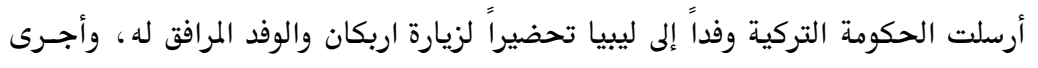

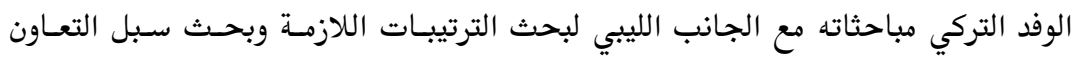

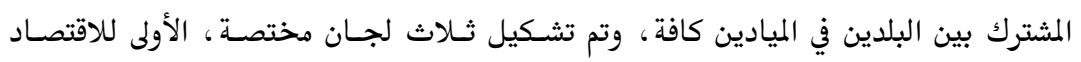
والتجارة والثانية للتعاون الصناعي والمصرفي، فيما خصصت الثالثة للتعاون التقني (42).

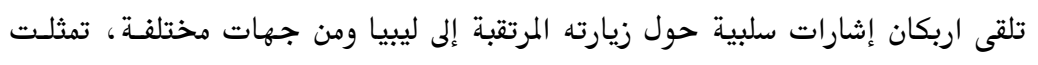

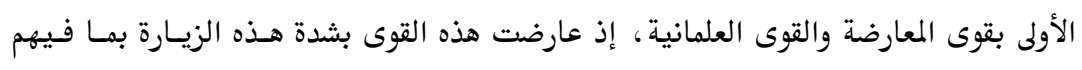

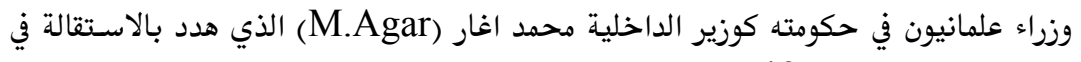
حالة تنفيذ هذه الزيارة(43)، أما الجهة الثانية فتمثلت بالولايات المتحدة الأميركيسة ، الـتي

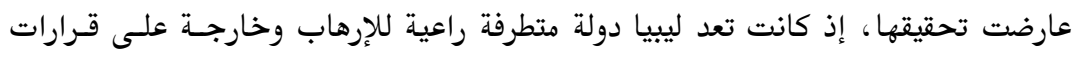

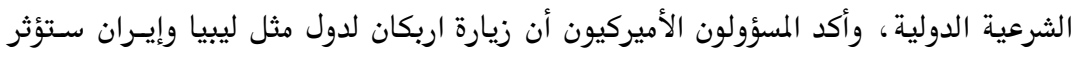

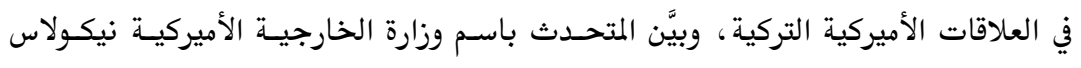

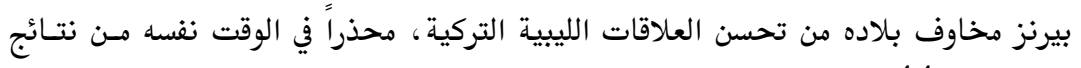

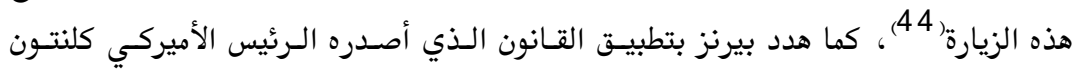

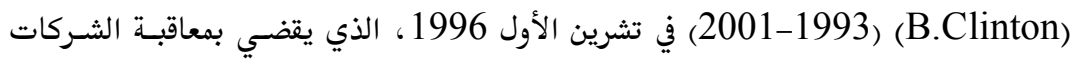

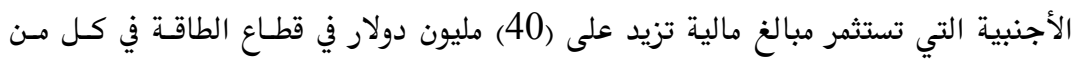

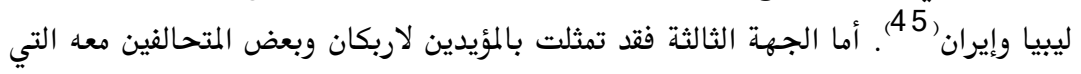

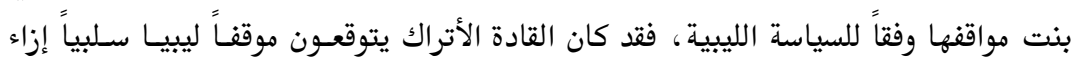

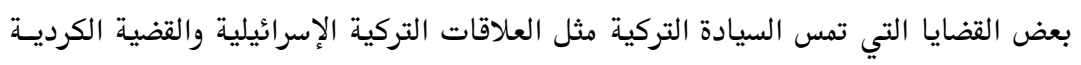

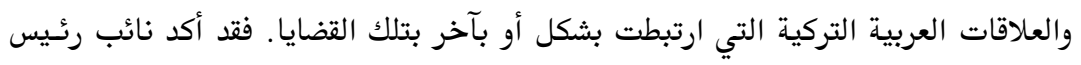

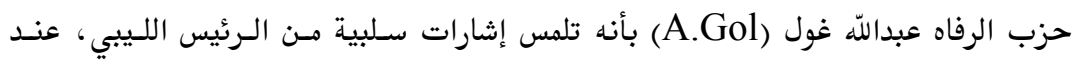

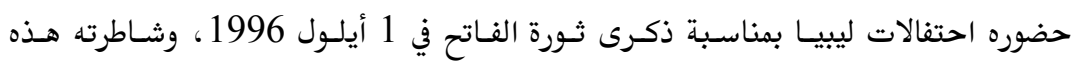




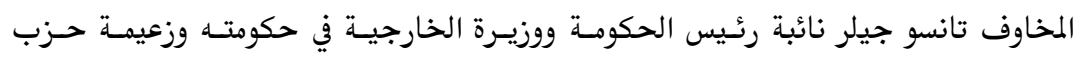

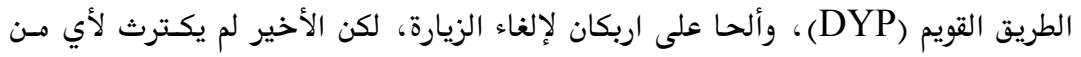

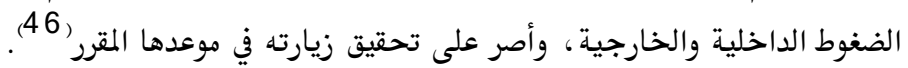

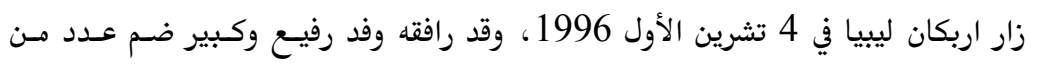

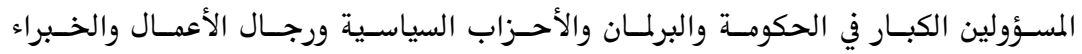

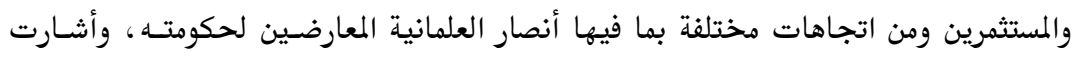

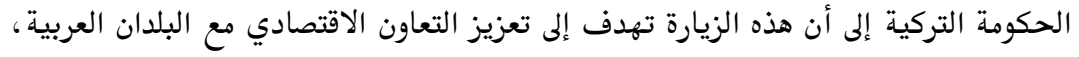

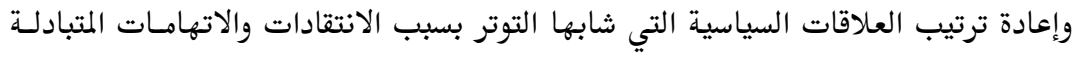

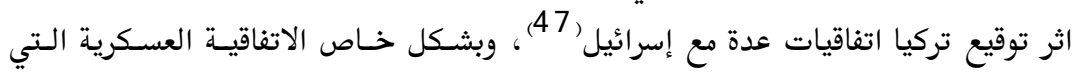

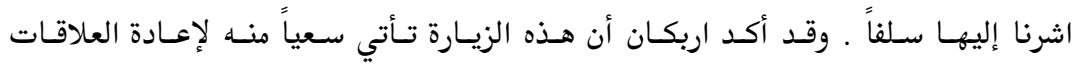

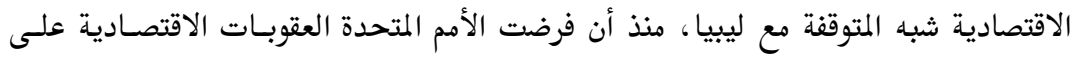

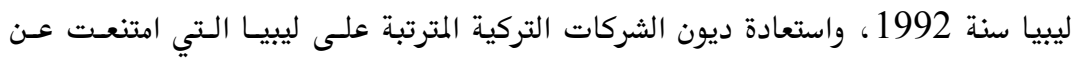

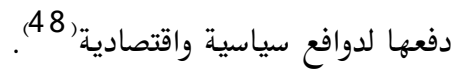

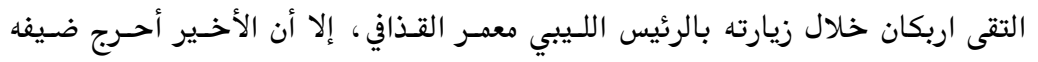

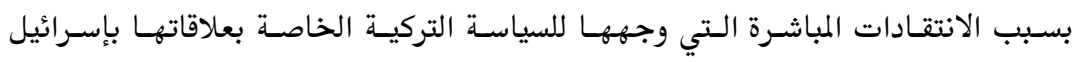
والولايات المتحدة الأميركية وحلف الناتو والقضية الكردية، فقد هـاجم بشـدة تركيـا، وقـال

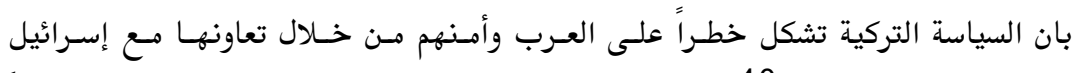

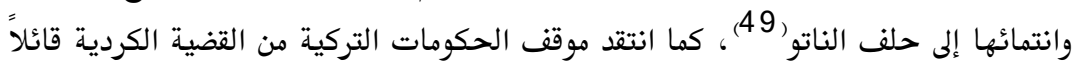
"يجب أن يأخذ الأكراد مكانهم كدولة ضسمن منطقـة الشـرق الأوسط وان على التى تركيـا أن لا لا

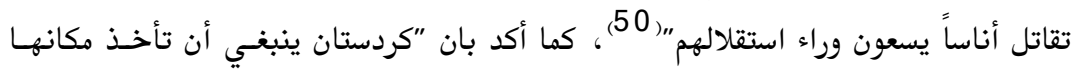

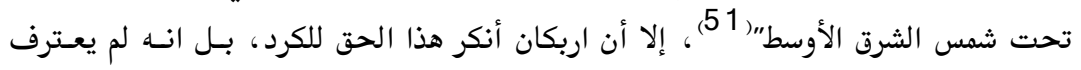

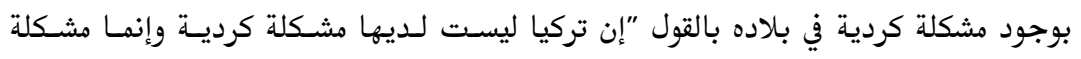

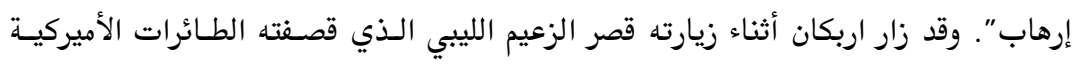

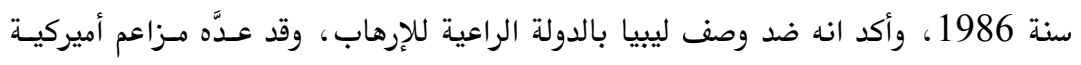

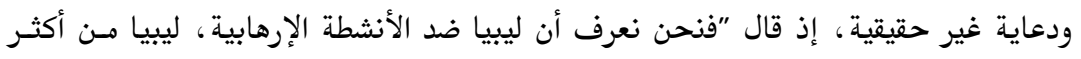




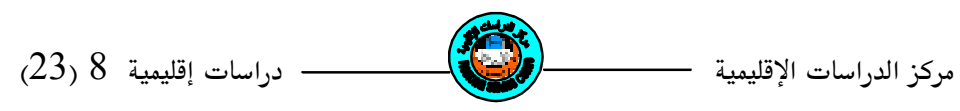

الدول التي تعـاني مـن الإرهـاب"(525، كهـا أعلـن اربكـان عـن موقفه الـرافض للعقوبـات

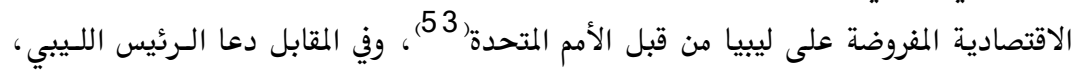

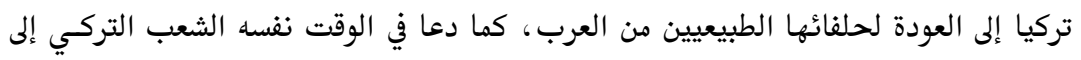

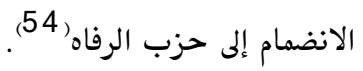

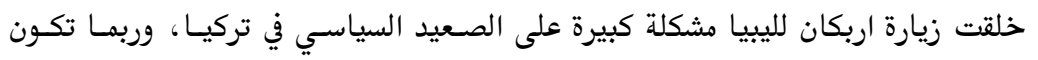

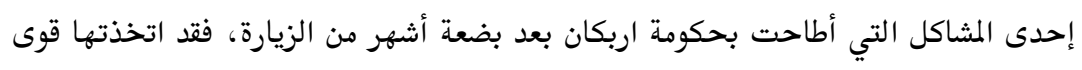

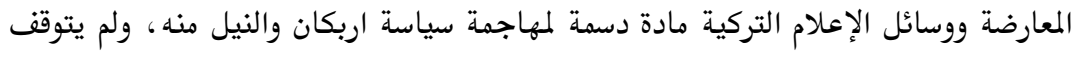

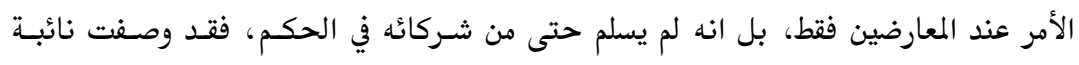

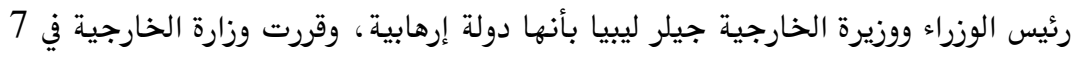

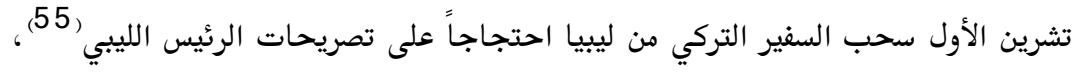

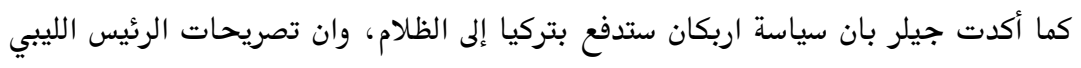

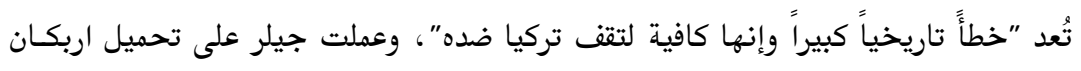

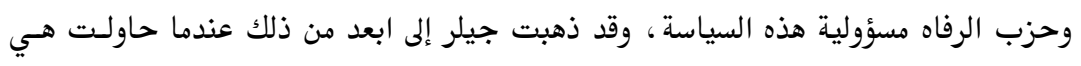

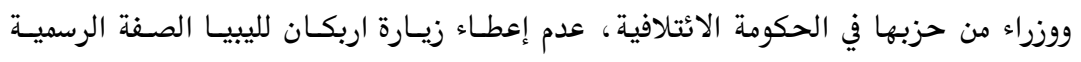

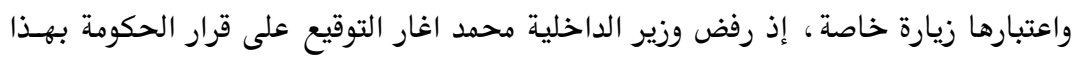

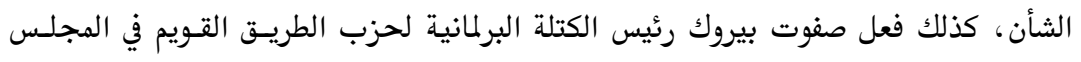

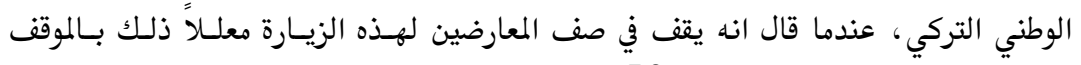

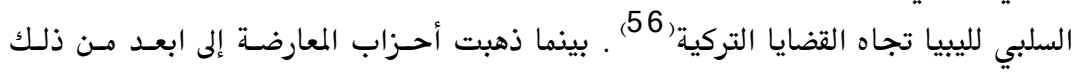

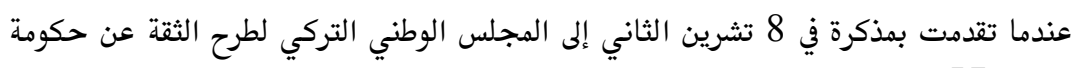

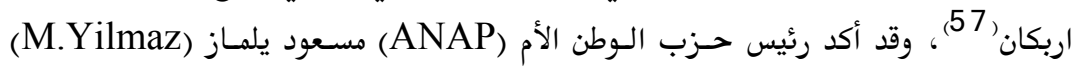

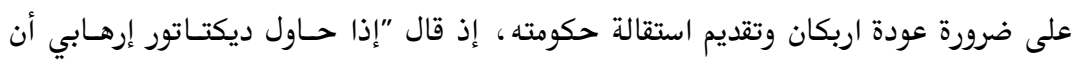

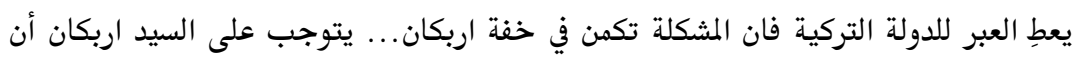

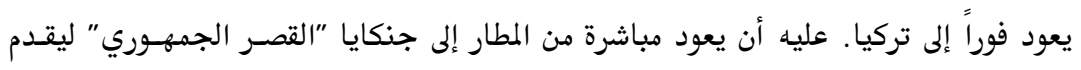

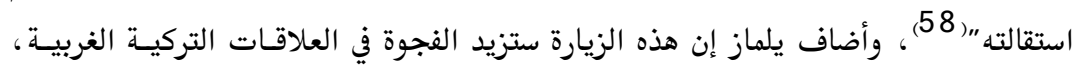

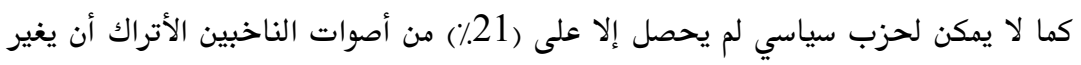




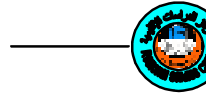

السياسة الخارجية للبلاد. وفي السياق نفسه أكد احد قادة حـزب اليسـار الديمقراطي ممتـاز

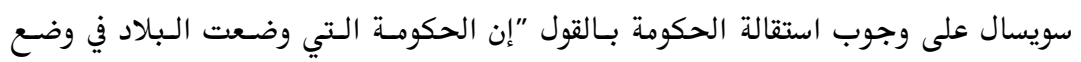

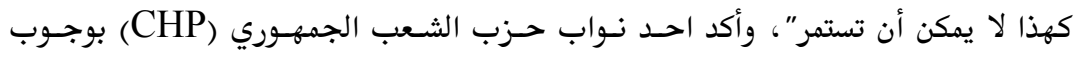

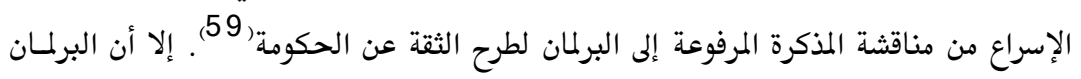

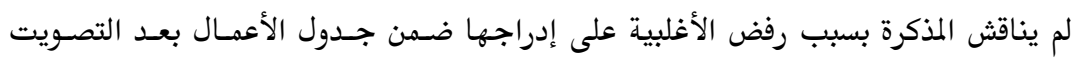

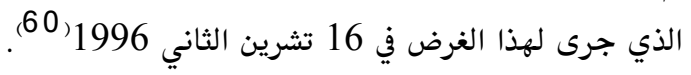

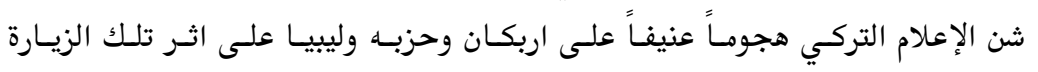

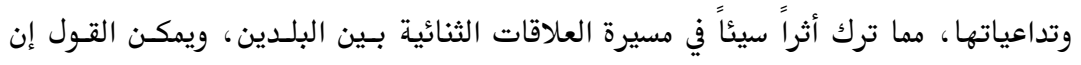

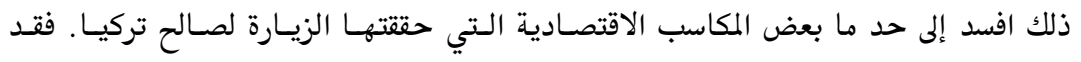

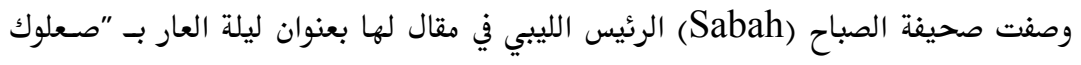

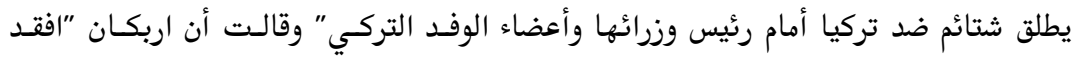

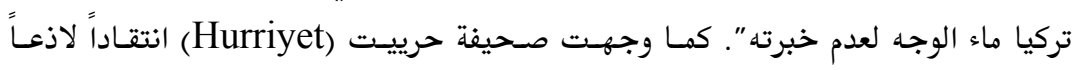

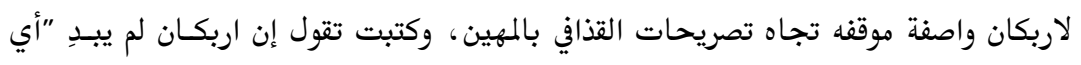

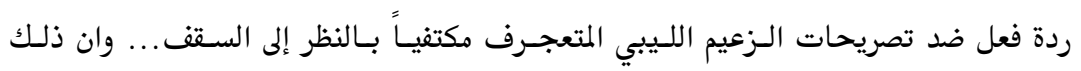

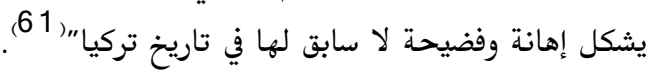

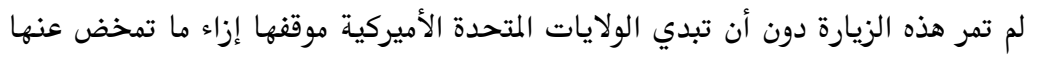

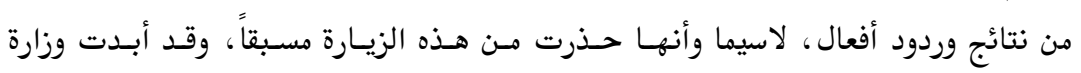

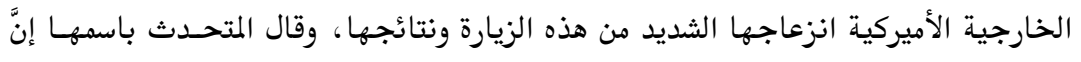

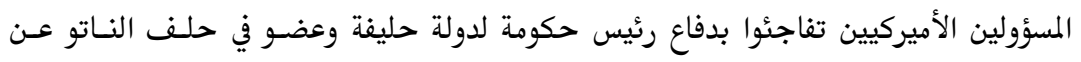

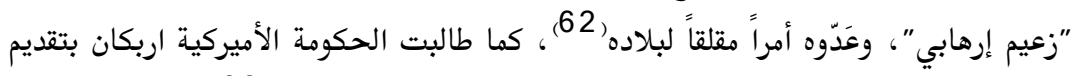

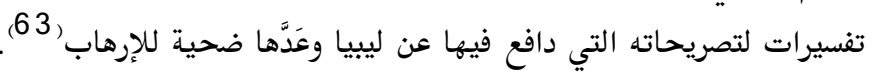

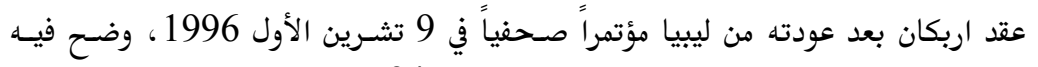

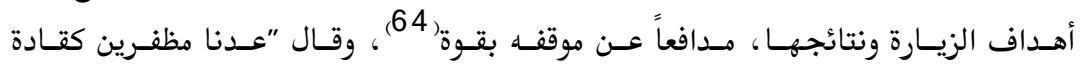

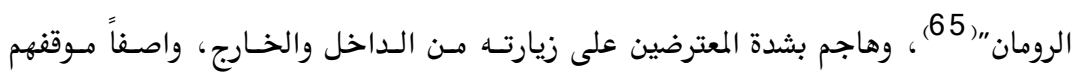

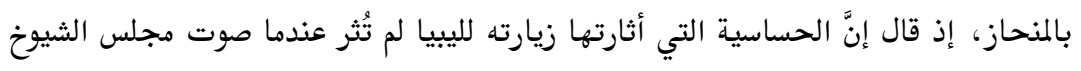




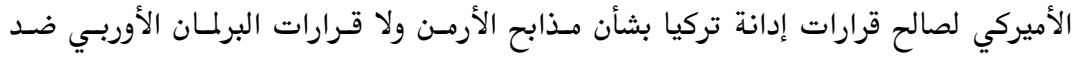

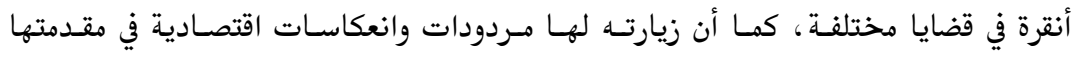

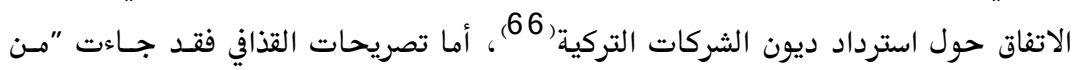

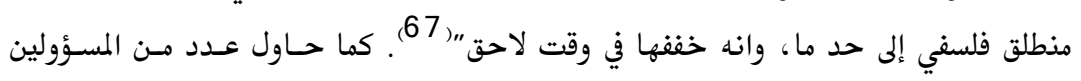

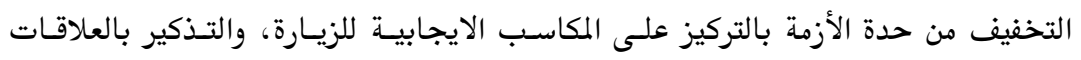

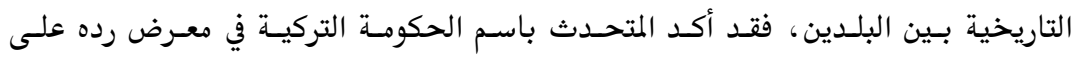

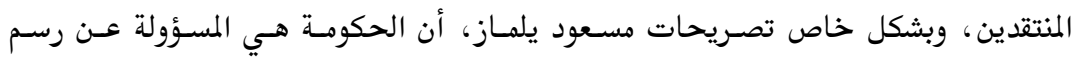

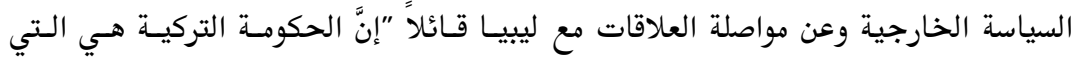

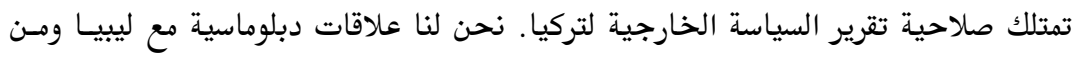

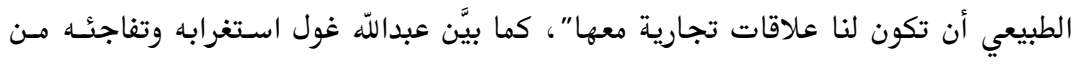

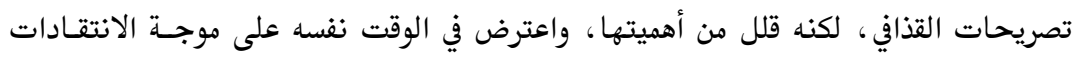

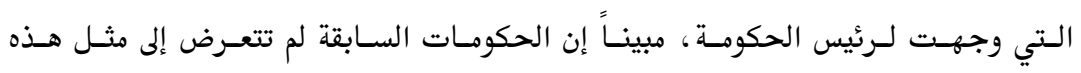

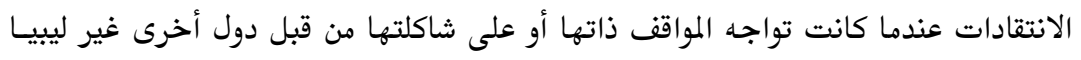

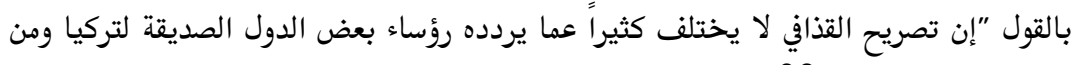

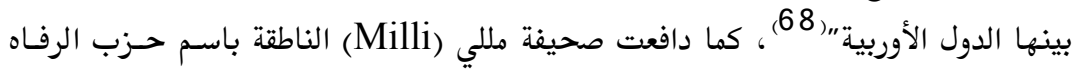

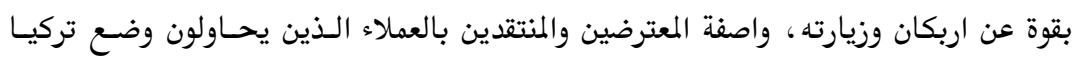

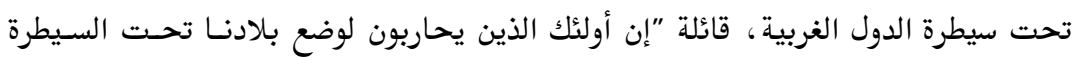

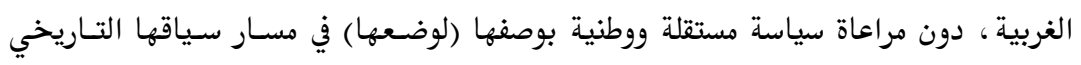

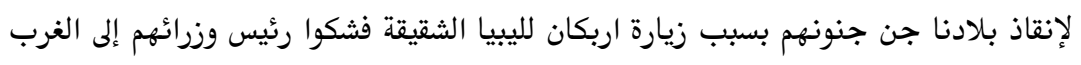

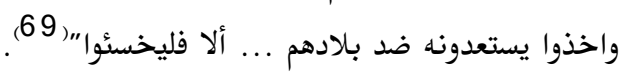

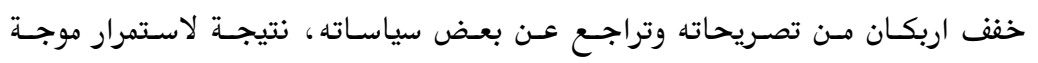

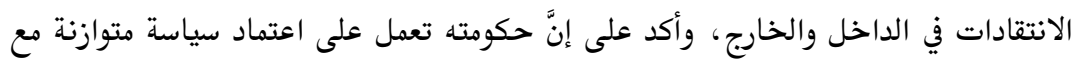

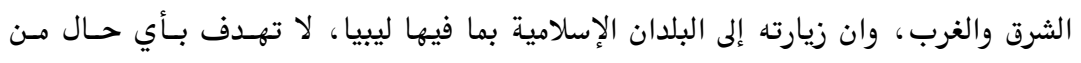

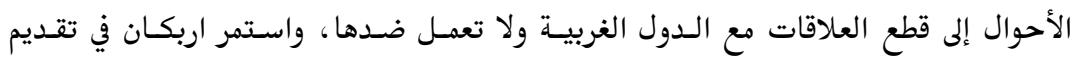

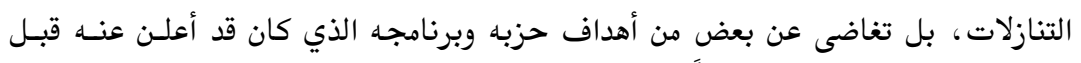


استلام السلطة، منها إخراج تركيا من حلف الناتو والتخلي عن مسـاعي تركيـا في الانضمام

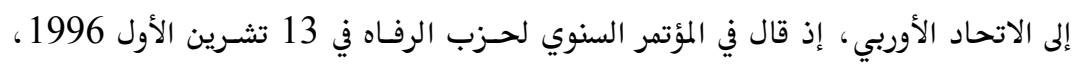

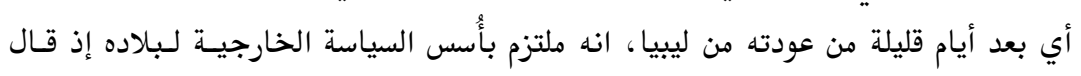

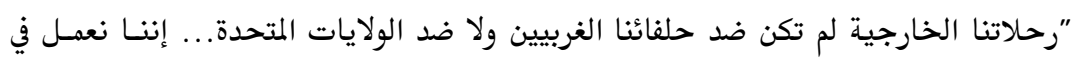

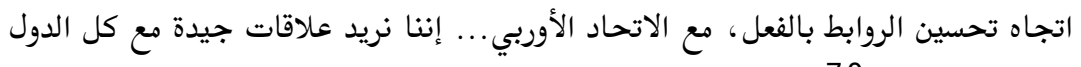

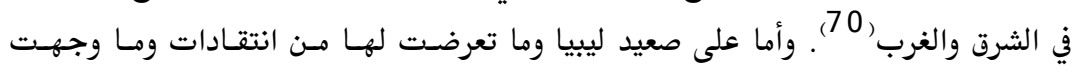
للحكومة التركية، فقد لخصها الرئيس الليبي في أنها تأتي لخدمة المصالح الأجنبية ولا تـنم

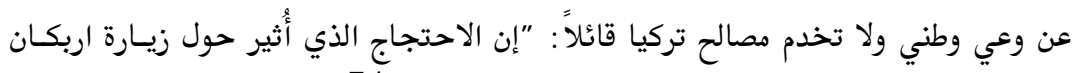

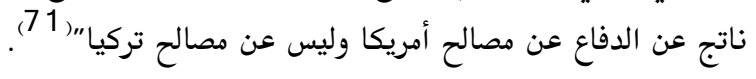

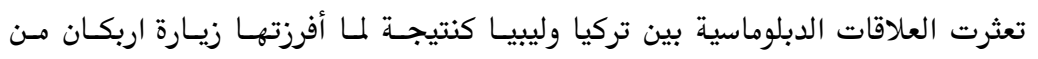

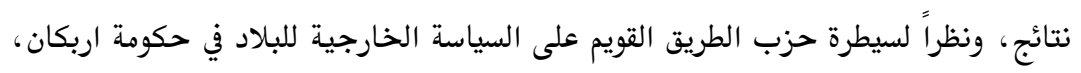

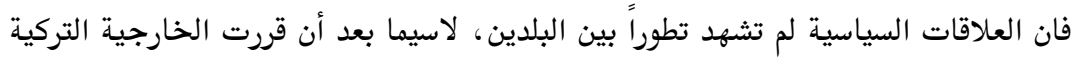

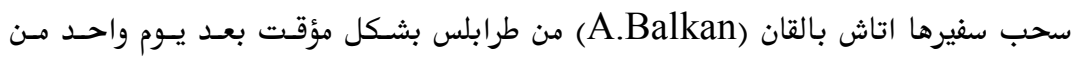

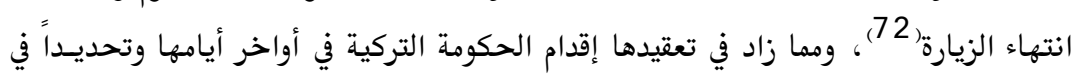

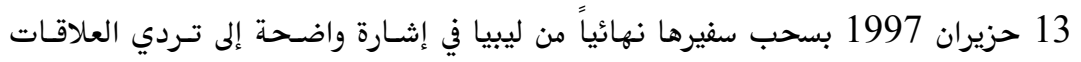

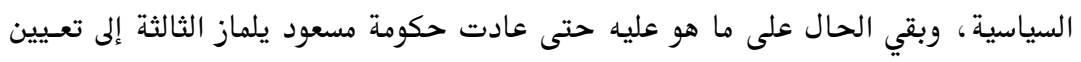

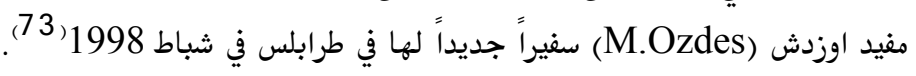
توتر العلاقات السورية التركية وقضية حزب العمال الكردستاني

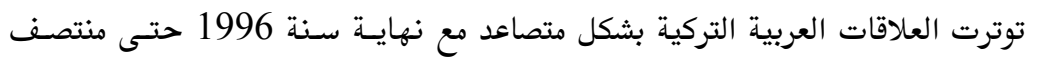

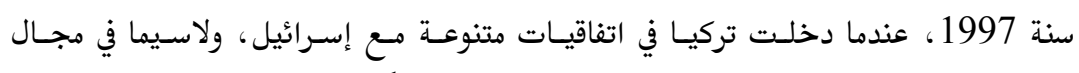

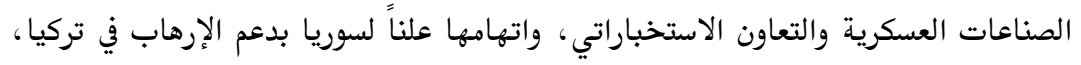

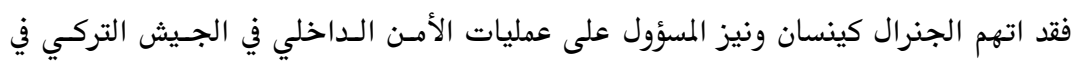

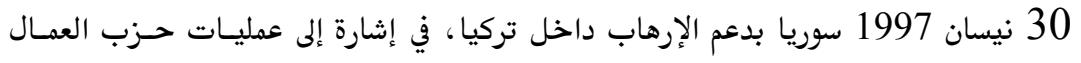

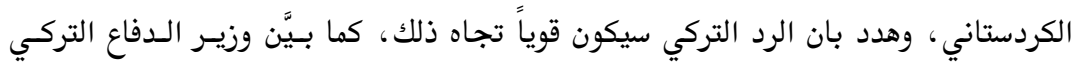
تورهان تايان (T.Tayan) قلق بلاده وحلف الناتو تجاه امتلاك سـوريا لأسـلحة كيمياويسة 
مركز الدراسات الإقليمية ـ (23)

وصواريخ باليستية ، وقد جـاءت هـذه التصـريحات منسـجمة مـع الموقـف الإسـرائيلي (74)، وعادت إلى الواجهة مرة أخرى مشكلة المياه بين البلدين، هذه المشكلة التي ارتبطت إلى حسدٍ

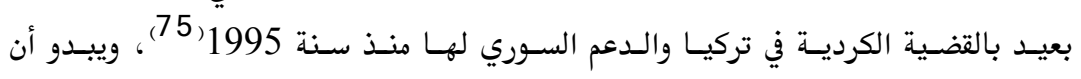
العلاقات السورية التركية بدأت تشهد مرحلة جديدة من التصعيد مع وصول مسعود يلماز إلى رئاسة الحكومة في 28 حزيران 1997 في أعقاب استقالة حكومسة اربكـان في 18 حزيسران، وأصبحت سياسة التصعيد مع سوريا متناغمة ما بـين رئاسـة الجمهوريسة ورئاسـة الحكومسة والمؤسسة العسكرية(76)

تطورت الأزمة بشكل خطير بسين البلسدين في منتصفف 1997، عنـدما تبـادل الطرفـان

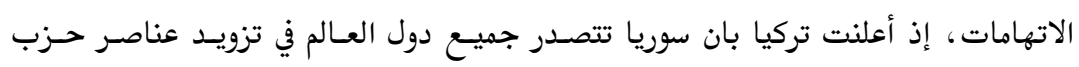

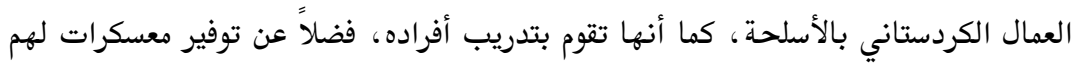

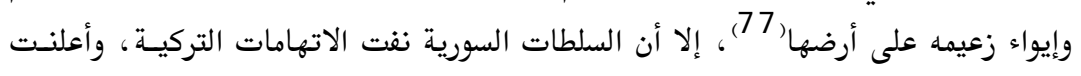
أن القضية الكردية شأن داخلي تركي على تركيا حلهها بنفسها. إلا أنهـا في الوقـت نفسـه أججت الموقف عندما نددت بالعمليات العسكرية التركية في الأراضي العراقية بحجة ملاحقة عناصر الحزب، كما أن سوريا اتهمت إسرائيل في أنهـا تقف وراء تصعيد الموقف التركي ضدها (78). بينت ليبيا موقفها إزاء هذه التطورات الجديدة في المنطقة ، وأدلى رئيسها القذافي بتصريح

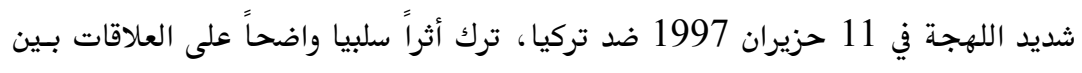

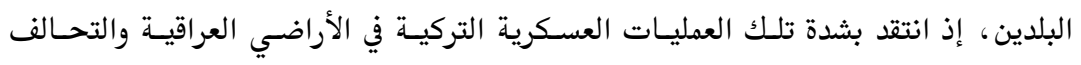

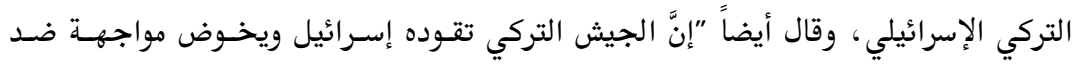

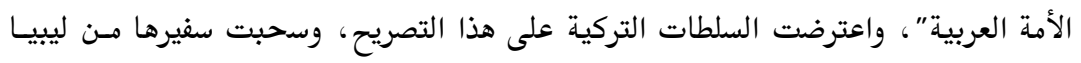
نهائياً ووصفت الحكومة التركية التصريح الليبي بالعدوانية ضد بلادها وقواتها المسلحة ، كما هاجم البيان التركي ليبيا ورئيسها، مما دفع باللجنة الشعبية للشؤون الخارجية إلى أن تعلن

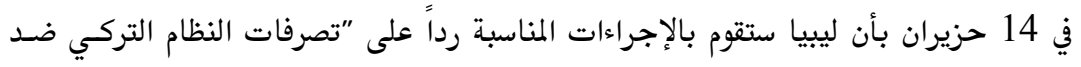
الشعب العربي الليبي"، واعتبرت ما جاء في البيان التركي " إسـاءة بالغـة للشعب اللـيبي

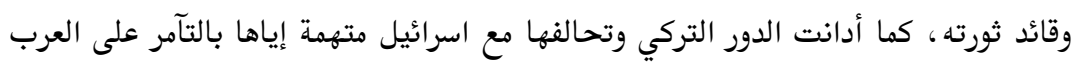


ويتضح ذلك في "عدوان تركيا غير المبرر على أراضي العراق في انتهاك صريح لسيادته ، وتبرز

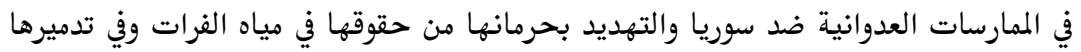

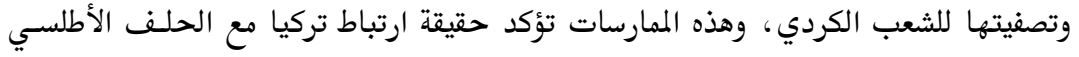
والعدو الإسرائيلي"، وأكدت هذا الموقف مصادر دبلوماسية ليبية في القـاهرة وعـدَّت الإجـراء

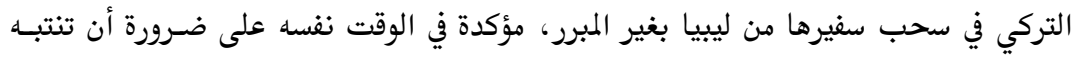

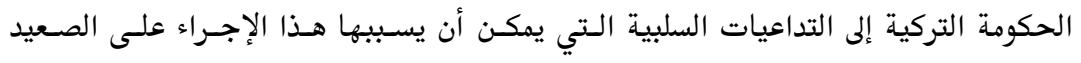

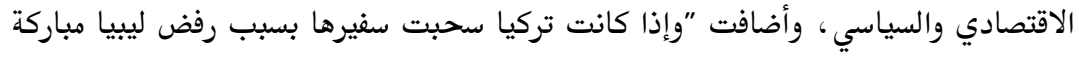

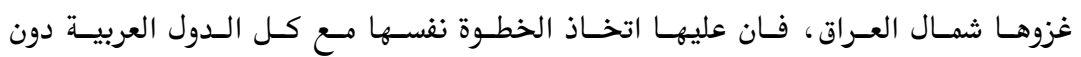
استثناء"(79). والجدير بالذكر أن السفير التركي مغيد اوزدش لم يعد إلى وظيفته في ليبيـا إلا

في شباط 1998) (80.

شهدت سنة 1998 تحولات كبيرة على صعيد علاقات تركيا الخارجيـة ، لاسيما بعـد

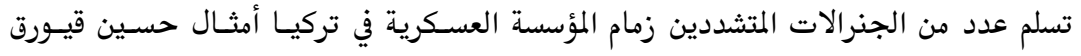

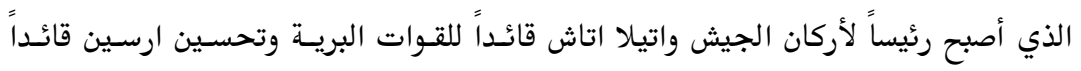

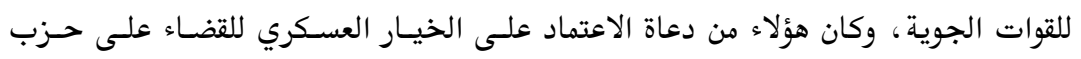

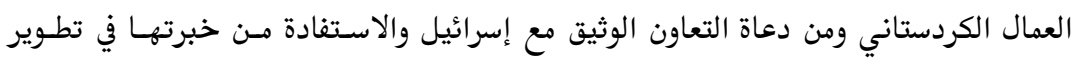

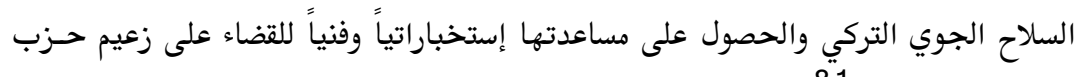
العمال الكردستاني (81). وبعد فشل المفاوضات السورية التركية خلال النصف الأول من سنة 1998 لحل الأزمسة

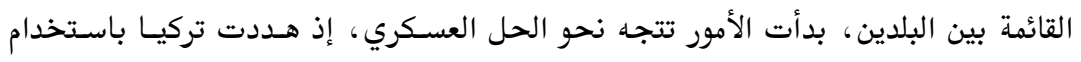

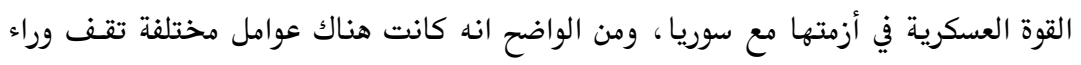

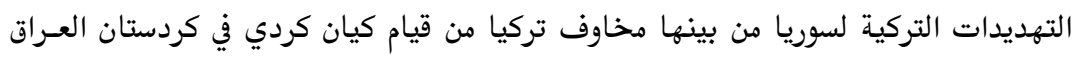

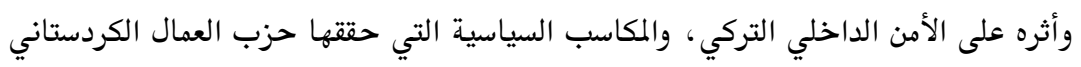

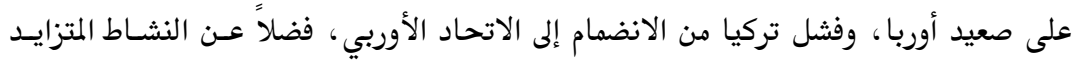

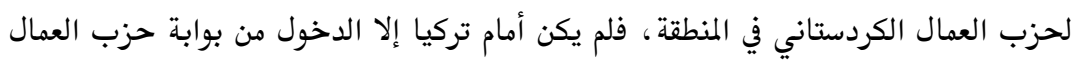

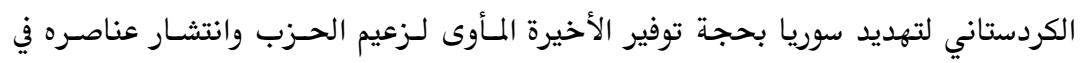




\section{دراسات إقليمية 8 (23)}

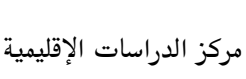

معسكرات متعددة في الأراضي السورية وسهل البقاع في لبنان(82)، وقد وصل التهديد التركي

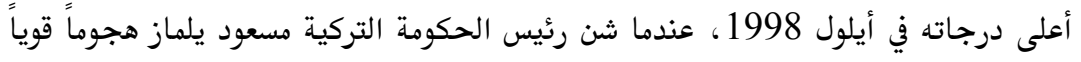

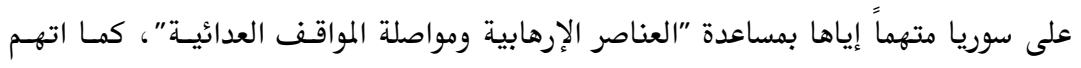

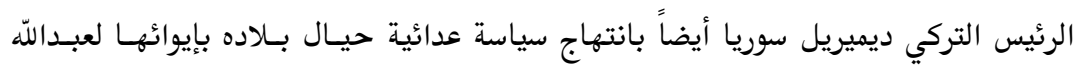

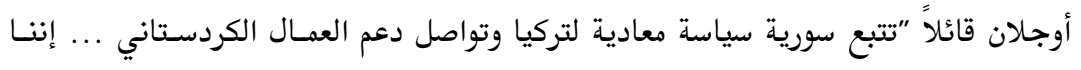

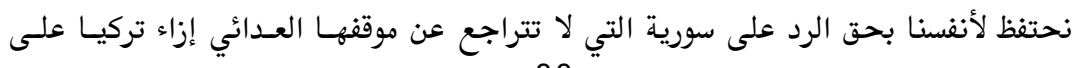

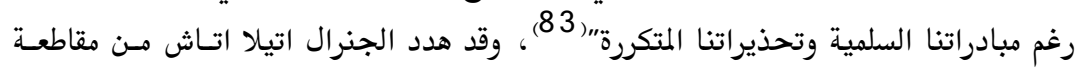

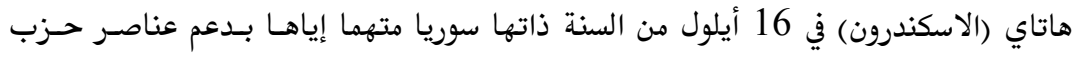

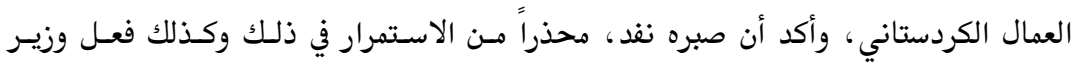
الخارجية التركي إسماعيل جم (I.Cem) (84).

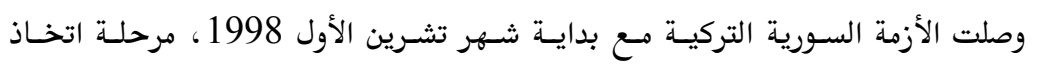

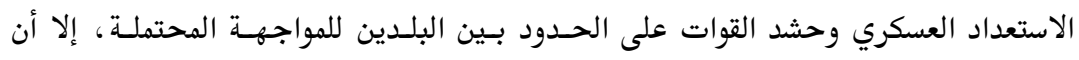

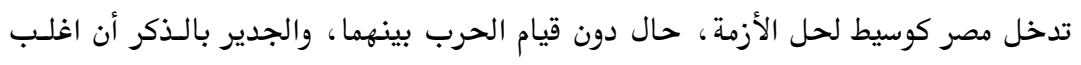

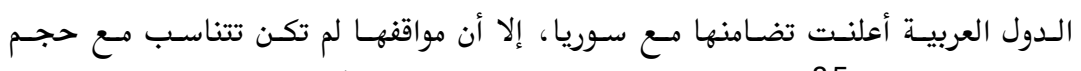

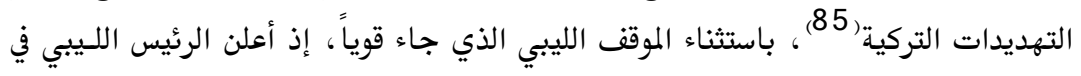

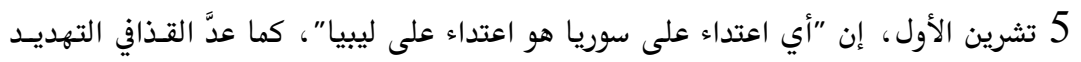

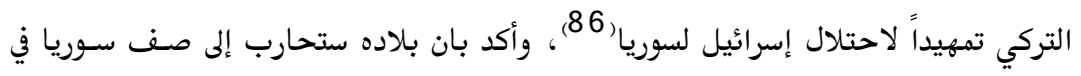

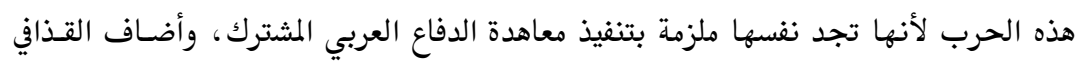

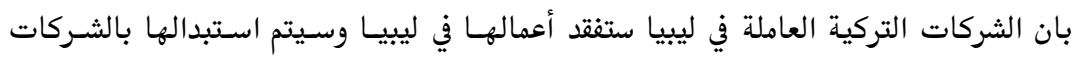

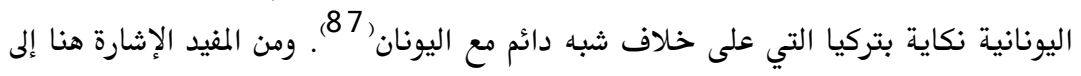

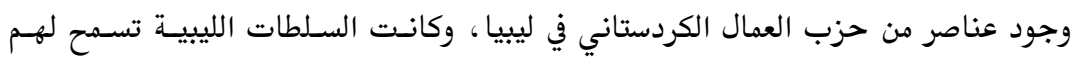

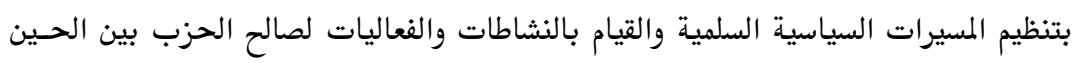

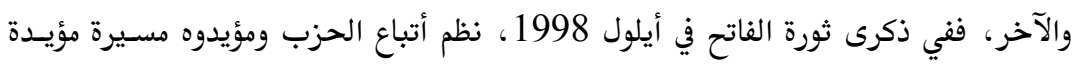

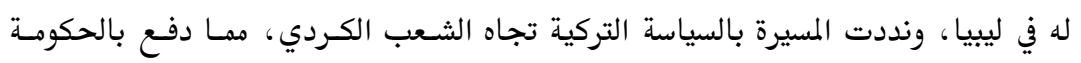

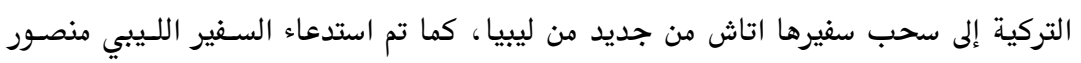




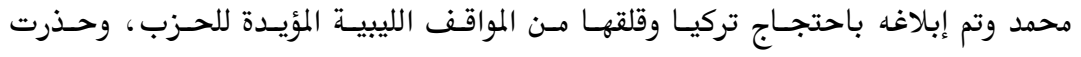

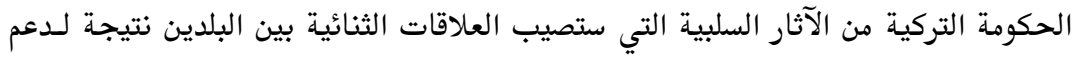

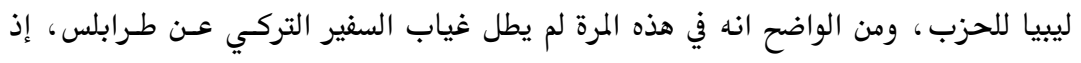

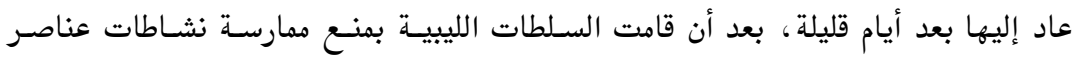

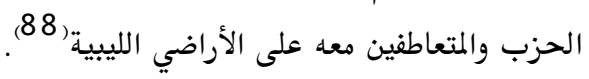

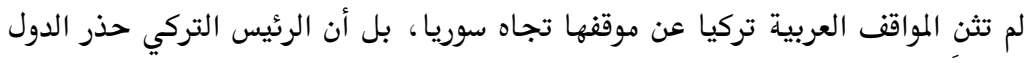

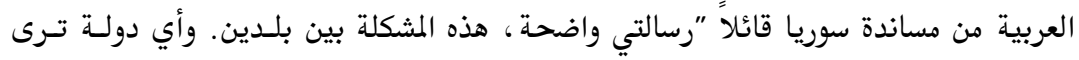

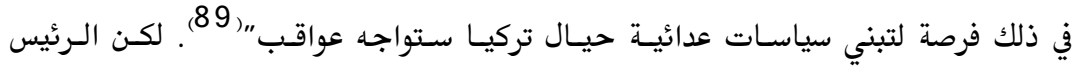

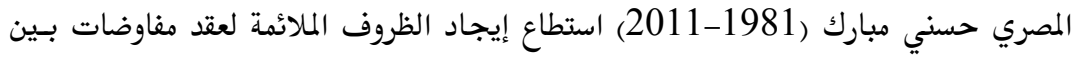

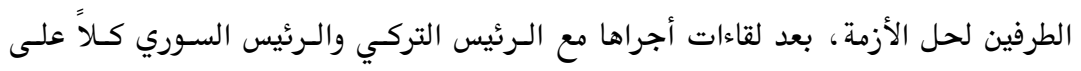

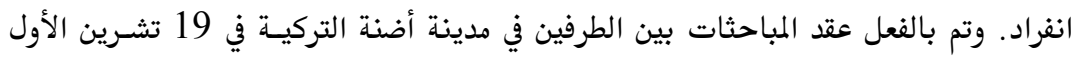

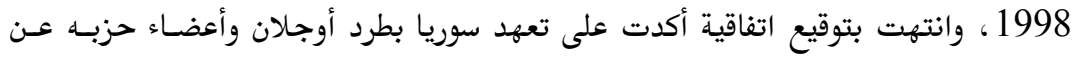

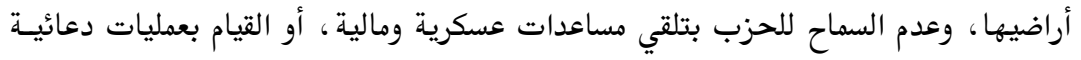

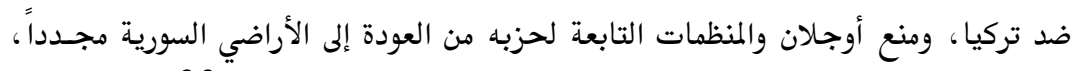

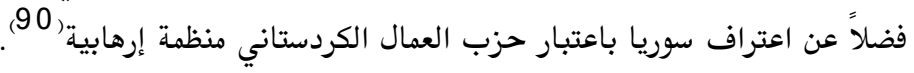

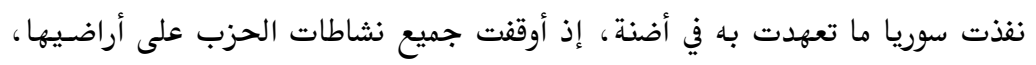

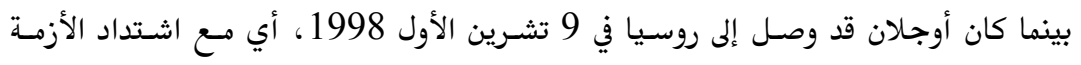

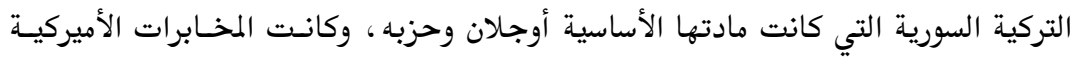

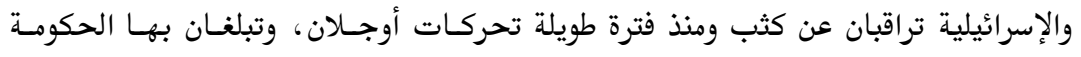

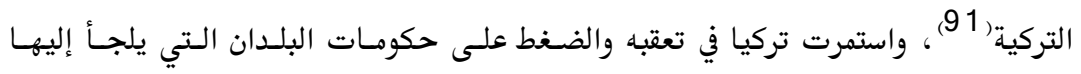
بتسليمه أو عدم مذحه حق اللجوء السياسي، وقد أثمرت هذه السياسة ، إذ اضطر أوجلان إلى إلى

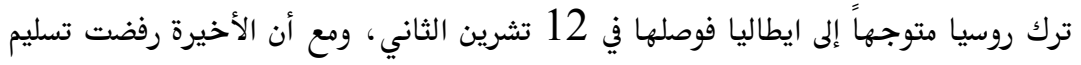

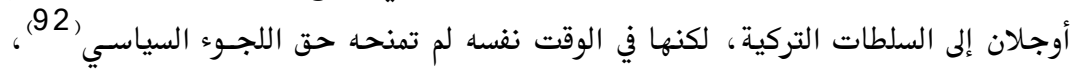

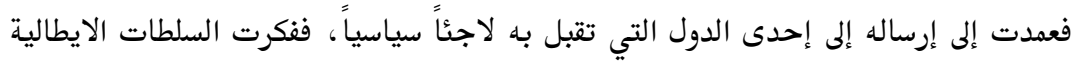

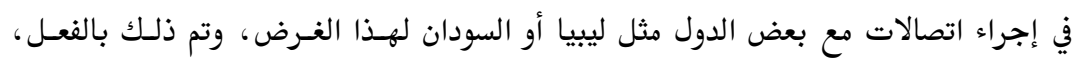




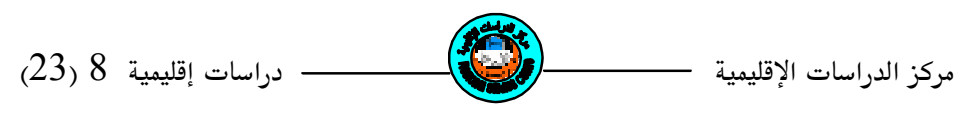

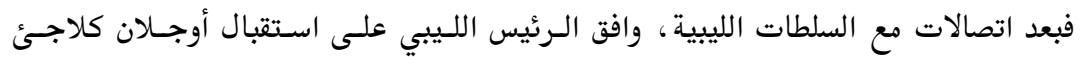

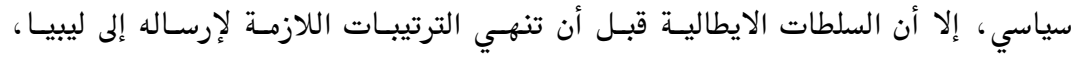

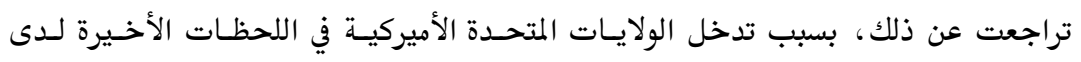

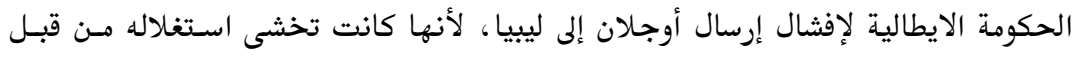

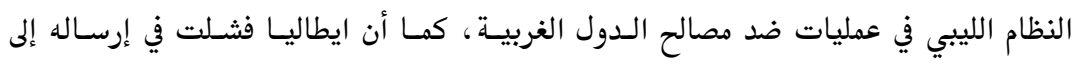

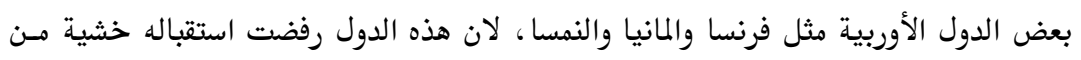

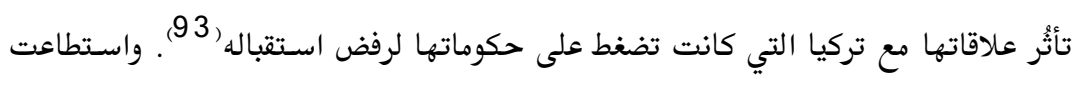

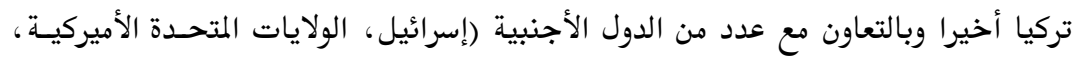

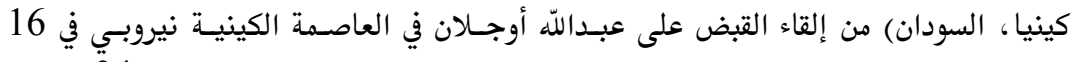

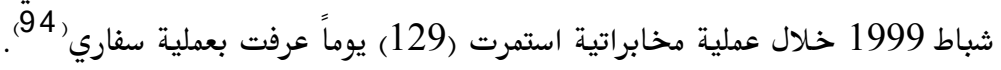

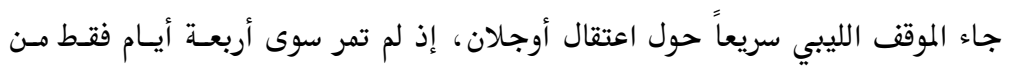

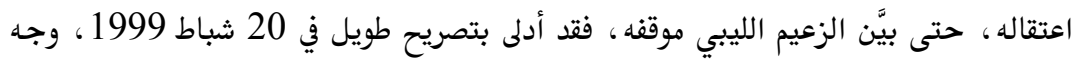

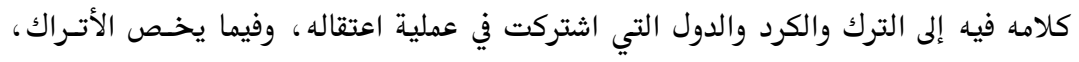

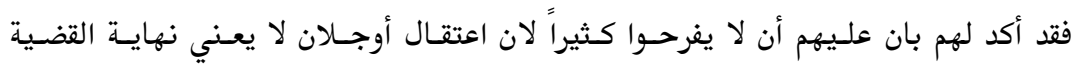

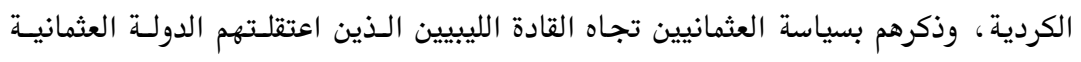

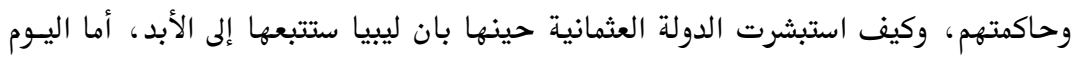

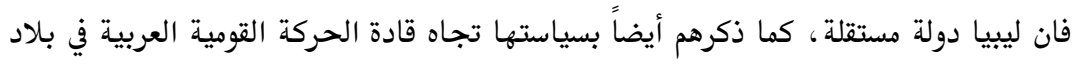

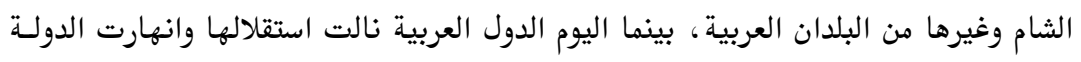

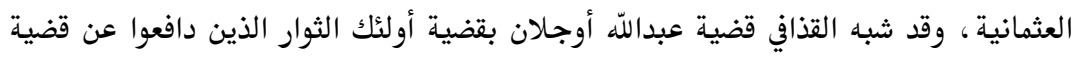

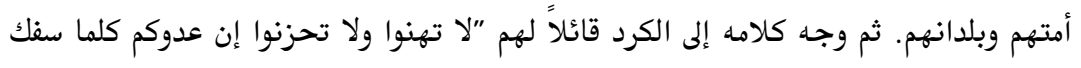

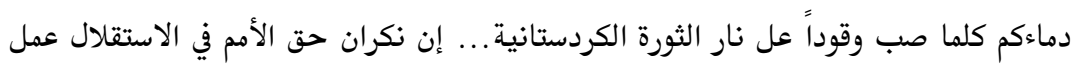

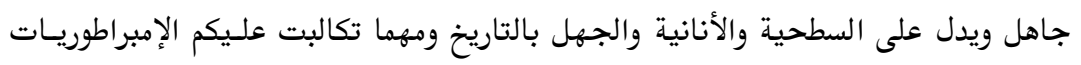

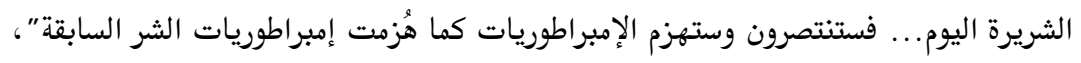

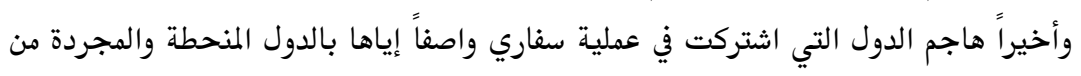

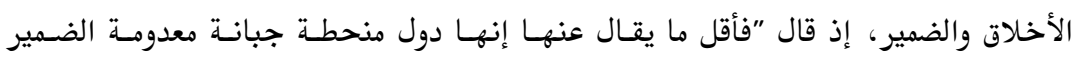


والأخلاق... إنها تآمرت على شخص واحد مقابل رشاوى وصفقات دنيئة أنانية. هذه الدول

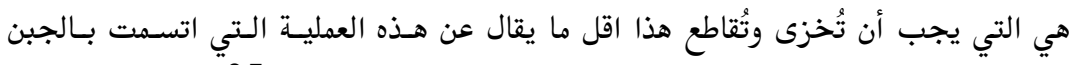
والغرور.. وكفاحكم أيها الإخوة الأكراد مستمر حتى الاستقلال حتماً") (95).

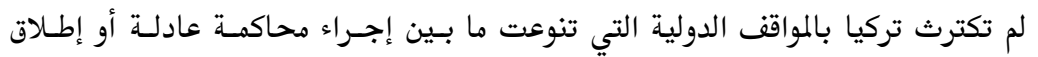

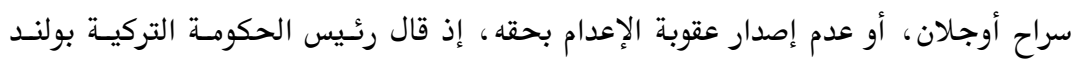

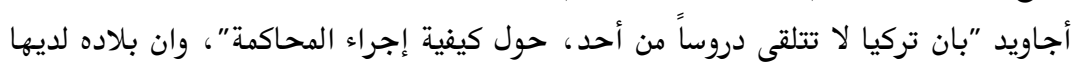

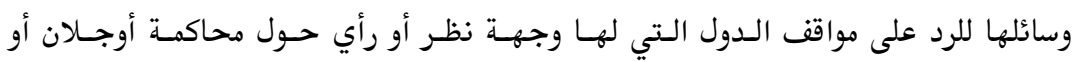

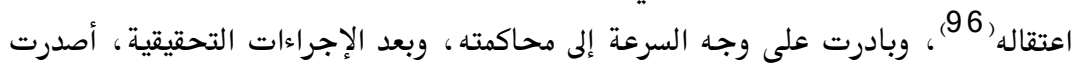

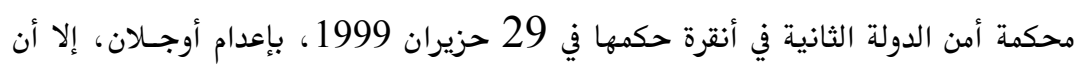
تنفيذ الحكم تم تعليقه (م) بطلب من محكمة حقوق الإنسـان الأوربيـة' (97). أمسا ليبيـا فإنهـا

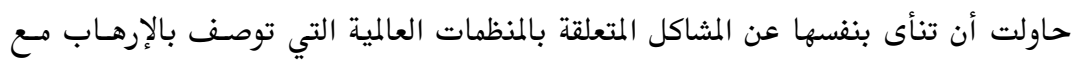

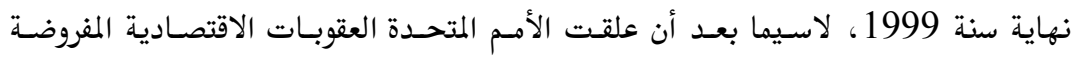
عليها، فقد سعت إلى إبعاد تهمة الإرهـاب عـن طريـق وقفـ التصريحات والـدعم والتأييـد

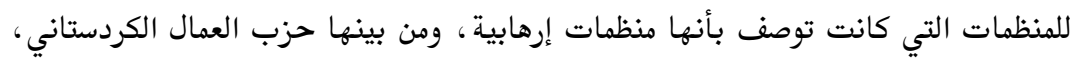

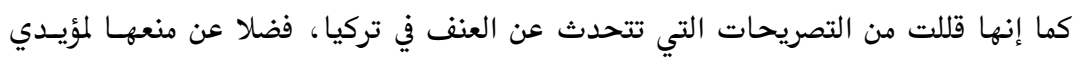

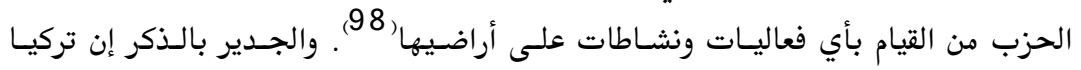

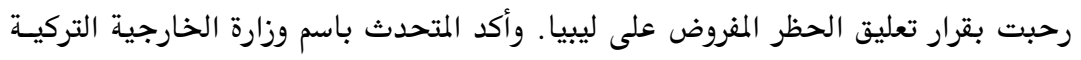

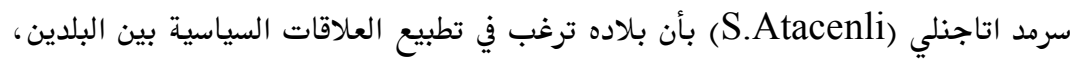

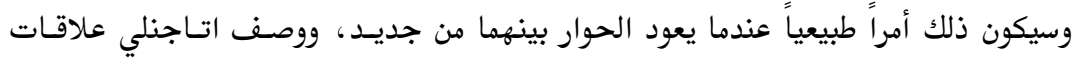

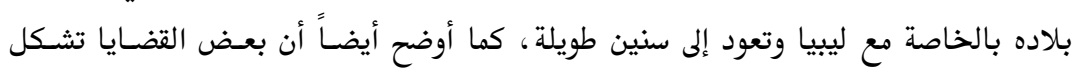

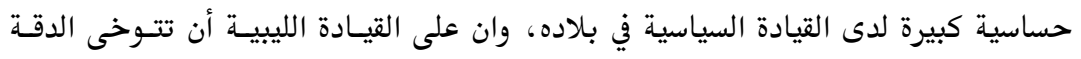

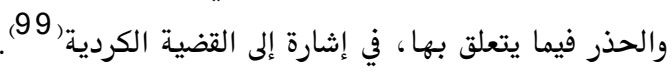




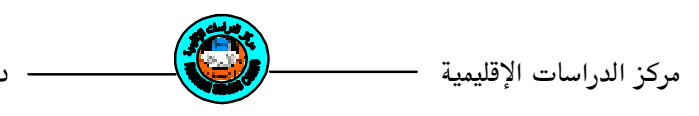

تراجعت العلاقات الاقتصـادية بـين ليبيـا وتركيـا خـلال السـنوات الأخسيرة هـن عقـد

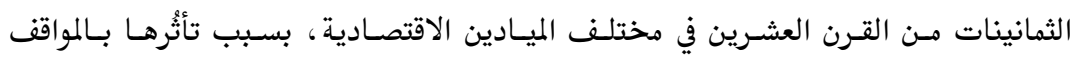

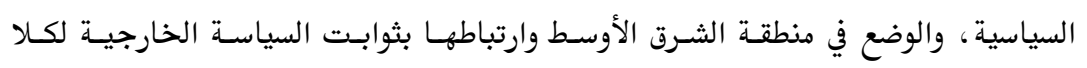

البلدين، فضلاً عن الصعوبات والمشاكل الاقتصادية التي كانت تركيا تعاني منها (100).

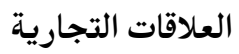

تأثرت تجارة ليبيا الخارجيسة بشـل عـام، خـلال تسعينيات القـرن الماضسي، نتيجـة

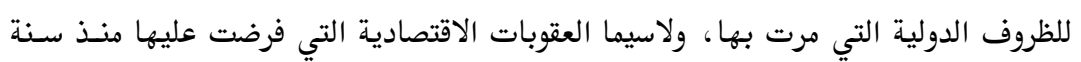

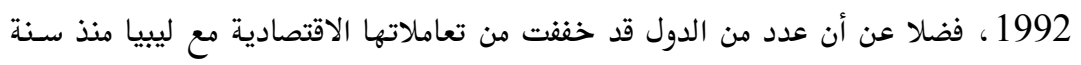

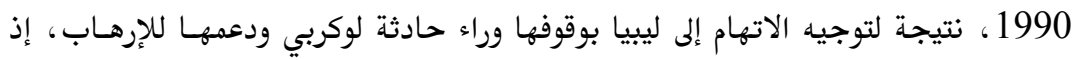

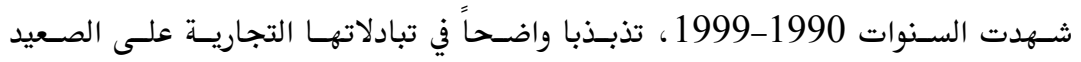
الخارجي بما فيها تبادلاتها التجارية مع تركيا .

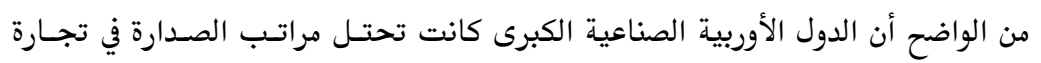

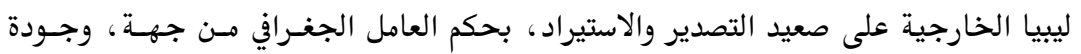

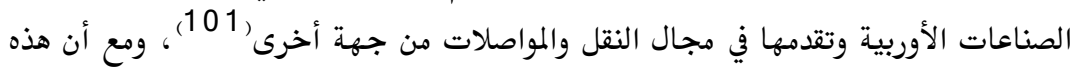

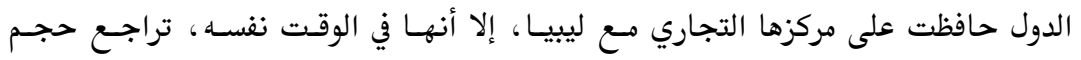

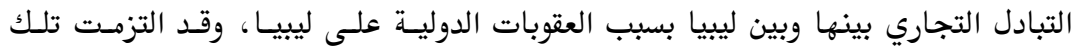

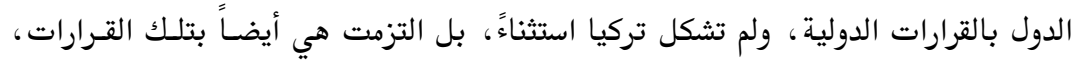

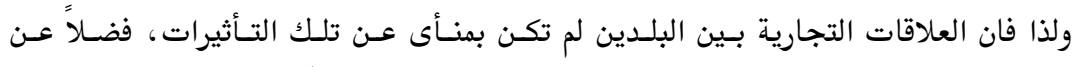

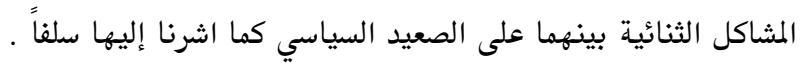

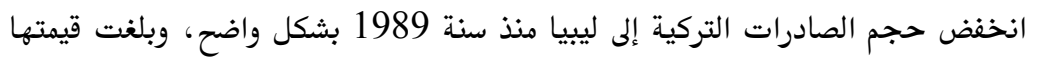

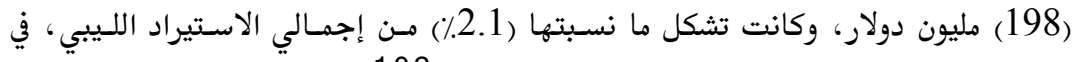

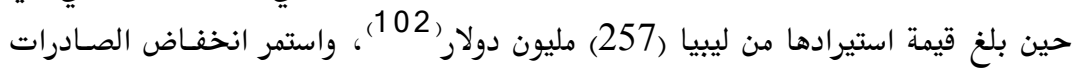

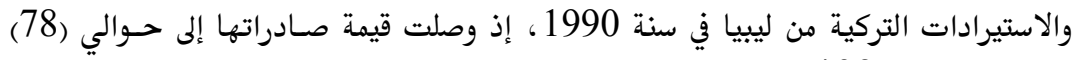

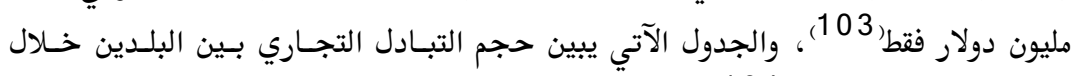

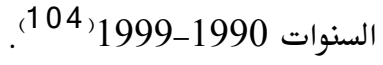


(مليون دولار)

التجارة الليبية التركية 1990-1999

\begin{tabular}{|c|c|c|c|c|}
\hline نسبة الاستيراد من & الاستيراد & من إجمالي الصادرات إلى تركيا & الصادرات & السنة \\
\hline 3.2 & 220.5 & 3.6 & 487.1 & 1990 \\
\hline 6.3 & 237.5 & 2.2 & 281.4 & 1991 \\
\hline 6.9 & 246.5 & 4.3 & 445.5 & 1992 \\
\hline 4.7 & 266.7 & 2 & 144.5 & 1993 \\
\hline 4.5 & 206.3 & 3.9 & 373.7 & 1994 \\
\hline 6.1 & 307.2 & 4.2 & 390.3 & 1995 \\
\hline 4 & 211.5 & 4.4 & 432.1 & 1996 \\
\hline 2.9 & 164.6 & 5.6 & 510.3 & 1997 \\
\hline 1.4 & 76.4 & 4.6 & 381.3 & 1998 \\
\hline 0.6 & 27.2 & 5.7 & 451.1 & 1999 \\
\hline 4.06 & 1964.4 & 4.05 & 3897.3 & المجموع \\
\hline
\end{tabular}

كانت ليبيا تحتل مرتبة متقدمة عالميـا في تعاملاتهـا التجاريـة مسع تركيـا، ففي مجـال

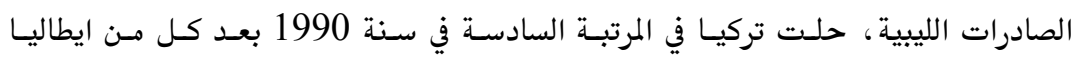

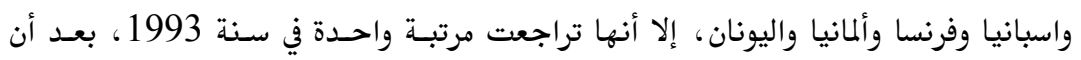

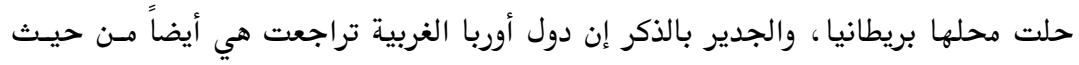

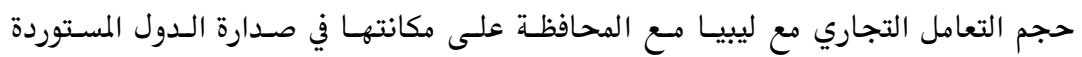

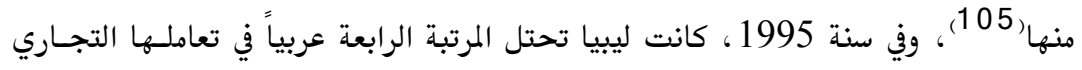

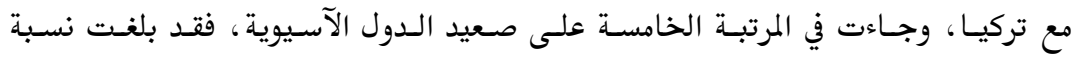

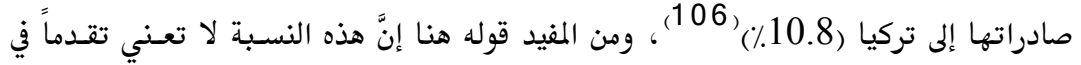

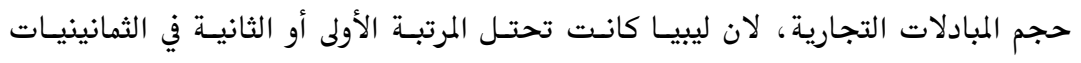

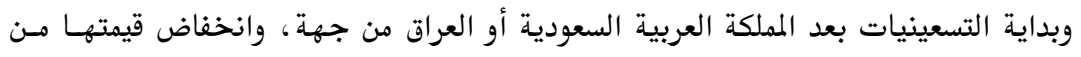




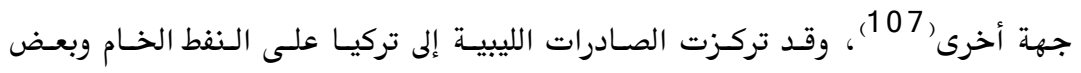

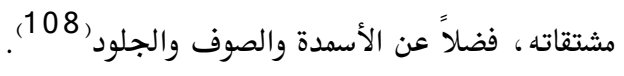

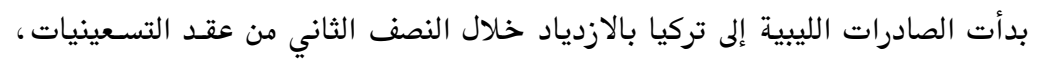

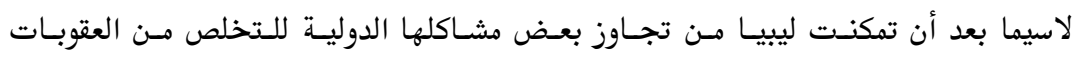

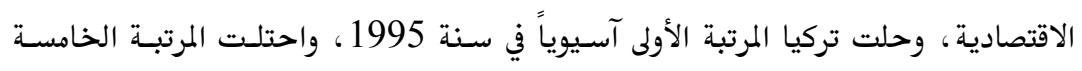

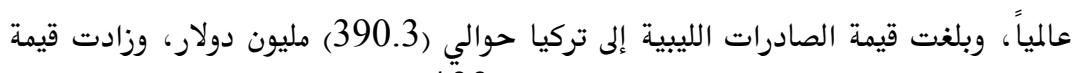

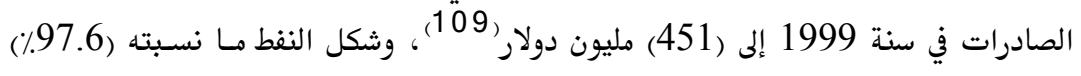

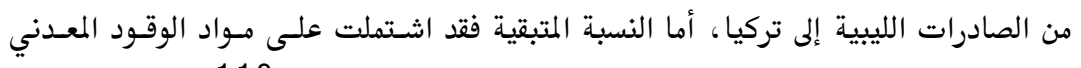

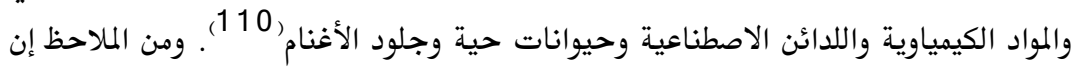

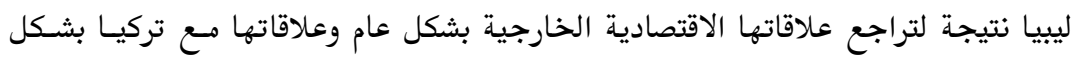

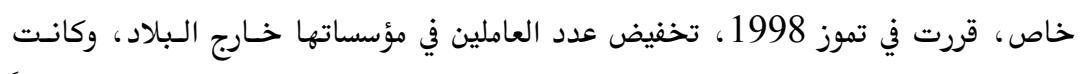

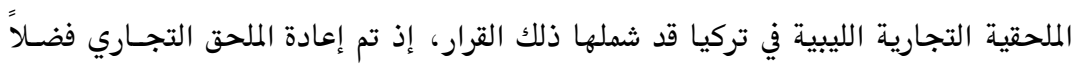

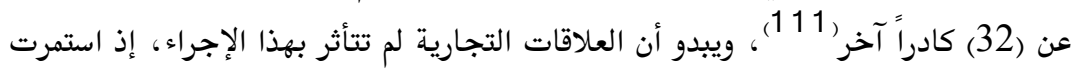

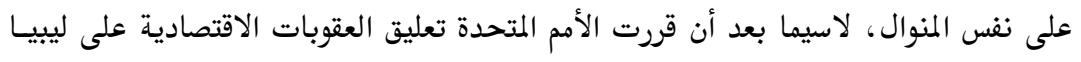

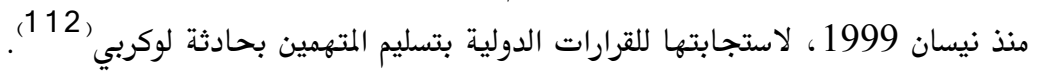

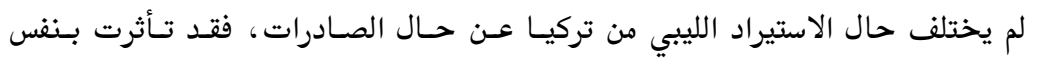

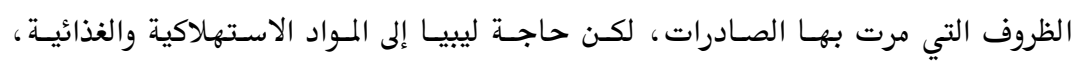

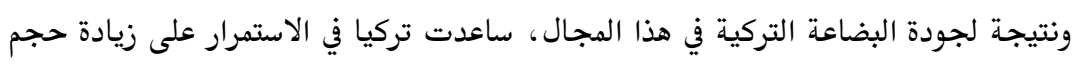
صادراتها حتى منتصف التسعينيات، فبعد أن كانت قيمة صادراتها إلى ليبيا في سنة 1990 فئن 1920.

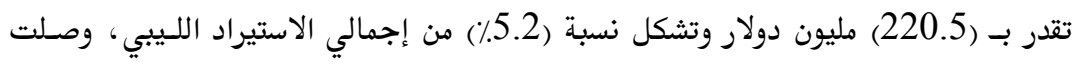

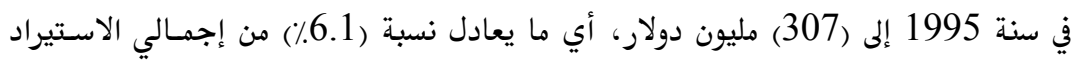

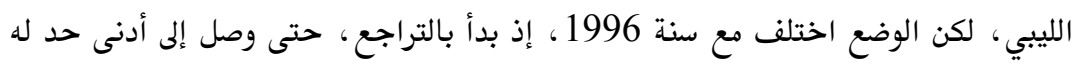

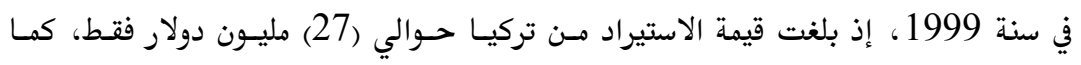

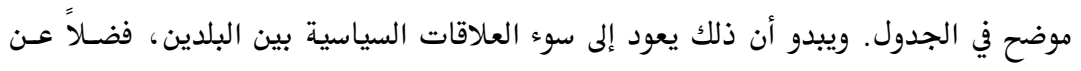

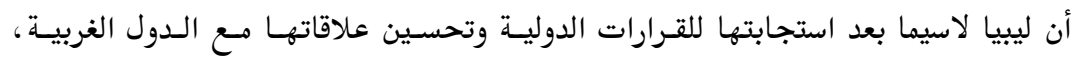


أخذت توجه تجارتها صوب أوربـا. والجـدير بالـذكر أيضـاً أن حفــاظ تركيـا على مسـتوى

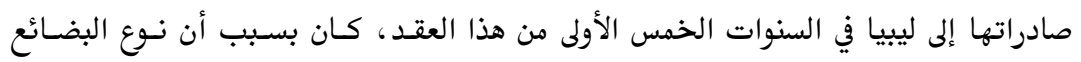

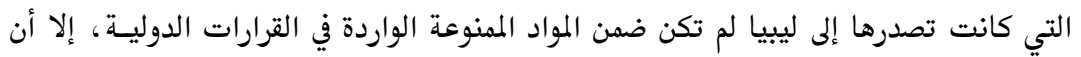

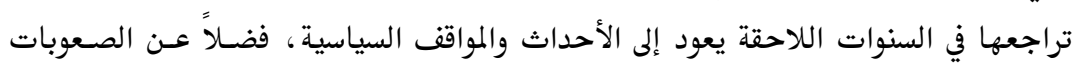
الاقتصادية التي كان يمر بها البلدان، وخاصة بعد انخفاض أسعار الـنفط في تلك الفتر الفترة في

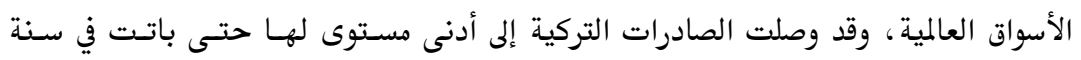

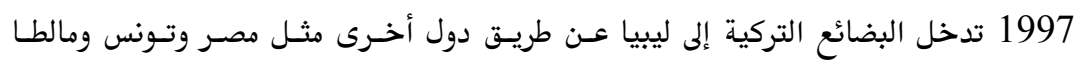

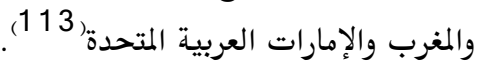
لقد تنوعت الصـادرات التركيـة إلى ليبيـا، إلا أن المـواد الغذائيسة والكهربائيسة كانست في مقدمة تلك البضائع، وأهمها الحبوب بأنواعها المختلفة والبقوليات والذرة والزيوت الندان الغذائيسة

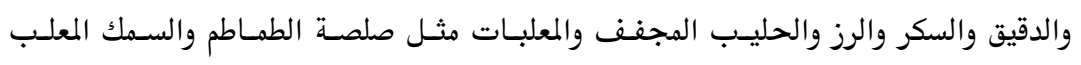

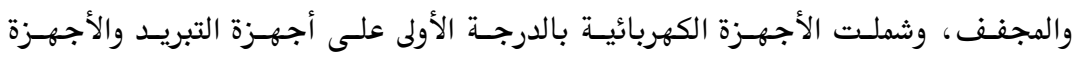

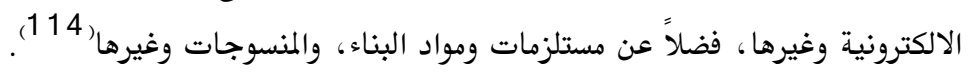

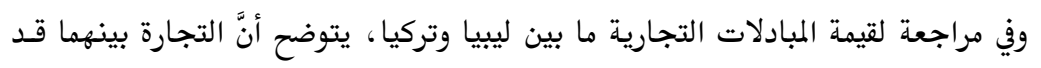

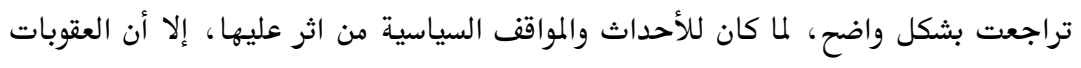

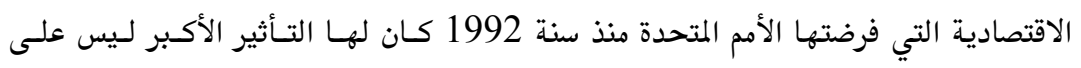

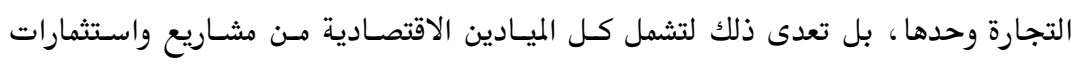

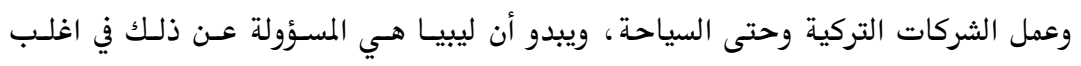

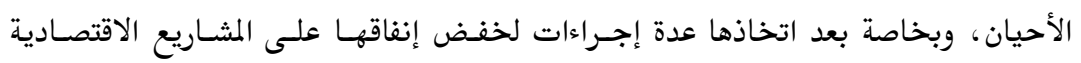

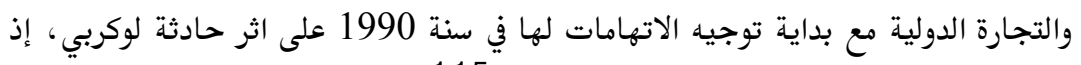
اتخذت تلك الإجراءات لمواجهة أي ظروف طارئة(115).

الشركات التركية العاملة في ليبيا كان عدد الشركات التركية العاملة في ليبيا يبلغ (78) شـركة في منتصف عـام اليبام 1990،

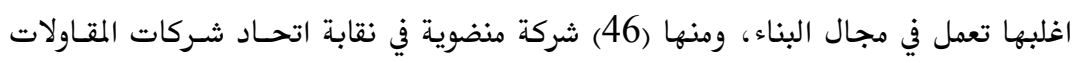




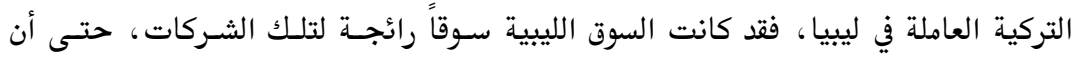

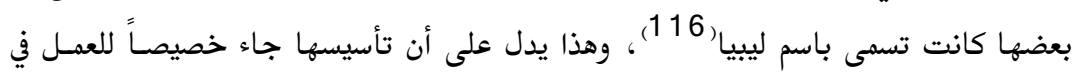

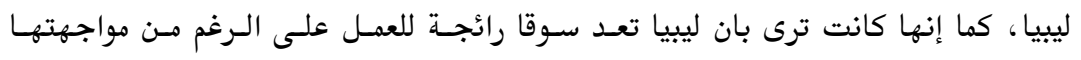

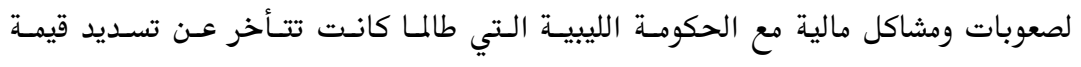

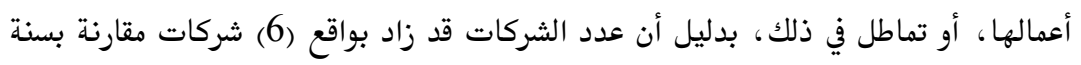

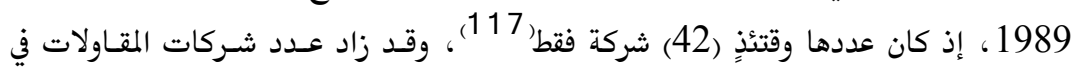

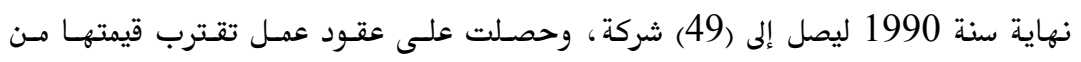

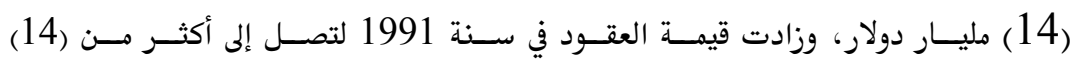

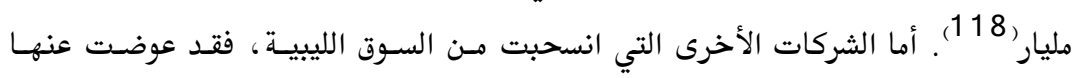

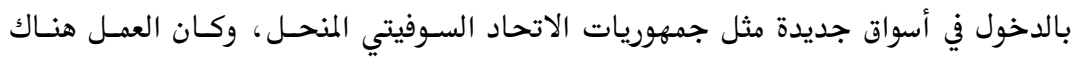

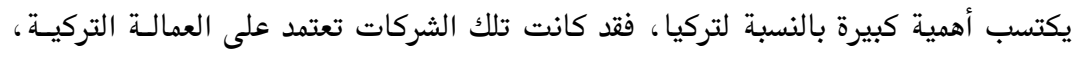

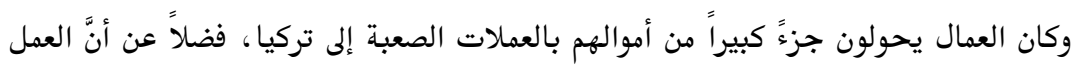

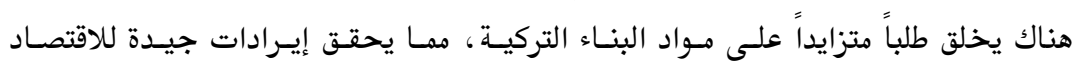
التركي (119). أنجزت الشركات التركيـة أعمـالاً عديـدة في ليبيـا خـلال فـترة موضسوع البحـث، ومسن

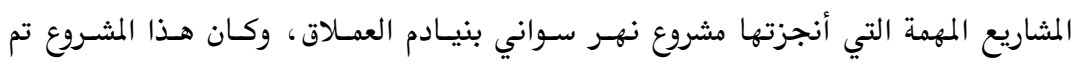

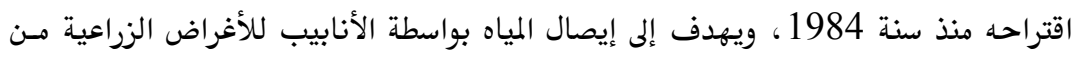

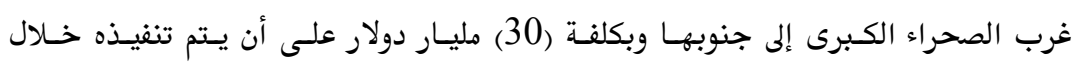

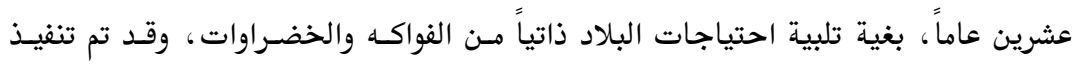

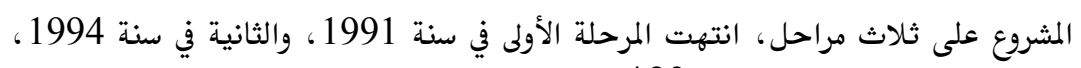

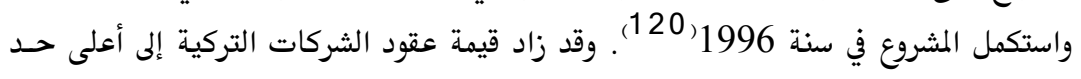

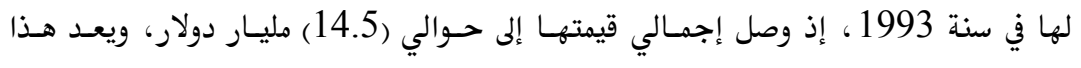

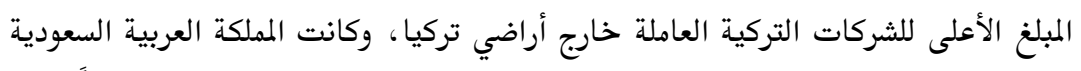

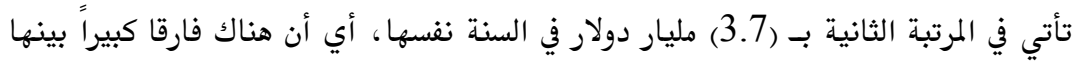

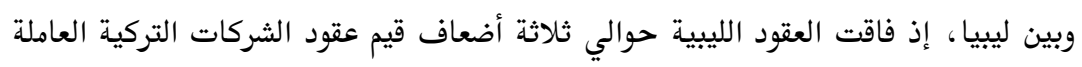


في المملكة العربية السعودية، الأمر الذي يدل على أهمية السـوق الليبيـة للشـركات التركيـة.

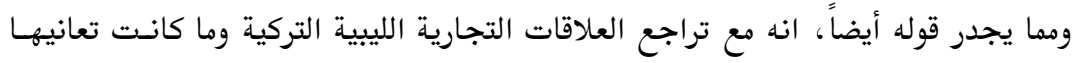

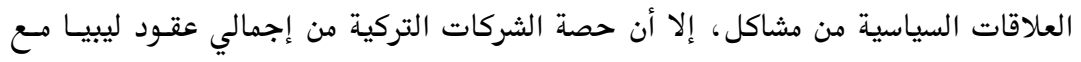

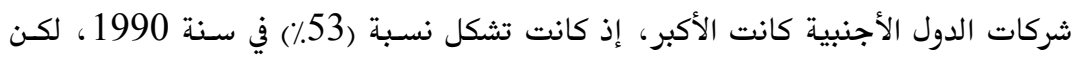

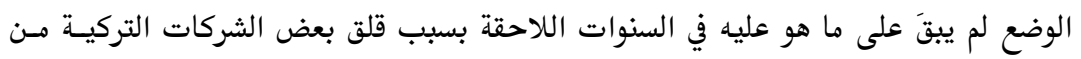

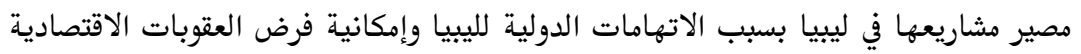
عليها (121). (121) - (20) استطاعت خمس شركات تركية في سنة 1991 من تنفيذ مشروع سكني يضسم (6600)

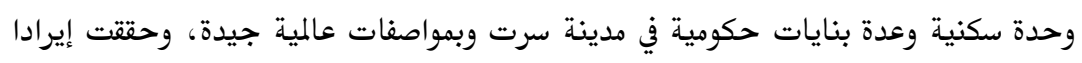

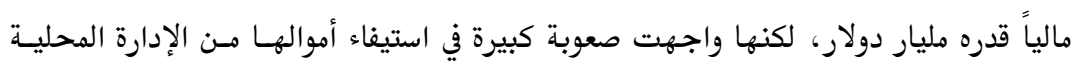

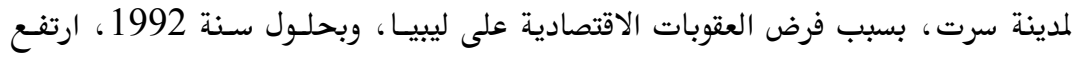

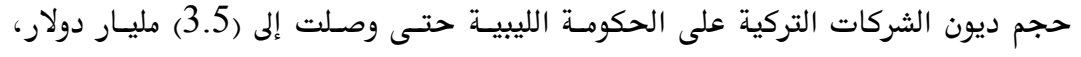

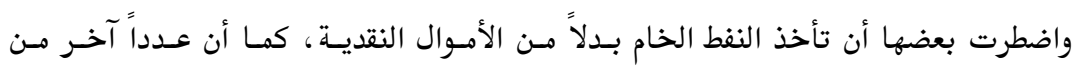

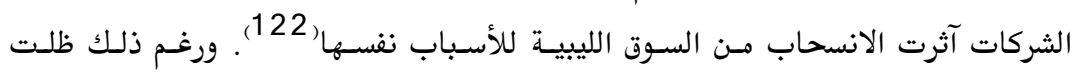

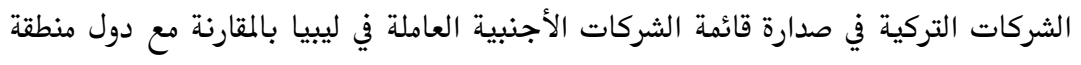

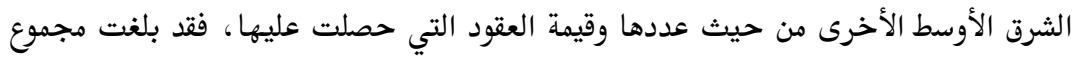

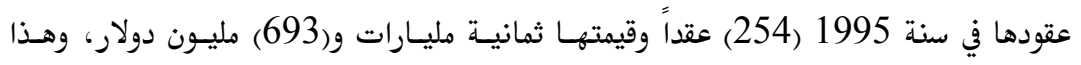

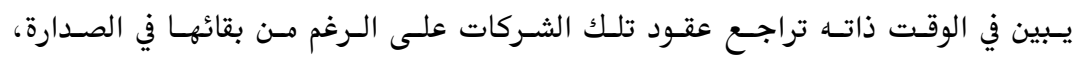

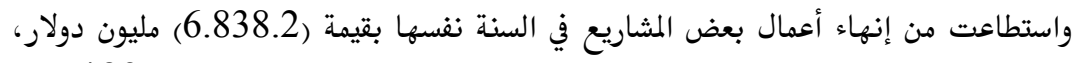

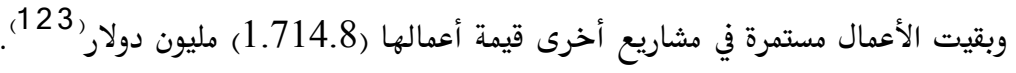

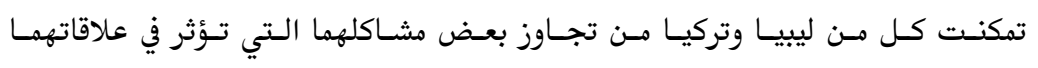

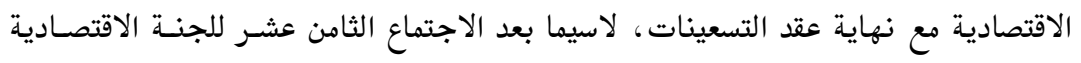

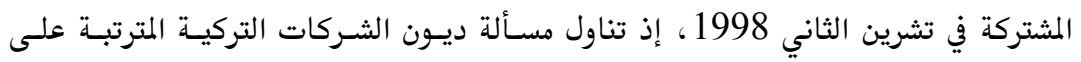

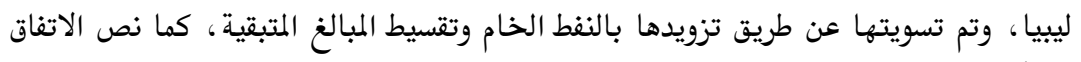

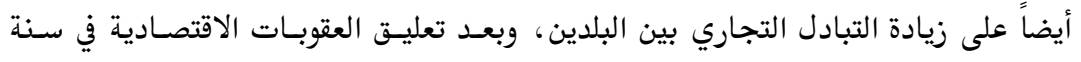




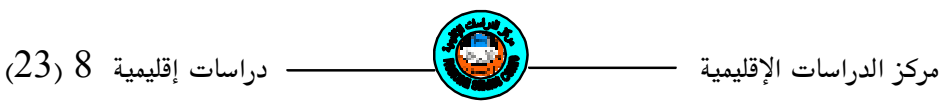

1999، بدأت السـفن التجاريـة الليبيـة القيـام برحلاتهـا بصـورة مباشـرة مسن والى المـوانئ التركية(124).

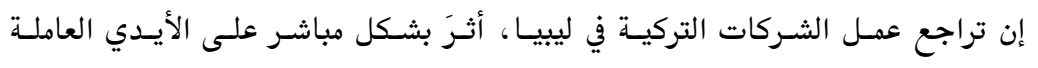

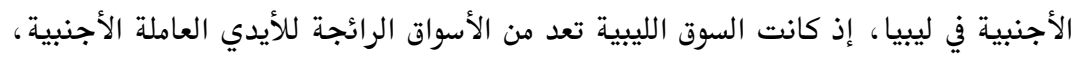

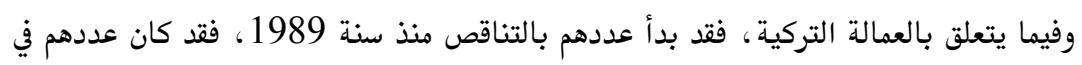

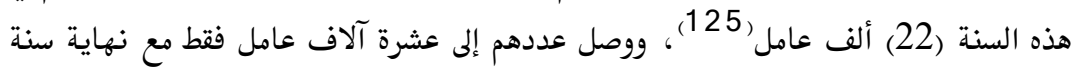

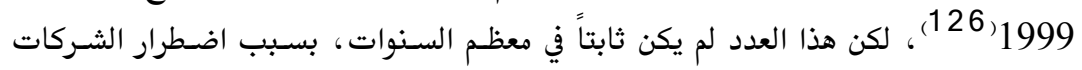

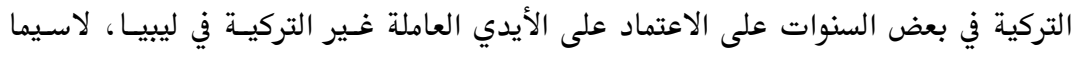

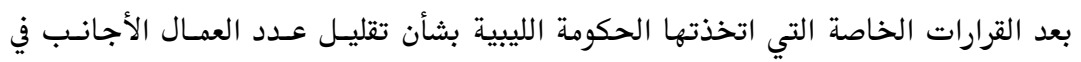

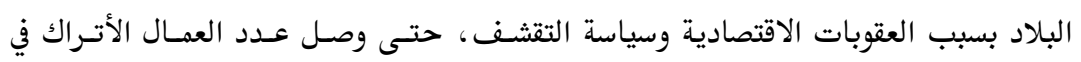

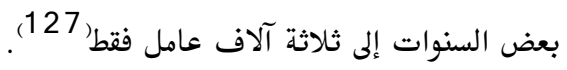

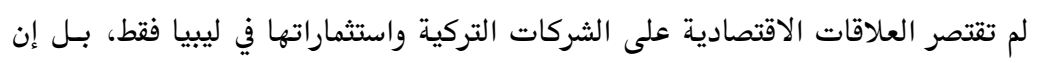

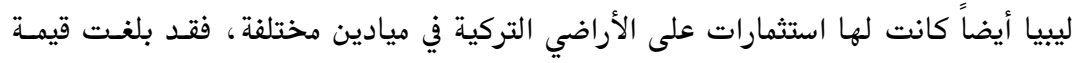

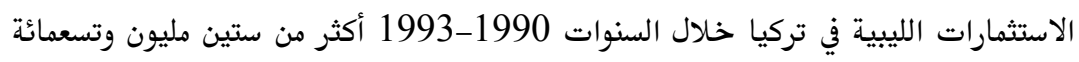

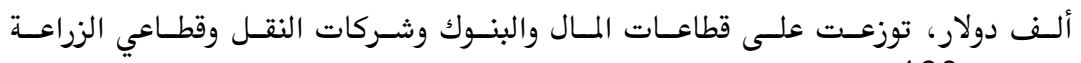

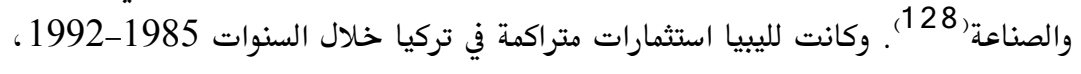

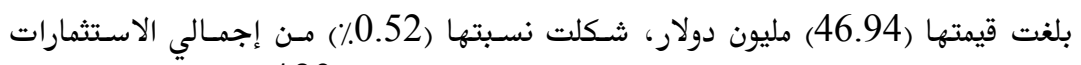

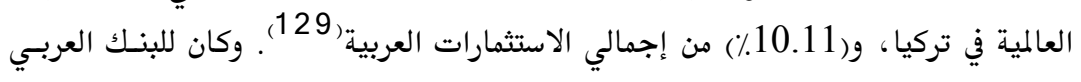

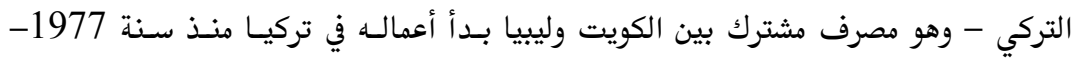

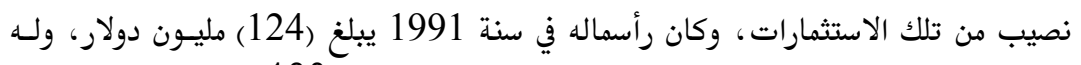

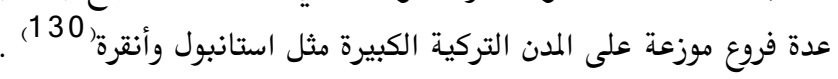

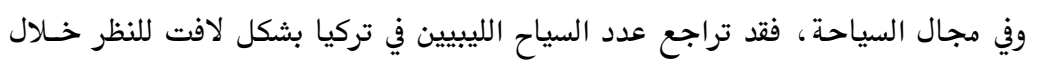

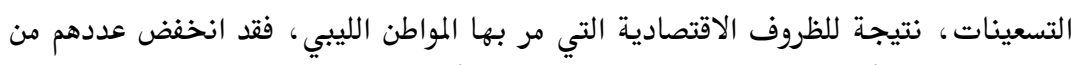

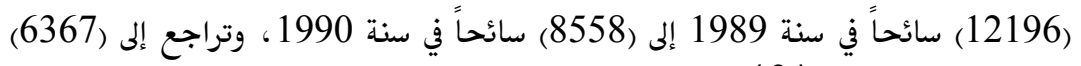

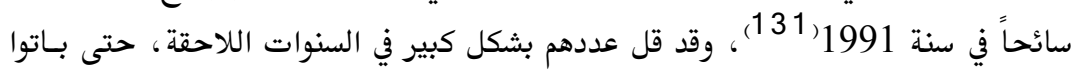

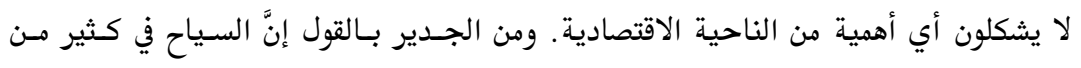




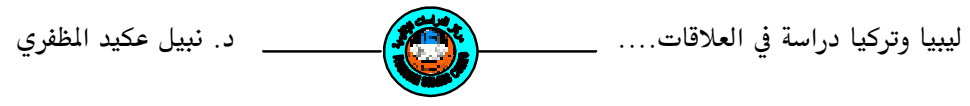
الأوقات كان يستغلون وجودهم للعمل في التجارة، وبخاصة تجارة حقائب السفر التي كانت

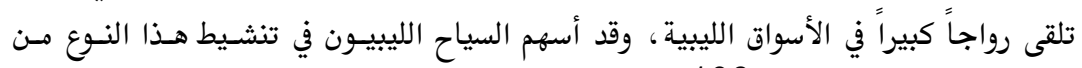

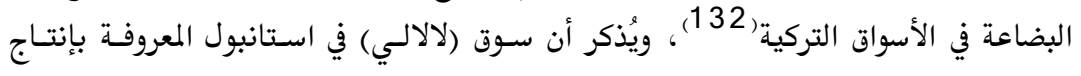

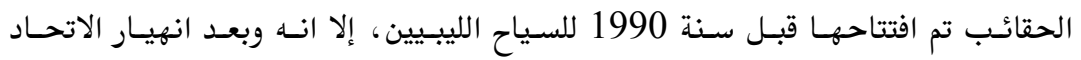

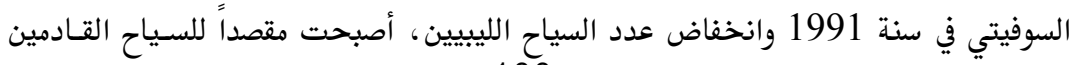
من روسيا ومناطق القفقاس والبلقان وأوكرانيا (133).

الخاتمة

تأثرت العلاقات الليبية التركية خلال حقبة التسعينيات من القرن العشـرين بجملـة مـن

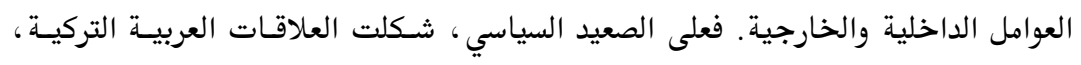

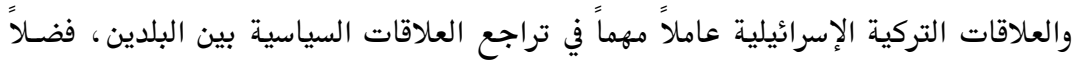

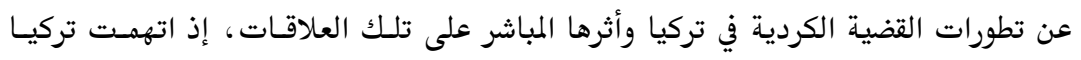
ليبيا بدعمها لحزب العمال الكردستاني.

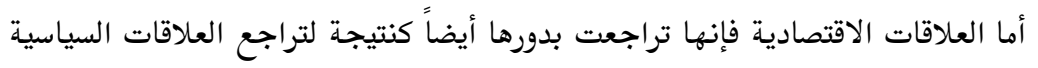
من جهة ، وفرض العقوبات الاقتصادية على ليبيا في سنة 1992 من قبل هيئة الأمم المتحدة

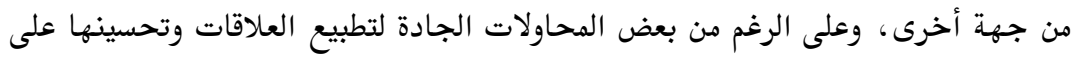

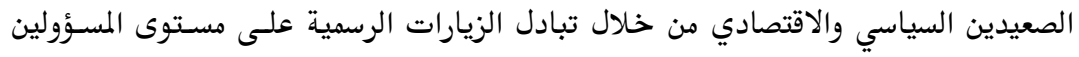

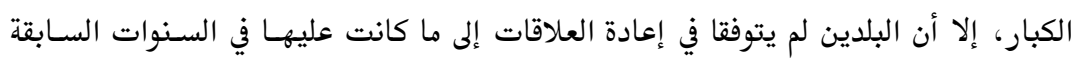




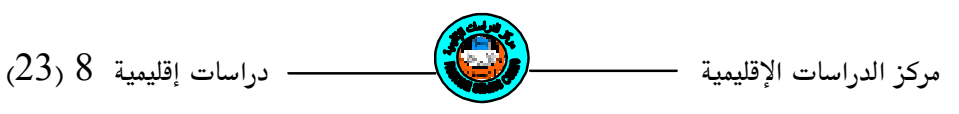

\title{
Libya and Turkey : Study in Political and Economic Relations during Nineties of Twentieth Century
}

\author{
Nabeel Ageed Mabmood al-Modafary \\ Univessity of Kiskuk Collage of Education Department of History
}

\begin{abstract}
This study talks two parts. First: The politic relations between Libya and turkey during the years 1990-1999. The dual relationships were affected because of the events that took place in the Middle East zone which left a distinct effect on relations between the two countries like Arab-Turkish relations, (PPK) case and second Gulf War.

The second parts: tackled the economic relations between the two countries. It dealt with the mass of commercial exchange between the two countries and the Turkish companies which work in Libya . and their works and values and also dealt with the effective factors on economic relations specially the political relations.
\end{abstract}


(1) للتفاصيل عن العلاقـات الليبيـة التركيـة خـلال الفترة 1969-1989 ينظـر : نبيـل عكيـد محمـود

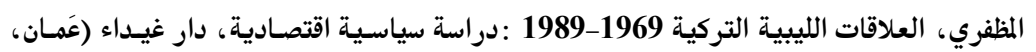

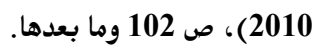

(2) تقارير السفارة العراقية في أنقرة، أرشيف مركز الدراسات الإقليمية (جامعة الموصل)، تقرير رقم

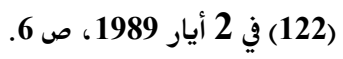

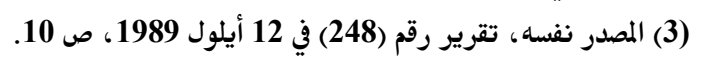

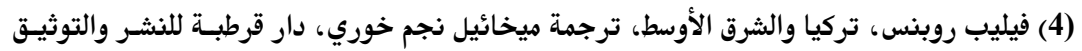

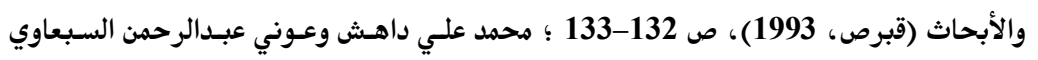

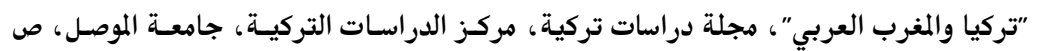

$$
90
$$

(5) تقارير السفارة العراقية في أنقرة، أرشيف مركز الدراسات الإقليمية (جامعة الموصل)، تقريـر رقم

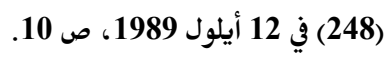

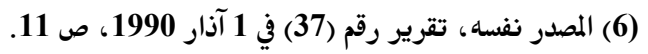

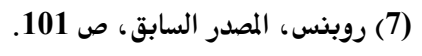

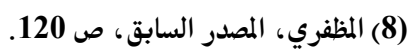

(9) تقارير السفارة العراقية في أنقرة، أرشيف مركز الدارئ الدراسات الإقليمية (جامعة الموصل)، تقريـر رقـم

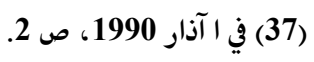

(10) Husnu Mahli, Turk-Libya iliskileri: 20 yillik iliskilerin karsilikli ekonomik Gelismelere katkisi, doktora tezi, (Istanbul universitesi, sosyal bilimler enstitusu, 1990), S. 39.

(11) Ayni Eser, S. 172.

(12) Ayni Eser, S. 172-173.

(13) تشارلز تريب، صفحات من تاريخ العراق، ترجمسة زينـة جـابر إدريسـ، الـدار العربيـة للعلـوم

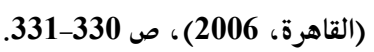


(15) (15) المصدر نفسه، ص 3331-331)

(15) هاينتس كرامر، تركيا المتغيرة تبحث عن ثوب جديـد، ترجمـة فاضل جتكر، مكتبـة العبيكـان

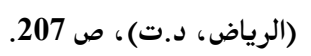

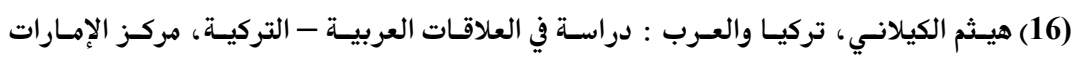

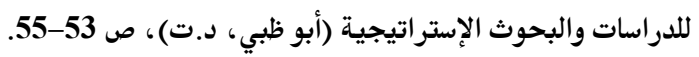

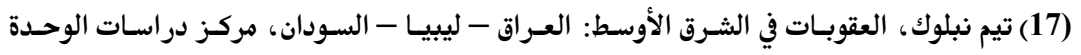

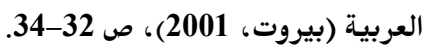

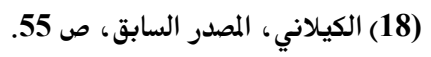

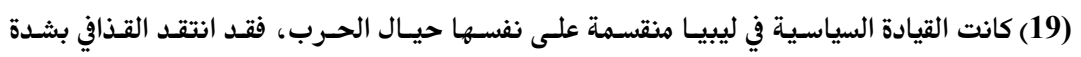

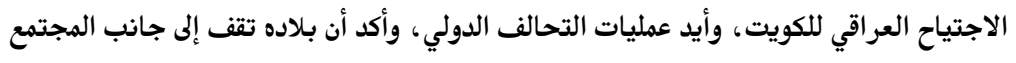

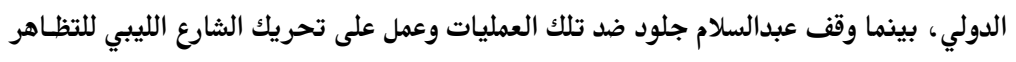

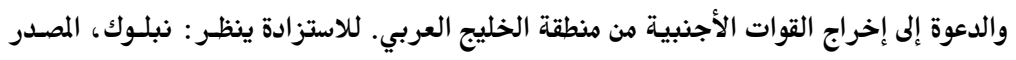

$$
\text { السابق، ص } 163 .
$$

(20) Orhan Kologlu, "Turkish-Libyan relations (1945-1993)", Turkish review of Middle East studies, Annual 1993, No 7, Istanbul, 1993, P. 145.

(21) http://www.moqatel.com.

(22) Kologlu, op. Cit, P.145.

(23) انفجرت طائرة ركاب أميركية فوق مدينـة لوكربي الاسكتلندية في سـنة 1988، كمـا انفجـرت

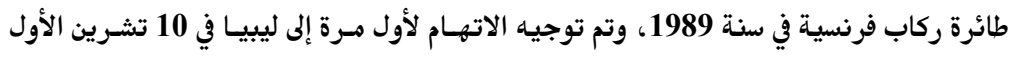

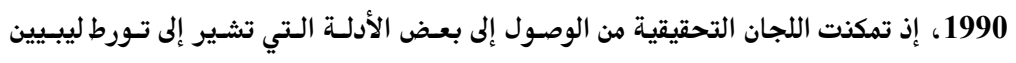

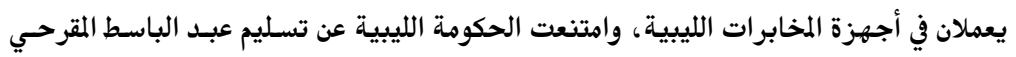

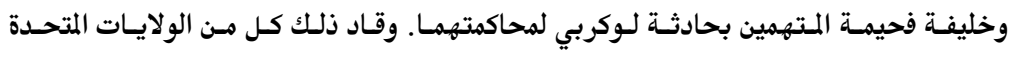

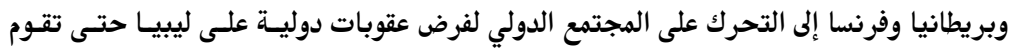

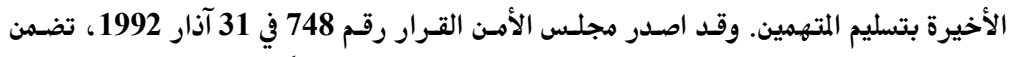

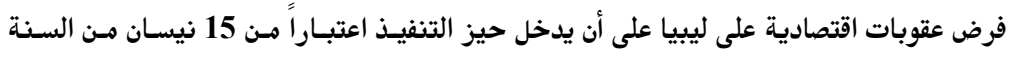

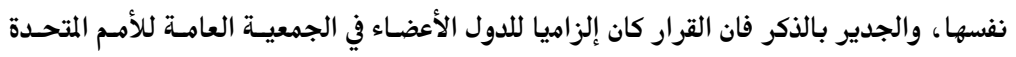

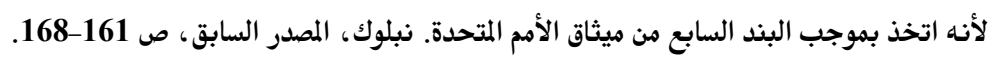




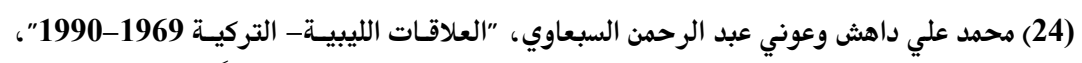

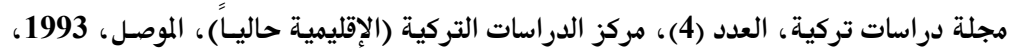
ص صج 43.

(25) Kologlu , op. Cit, P.145.

$$
\text { (26) نبلوك، المصدر السابق، ص 172-175. }
$$

(27) Kologlu , op. Cit , P. 144.

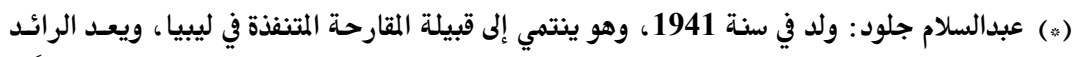

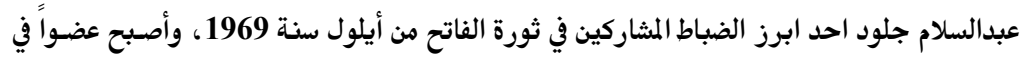

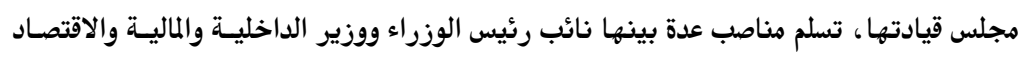

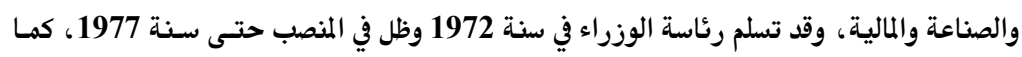

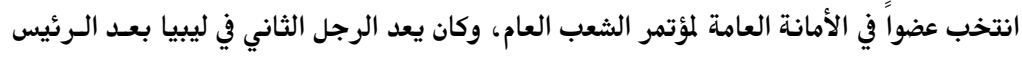

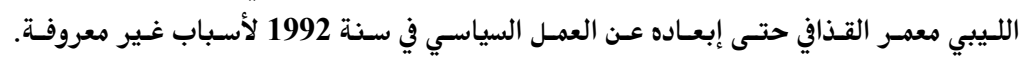
http://alwatanvoice.com/news

("* ) حزب العمال الكردستاني: أُسس الحزب في 27 تشرين الثاني 1978 خلال اجتماع في قرية فيس

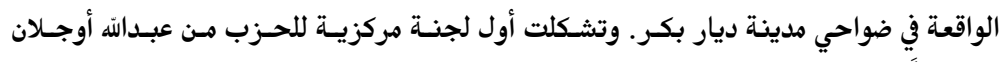

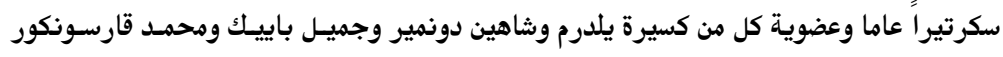

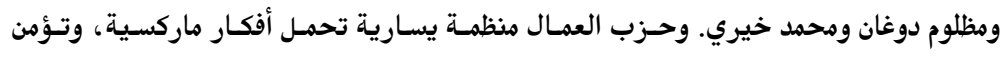

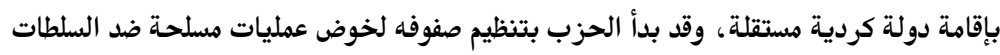

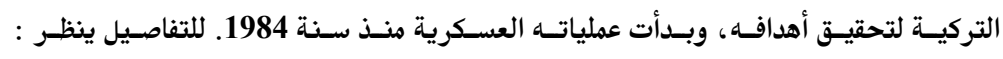

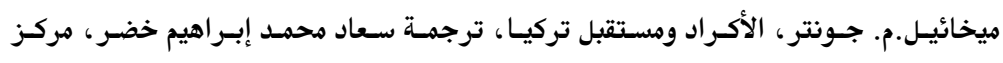

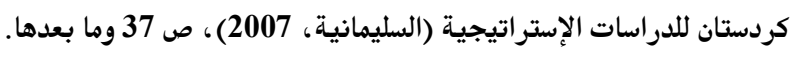

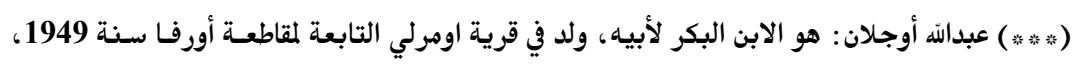

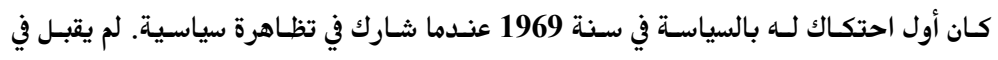

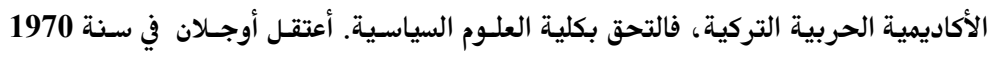

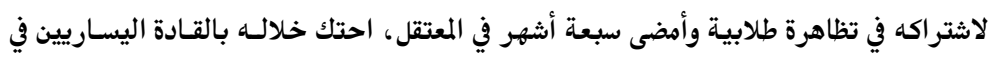

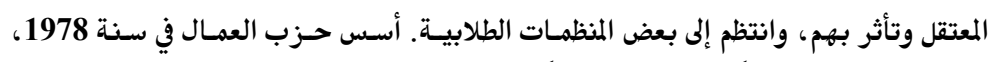

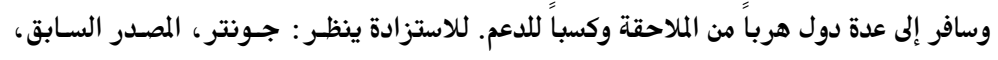




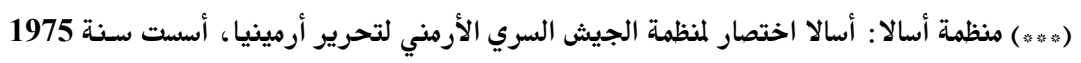

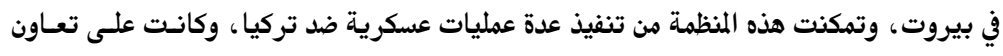

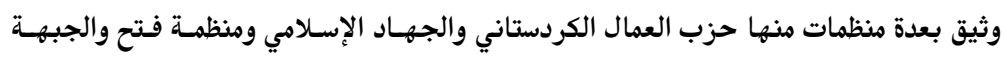

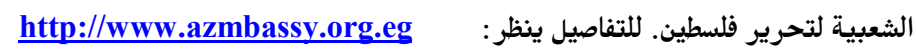

(28) Kologlu , op. cit , P. 144.

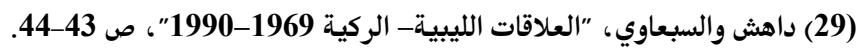

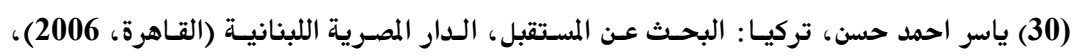

$$
\begin{aligned}
& \text { ص284-287. }
\end{aligned}
$$

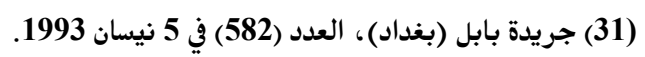

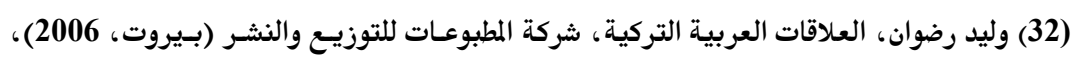

$$
\begin{aligned}
& \text { ص237-238. } \\
& \text { (33) جريدة المستقبل (بيروت)، العدد (1934) في } 1 \text { حزيران 2005؛ }
\end{aligned}
$$

http://www.onlineearabic.net

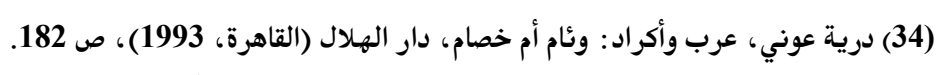

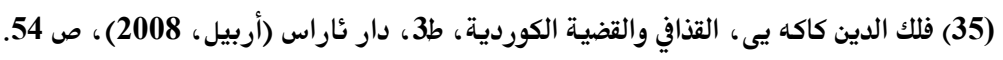

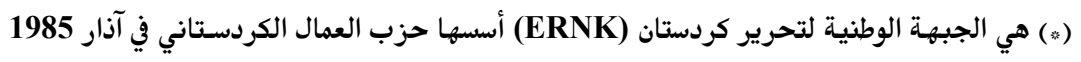

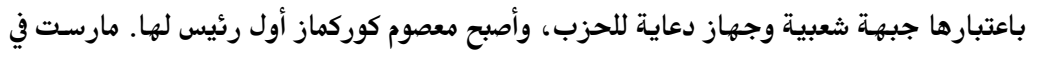

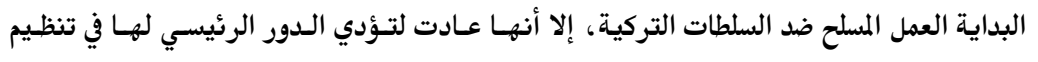

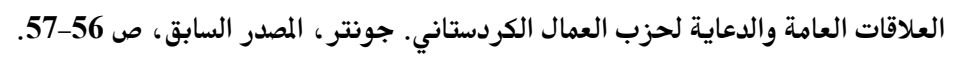

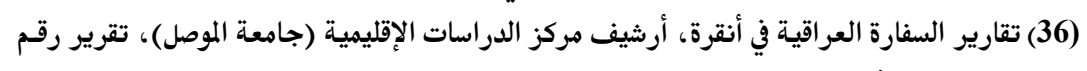

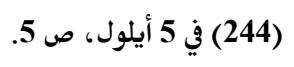

(37) Kologlu , op. Cit , P. 145.

(38) جلال عبدالهه معوض، صناعة القرار في تركيا والعلاقات العربية-التركية، مركز دراسات الوحسدة

$$
\begin{aligned}
& \text { العربية (بيروت، 1998)، ص 286-287. }
\end{aligned}
$$

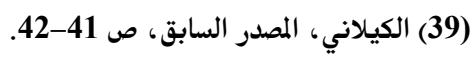

$$
\begin{aligned}
& \text { (40) رضوان، المصدر السابق، ص 282-284. } \\
& \text { (41) المصدر نفسه، صوان، المدر المابن، ص 249-251. }
\end{aligned}
$$




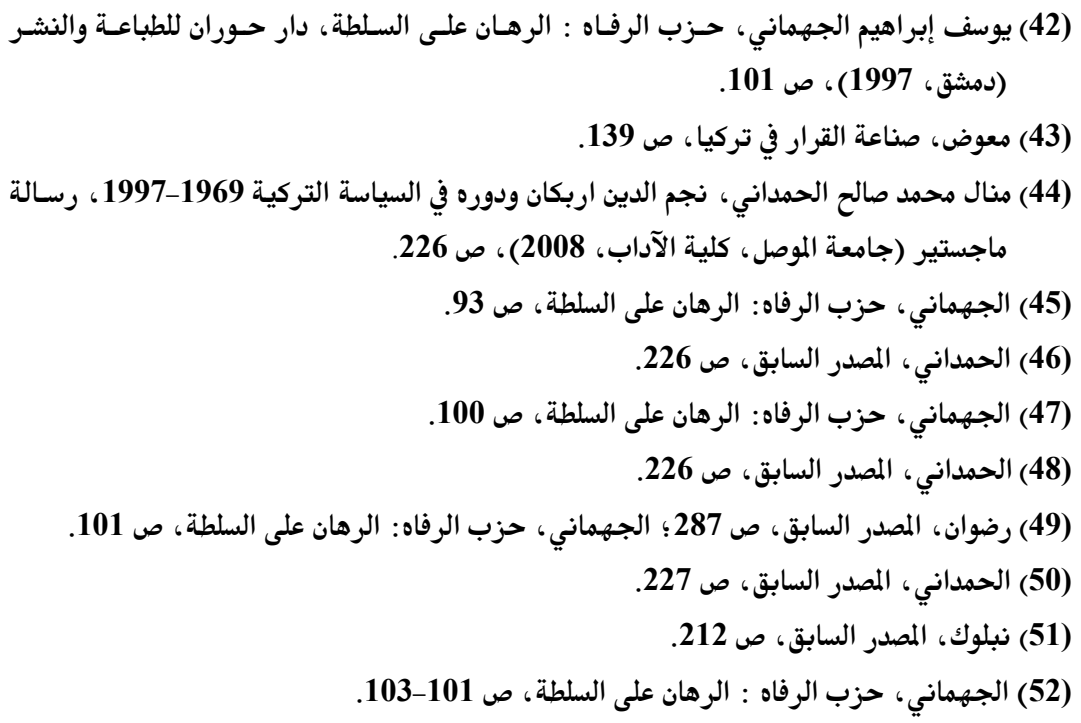

(53) http://www.almustaqbal.com.

$$
\begin{aligned}
& \text { (54) الجهماني، حزب الرفاه : الرهان على السلطة، ص } 103 .
\end{aligned}
$$

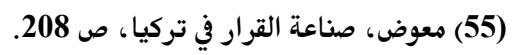

$$
\begin{aligned}
& \text { (56) الحمداني، المصدر السابق، ص صن } 228 .
\end{aligned}
$$

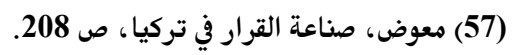

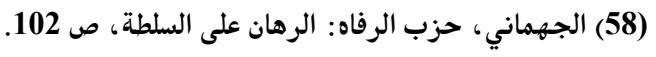

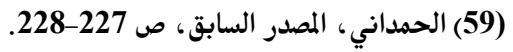

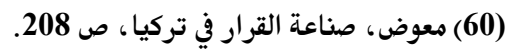

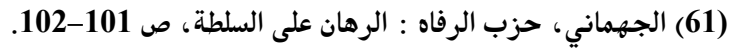

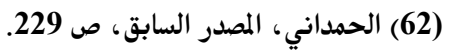

$$
\begin{aligned}
& \text { (63) رضوان، المصدر السابق، ص } 288 .
\end{aligned}
$$

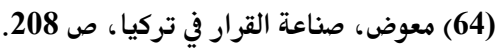

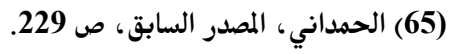

$$
\begin{aligned}
& \text { (66) رضوان، المصدر السابق، ص } 288 \text { (65) } \\
& \text { (67) معوض، صناعة القرار في تركيا، ص ص208، } 288 .
\end{aligned}
$$




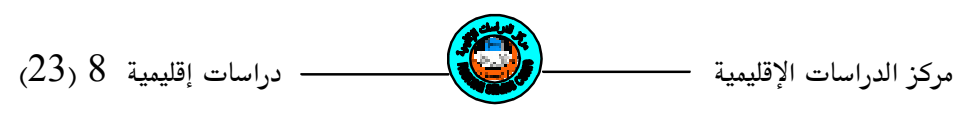

$$
\begin{aligned}
& \text { (68) الحمداني، المصدر السابق، ص } 228 \text { (69) الجيمان }
\end{aligned}
$$

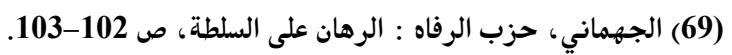

$$
\begin{aligned}
& \text { (70) المصدر نفسه، ص الجماني، حزب 101-102. }
\end{aligned}
$$

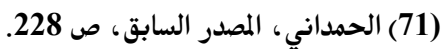

$$
\begin{aligned}
& \text { (72) معوض، صناعة القرار في تركيا، ص } 208 .
\end{aligned}
$$

(73) Ahmet Kavas, " Turkiye - Libya iliskileri", stratejik ongoru, sayi (6), 10 yti, Ankara, 2005, S. 51; Zeynep Arikanli, "Afrikanin hasin alani evcillesiyor", Turkish Time, 15 Temuz-15 Agustos 2004.

htth//www.turkishtime.org/tr.

$$
\text { (74) يوسف ابراهيم الجهماني، تركيا وإسرائيل، دار حوران للطباعة والنشـر (دمثـق ، 92-90. }
$$

(80) Kavas, Adi Gecen Eser, S.51.

$$
\text { (81) إبراهيم الداقوقي، أكراد تركيا، ط 2، دار ئاراس للطباعة والنشر (أربيل، 2008)، ص } 205 \text { (8205. }
$$

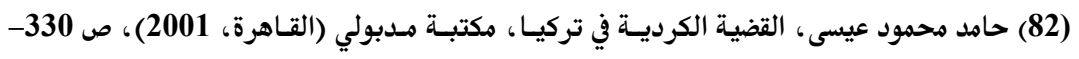

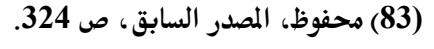

(84) عايدة العلي سري الدين، المسألة الكردية في ملف السياسة الدولية، دار الآفاق الجديدة (بـيروت، صلئ

$$
\text { 2000)، ص 200 }
$$

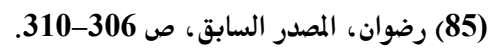

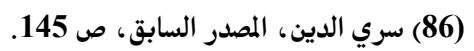

(87) رضوان، المصدر السابق، ص 311؛ سري الدين، المدر، المصد المدر السابق، ص 145.

(88) Kavas, Adi Gecen Eser, S.51. 


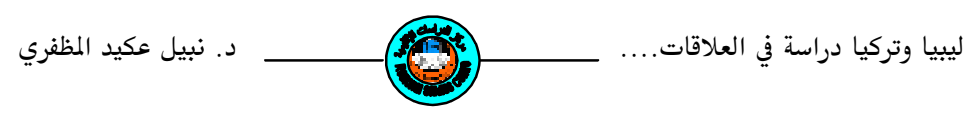

$$
\begin{aligned}
& \text { (89) (89) سري الدين، المصدر السابق، ص } 55 \text { (90) } \\
& \text { (90) عيسى، المصدر السابق، ص 332-333. }
\end{aligned}
$$

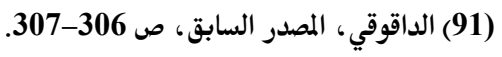

$$
\begin{aligned}
& \text { (92) عيسى، المصدر السابق، ص 340-344. } \\
& \text { (93) سري الدين، المصدر السابق، ص } 235 \text { ؛ ؛ عيسى، المصدر السابق، ص ص240 340-344. } \\
& \text { (94) رضوان، المصدر السابق، ص } 321 \text { (93) }
\end{aligned}
$$

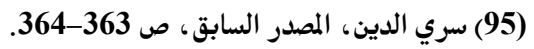

$$
\begin{aligned}
& \text { (96) المصدر نفسه، ص 285-286. }
\end{aligned}
$$

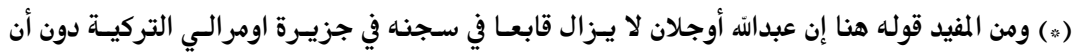

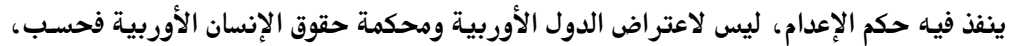

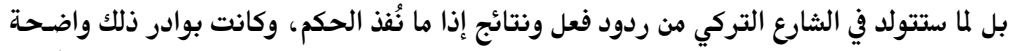

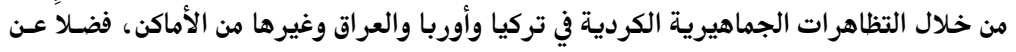

$$
\begin{aligned}
& \text { تهديدات حزب العمال الكردستاني. }
\end{aligned}
$$

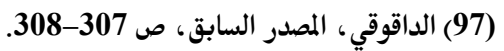

(98) Arikanli , Adi Gecen Eser, htth//www.turkishtime.org/tr.

(99) htth//www.albayan.co.ae.

(100) للوقوف على تفاصيل العلاقات الاقتصادية بين ليبيا وتركيا قبل سنة 1990. ينظر : المظفري،

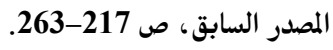

(101) يوسف أبو الفضـل محمـد مصطفى، التجـارة الخارجيـة للجماهيريـة العربيـة الليبيـة، رسالة

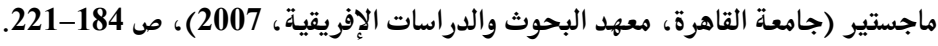

(102) Mahli , Adi Gecen Eser, S. 185.

$$
\text { (103) مصطفى، المصدر السابق، ص } 234 .
$$

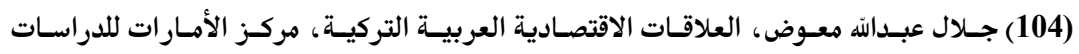

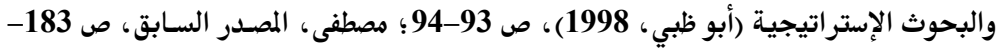

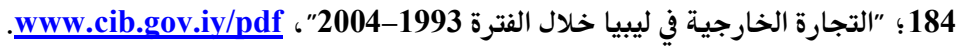

(105) مصطفى، المصدر السابق، ص 183-184.

(106) علي اومليـل وآخـرون، العـرب والأتـراك: الاقتصساد والأمسن الإقليمي، منتـدى الفكر العربي

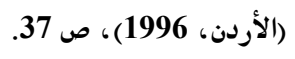




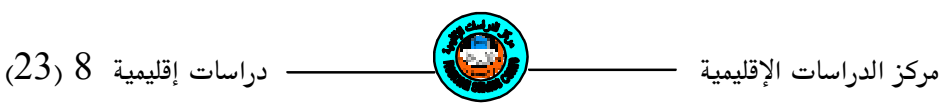

(107) المصدر نفسه، ص 21-22.

(108) http://www.forumfuar.com.

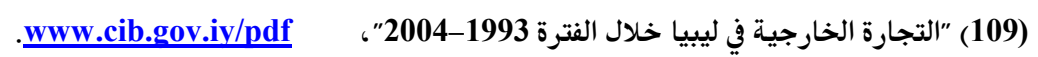

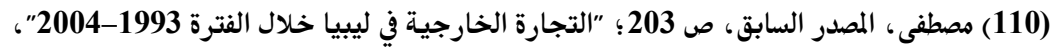

www.cib.gov.iy/pdf

(111) Kavas, Adi Gecen Eser, S. 51.

(112) نبلوك، المصدر السابق، ص 183-184.

(113) Kavas, Adi Gecen Eser, S. 54.

(114) Kologlu, op. Cit, P. 146; Kavas, Adi Gecen Eser, S. 54.

(115) لمعرفة آثار العقوبات الاقتصادية على ليبيا ينظر : نبلوك، المصدر السابق، ص 185-209.

(116) Mahli, Adi Gecen Eser, S. 176-178.

$$
\text { (117) معوض، العلاقات الاقتصادية العربية التركية، ص } 105 .
$$

(118) Prime ministry state institute of statistics, statistical yearbook of Turkey 1993, (Ankara, 1993), p.138.

$$
\text { (119) معوض، العلاقات الاقتصادية العربية التركية، ص } 105 .
$$

(120) Kavas, Adi Gecen Eser, S. 55.

(121) Kologlu , op. Cit, P. 146 .

(122) Kavas, Adi Gecen Eser, S. 56.

$$
\text { (123) أومليل وآخرون، المصدر السابق، ص } 38 .
$$

(124) Kavas, Adi Gecen Eser, S.54; Arikanli, Adi Gecen Eser, htth//www.turkishtime.org/tr.

$$
\text { (125) معوض، العلاقات الاقتصادية العربية التركية، ص } 106 .
$$

(126) Kologlu , op.cit , P. 146.

(127) Kavas, Adi Gecen Eser, S. 55.

$$
\begin{aligned}
& \text { (128) بطرس لبكي "العلاقات الاقتصادية العربية - التركية الراهنة"، مجلة المستقبل العربسي، العـدد }
\end{aligned}
$$

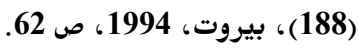

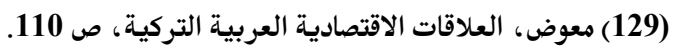

$$
\begin{aligned}
& \text { (130) لبكي، المصدر السابق، صوصن } 63 .
\end{aligned}
$$




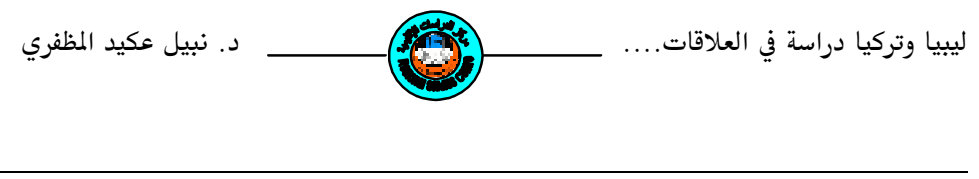

(131) معوض، العلاقات الاقتصادية العربية التركية، ص 124.

(132) Kavas , Adi Gecen Eser, S. 56 .

(133) Ayni Eser, S. 54. 